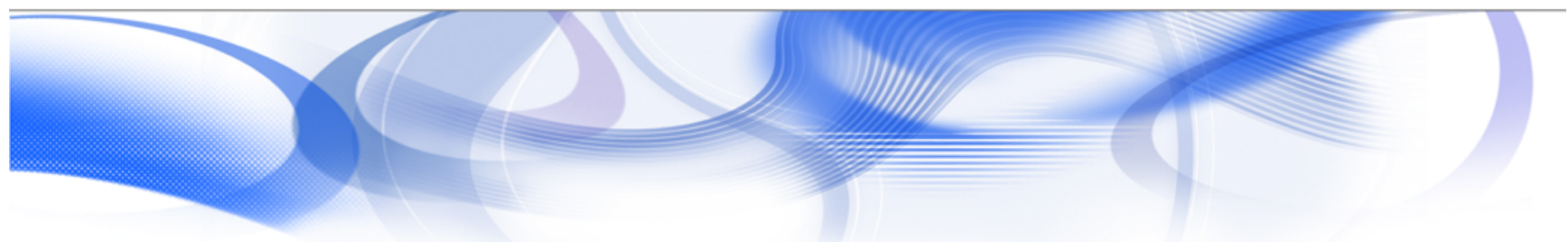

\title{
Assessment of Existing Steel Structures: Recommendations for Estimation of Remaining Fatigue Life
}

B. Kühn, M. Lukić, A. Nussbaumer, H.-P. Günther, R. Helmerich, S. Herion, M.H. Kolstein, S. Walbridge, B. Androic, O. Dijkstra, Ö. Bucak Background documents in support to the implementation, harmonization and further development of the Eurocodes

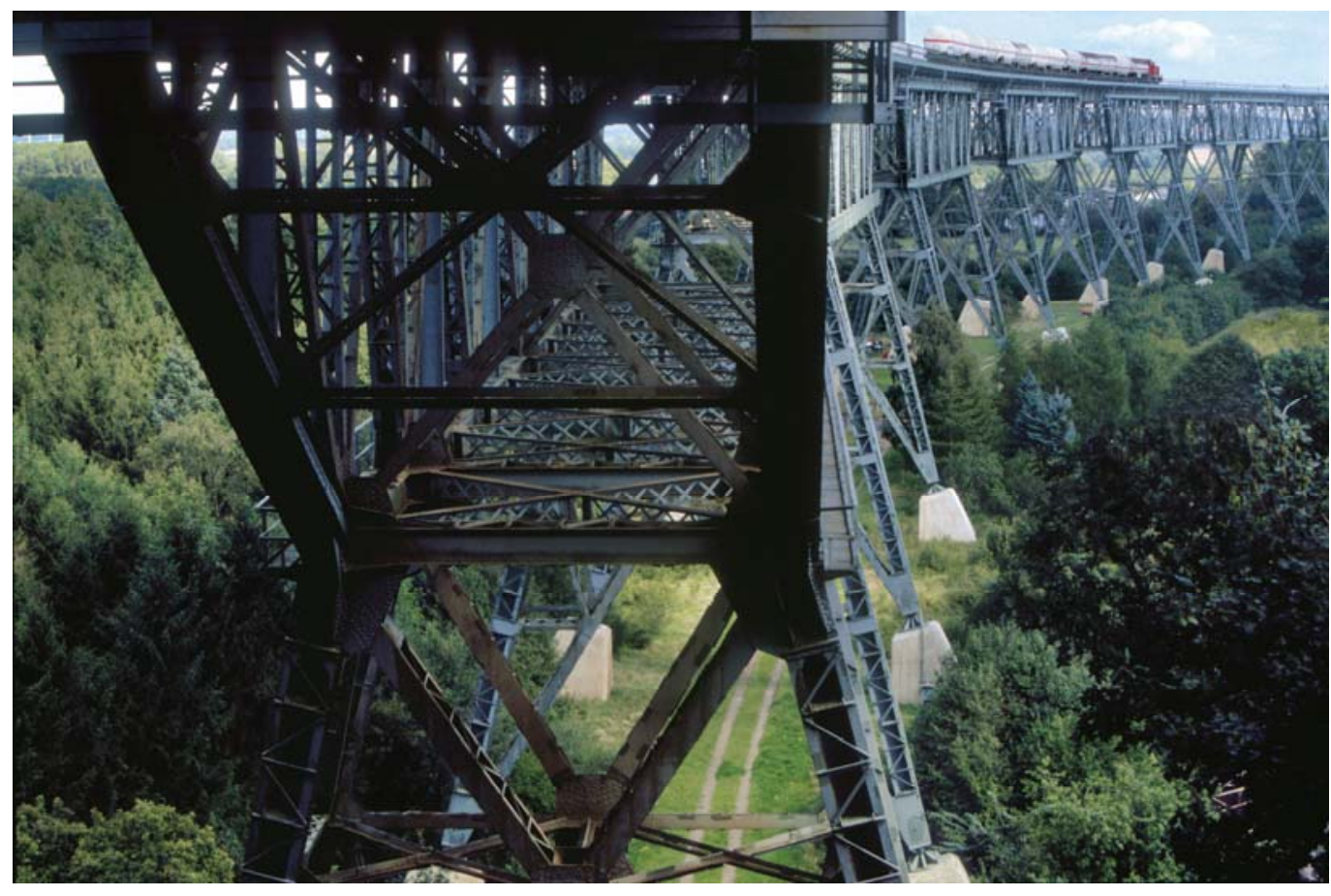

Joint Report

Prepared under the JRC - ECCS cooperation agreement for the evolution of Eurocode 3 (programme of CEN / TC 250)

Editors: G. Sedlacek, F. Bijlaard, M. Géradin, A. Pinto and S. Dimova First Edition, February 2008 EUR 23252 EN - 2008 



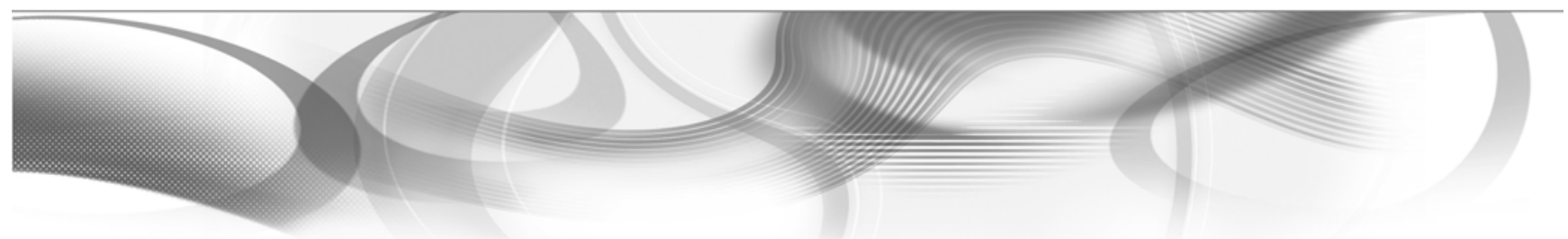

\section{Assessment of Existing Steel Structures: Recommendations for Estimation of Remaining Fatigue Life}

B. Kühn, M. Lukić, A. Nussbaumer, H.-P. Günther, R. Helmerich, S. Herion, M.H. Kolstein,

S. Walbridge, B. Androic, O. Dijkstra, Ö. Bucak

Background documents in support to the implementation, harmonization and

further development of the Eurocodes

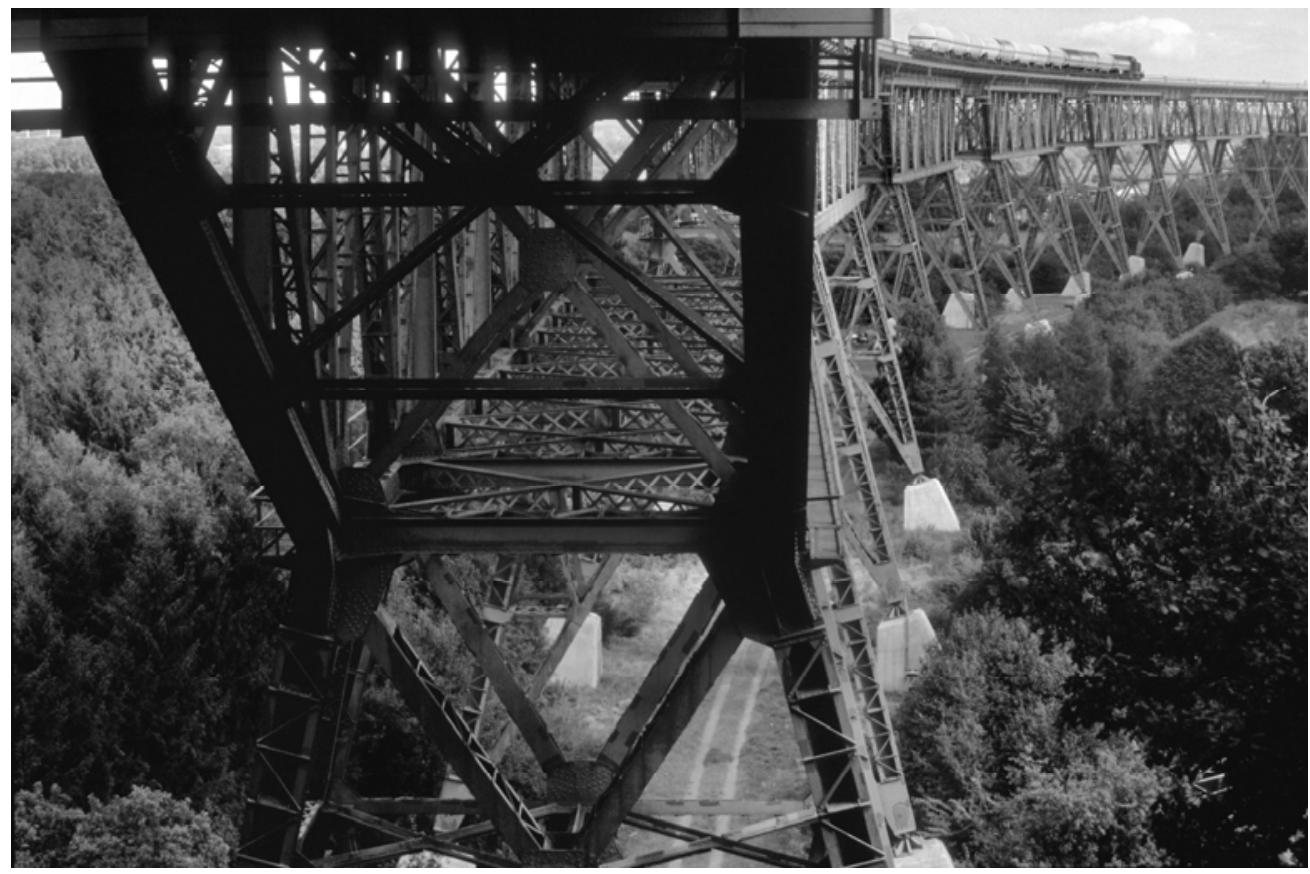

Joint Report

Prepared under the JRC - ECCS cooperation agreement for the evolution of Eurocode 3 (programme of CEN / TC 250)

Editors: G. Sedlacek, F. Bijlaard, M. Géradin, A. Pinto and S. Dimova

First Edition, February 2008

EUR 23252 EN - 2008 

The mission of the JRC is to provide customer-driven scientific and technical support for the conception, development, implementation and monitoring of EU policies. As a service of the European Commission, the JRC functions as a reference centre of science and technology for the Union. Close to the policy-making process, it serves the common interest of the Member States, while being independent of special interests, whether private or national.

European Commission

Joint Research Centre

The European Convention for Constructional Steelwork (ECCS) is the federation of the National Associations of Steelwork industries and covers a worldwide network of Industrial Companies, Universities and Research Institutes.

http://www.steelconstruct.com/

\section{Contact information}

Address: Mies-van-der-Rohe-Straße 1, D-52074 Aachen

E-mail: sed@stb.rwth-aachen.de

Tel.: +492418025177

Fax: +492418022140

http://www.stb.rwth-aachen.de

\section{Legal Notice}

Neither the European Commission nor any person acting on behalf of the Commission is responsible for the use which might be made of this publication.

A great deal of additional information on the European Union is available on the Internet. It can be accessed through the Europa server

http://europa.eu/

JRC 43401

EUR 23252 EN

ISSN 1018-5593

Luxembourg: Office for Official Publications of the European Communities

(C) European Communities, 2008

Reproduction is authorised provided the source is acknowledged

Printed in Italy 



\section{Acknowledgements}

Both ECCS and the JRC acknowledge the major contribution of Dr.-Ing. Bertram Kühn, PSP Prof. Sedlacek \& Partner - Planung und Entwicklung im Bauwesen GmbH Aachen for the coordination of the works and for the final editing, to which in particular Prof. Haig Gulvanessian, UK, has contributed with substantial improvements.

The contribution of the many international experts, who have supported the works by their comments and reviews, as stated in the preface, is also acknowledged. 


\section{Foreword}

The EN Eurocodes are a series of European standards which provide a common series of methods for calculating the mechanical strength of elements playing a structural role in construction works, i.e. the structural construction products. They make it possible to design construction works, to check their stability and to give the necessary dimensions of the structural construction products.

They are the result of a long procedure of bringing together and harmonizing the different design traditions in the Member States. In the same time, the Member States keep exclusive competence and responsibility for the levels of safety of works.

According to the Commission Recommendation of 11 December 2003 on the implementation and use of Eurocodes for construction works and structural construction products, the Member States should undertake research to facilitate the integration into the Eurocodes of the latest developments in scientific and technological knowledge. Member States should pool the national funding available for such research so that it can be used at Community level to contribute to the existing technical and scientific resources for research within the European Commission, in cooperation with the Joint Research Centre, thus ensuring an ongoing increased level of protection of buildings and civil works.

This report is part of the so-called background documents on Eurocodes. It has been prepared to provide technical insight on the way existing steel structures could be assessed and the remaining fatigue life could be estimated.

It may be used as a main source of support to:

- further harmonize design rules across different materials, and

- further develop the Eurocodes.

The European Convention for Constructional Steelwork (ECCS) has initiated the development of this report in the frame of the cooperation between the European Commission (the JRC) and the ECCS for works on the further evolution of the Eurocodes. It is therefore published as a Joint JRC ECCS report.

Due to the demand for freight volume on rail and road, traffic has increased significantly in the past years leading to increasing number of heavy vehicles in the traffic flows and greater exploitation of their loading capacities. Because of environmental considerations there is also a tendency to further enhance the admissible loads in the design of new heavy vehicles (e.g. by increasing axle loads or using road trains). This all may affect the safety, serviceability and durability of existing bridges. Bridge authorities are therefore interested in agreed methods to assess the safety and durability of existing bridges and to make appropriate provisions for more refined maintenance methods, possible restriction of traffic, bridge-rehabilitation or substitution of old bridges by new ones where necessary.

For steel bridges including the old riveted ones there are numerous approaches to such assessments, partly standardized by national codes or recommendations. In the light of the development of the European single market for construction works and engineering services there is thus a need to harmonize them and to develop agreed European technical recommendations for the safety and durability assessment of existing structures. These recommendations should follow the principles and application rules in the Eurocodes and provide a scheme with different levels of analysis: a basic level with general methods and further levels with higher sophistication that call for specific expertise.

The European Convention for Constructional Steelwork (ECCS) has in its Technical Committee 6 Fatigue (that also laid the basis for EN 1993 - Eurocode 3 - Part 1-9 - Fatigue) agreed to support the preparation of such European technical "Recommendations for the estimation of remaining 
fatigue life", that could be used as a basis for harmonising National procedures and for the further evolution of the Eurocodes.

Aachen, Delft and Ispra, February 2008

Gerhard Sedlacek

ECCS - Director of Research

Frans Bijlaard

Chairman of CEN/TC 250/SC 3

Michel Géradin, Artur Pinto and Silvia Dimova

European Laboratory for Structural Assessment, IPSC, JRC 


\section{PREFACE}

During the 90's of the last century, a great deal of research focused on the assessment of existing steel structures, mainly those dominantly exposed by fatigue loading such as bridges or crane supporting structures. These works, as well as lessons learned from the unnecessary demolition of great structures or the poor performance of strengthening measures of some old structures has led to a better understanding of the behaviour of existing structures and therefore led to better assessments methods.

Nowadays more than half of the budget for the development of infrastructure in Europe is for maintenance and modernisation of the existing infrastructure while less than half is for extension and renewing of it. Due to this fact, it is not sufficient for the design engineer to know the rules and guidelines for the design of new structures. He needs knowledge and experience in the assessment of existing structures, in particular on fatigue loaded structures with a limited design service life. In order to produce recommendations for the general practitioner on assessment of existing steel structures and to prepare a basic paper for the future extension of the Eurocodes to cover this subject, a working group was created in 1993 within the framework of the ECCS Technical Committee 6 "Fatigue".

Many thanks to the members of this Technical Committee and to all the other persons, too numerous to mention here, who offered their continuous encouragement and suggestions. Many thanks also to the following external experts for the technically review of the recommendations:
K. Brandes
Germany
W. Dahl
Germany
M. Feldmann
Germany
J.W. Fisher
USA
H. Gulvanessian
United Kingdom
H.M.C.M. van Maarschalkerwaart
The Netherlands
G. Sedlacek
Germany
N. Stranghöner
Germany
R. Sweeney
Canada
M. Tschumi
Switzerland

Finally, many thanks to PSP Prof. Sedlacek \& Partner Planung und Entwicklung im Bauwesen $\mathrm{GmbH}$, Aachen, Germany, where this publication has been prepared.

Aachen, September 2007

Bertram Kühn

Chairman of the ECCS Working Group A 


\section{NOTATION}

$\beta \quad$ reliability index

$P_{f} \quad$ probability of failure

$z_{i} \quad$ probabilistic parameters characterising "load" or "resistance"

$\Phi($.$) \quad standard normal cumulative distribution$

$C$ constant of the Paris law

$m \quad$ exponent of the Paris law, slope of the S-N curves

$D \quad$ damage index, $0 \leq \mathrm{D} \leq 1.0$

$D$ (.) standard deviation of a random variable

$V \quad$ Variation coefficient

$E \quad$ modulus of elasticity of the material

$K_{I} \quad$ applied elastic stress intensity factor

$K_{\text {mat }}$ material fracture toughness

$\Delta K \quad$ applied elastic stress intensity factor range

$\Delta K_{t h}$ threshold value of the elastic stress intensity factor range

$\Delta K_{\text {eff }}$ effective stress intensity factor

$Y \quad$ stress concentration correction function, that is due to joint geometry and crack location

$N \quad$ number of cycles

$n_{i} \quad$ actual number of cycles at stress range $\mathrm{i}$

$N_{i} \quad$ theoretical fatigue life at stress range $\mathrm{i}$

$N_{\text {insp }} \quad$ number of cycles between two inspections

$T \quad$ main plate thickness (the plate in which the crack propagates)

$T_{F L} \quad$ fatigue life (in years)

$T_{S L} \quad$ service life in the past (in years)

$T_{R F L} \quad$ remaining fatigue life (in years)

$T_{i} \quad$ time

$T_{e} \quad$ material temperature

$T_{K 27}$ temperature related to a CVN absorbed energy of 27 Joules

$W \quad$ width of plate in which the crack propagates

$a \quad$ crack depth (or half its length according to crack configuration)

$a_{0} \quad$ initial crack depth

$a_{c} \quad$ final or critical crack depth

$a_{t} \quad$ crack depth at time $\mathrm{T}_{\mathrm{i}}$

$\Delta a \quad$ increase of crack depth per cycle

$c$ half crack length of a semi-elliptical crack (usually a function of a and a/c)

a/c crack shape; ratio of crack depth to half crack length

$d_{i} \quad$ damage increase per cycle

$R_{e L} \quad$ lower yield stress of the material (in civil engineering often also called $\mathrm{f}_{\mathrm{y}}$ )

$R_{e H} \quad$ upper yield stress of the material

$R_{m} \quad$ tensile stress of a material (in civil engineering often also called $\mathrm{f}_{\mathrm{u}}$ )

$n(t) \quad$ number of cycles at time $\mathrm{T}_{\mathrm{i}}$

$n_{i} \quad$ number of cycles occurring at stress range magnitude, $\Delta \sigma_{i}$ of a stress spectrum

$N_{i} \quad$ number of cycles corresponding to a particular fatigue strength at stress range magnitude, $\Delta \sigma_{\mathrm{i}}$ 


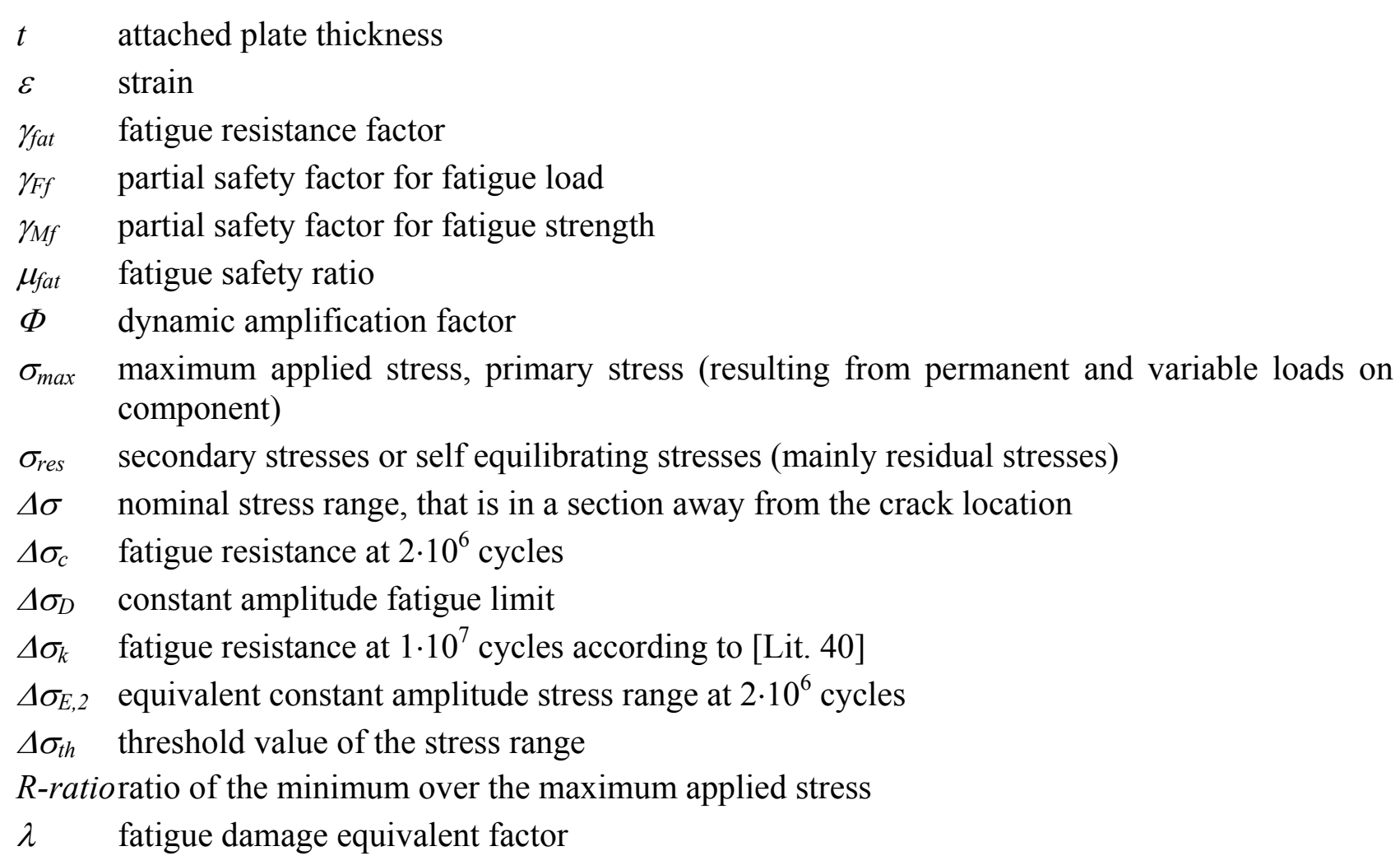




\section{Contents}

1

INTRODUCTION .................................................................................................................1

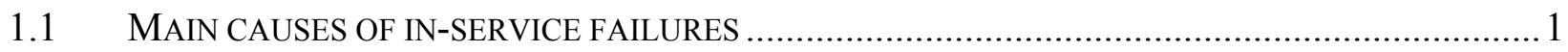

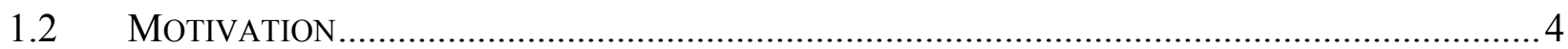

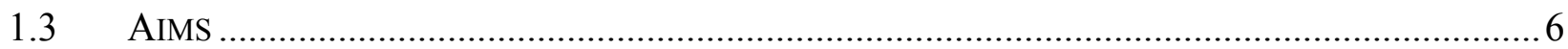

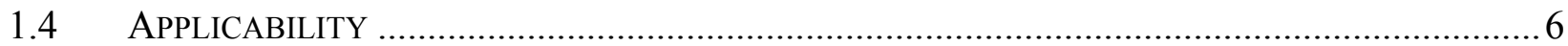

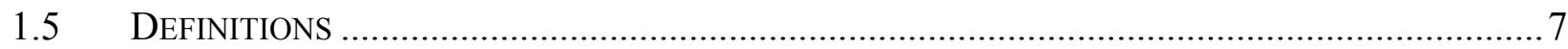

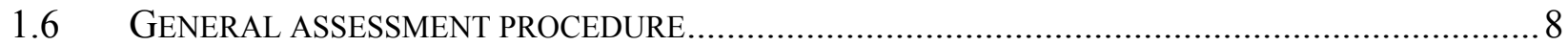

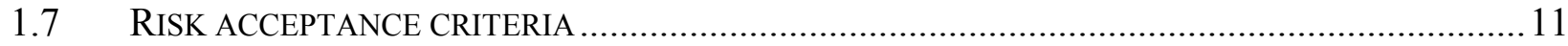

2 FATIGUE ASSESSMENT PROCEDURE FOR EXISTING STEEL BRIDGES ....13

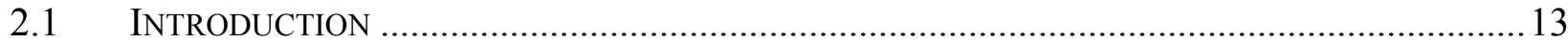

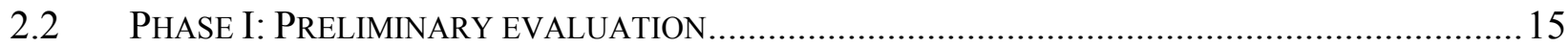

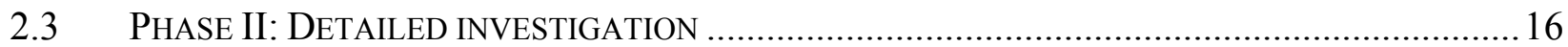

2.4 PHASE III: EXPERT INVESTIGATION.................................................................................... 19

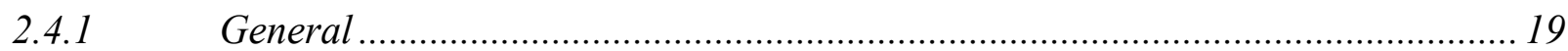

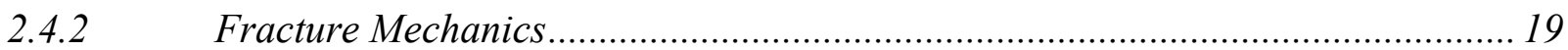

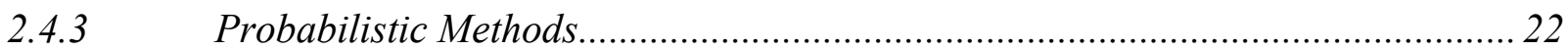

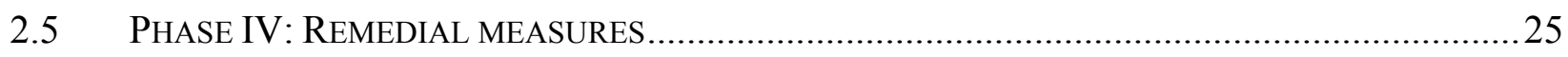

3 STRUCTURAL AND MATERIAL INFORMATION ..................................................26

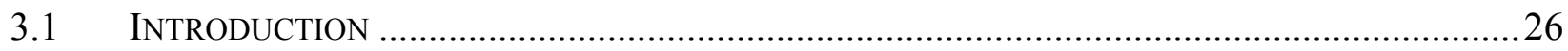

3.2 OBTAINING INFORMATION FROM DRAWINGS AND STATIC CALCULATIONS ..........................26

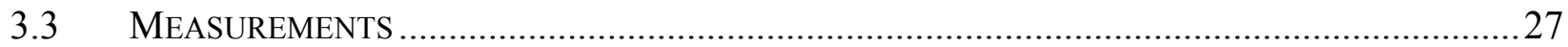

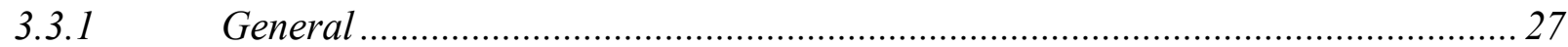

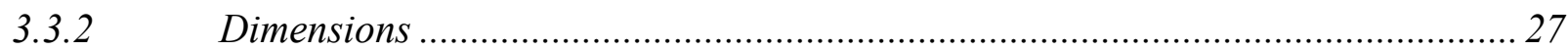

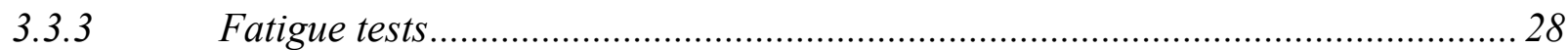

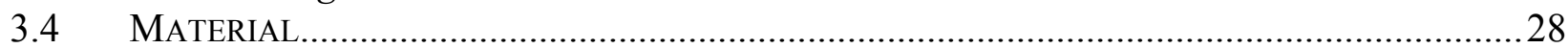

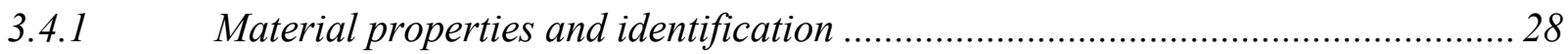

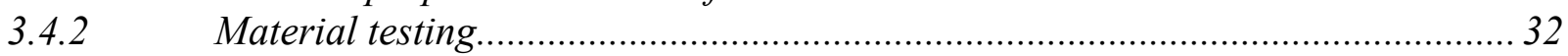

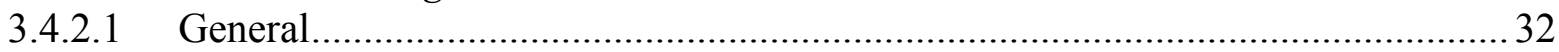

3.4.2.2 Kind of test specimens, sampling and test procedure ............................................33

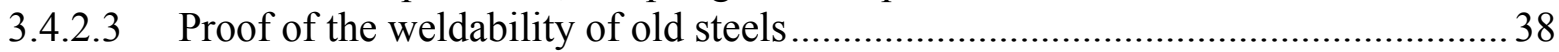

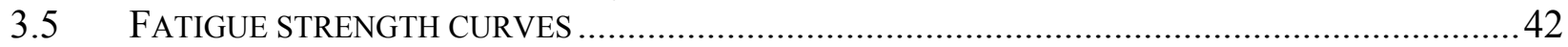

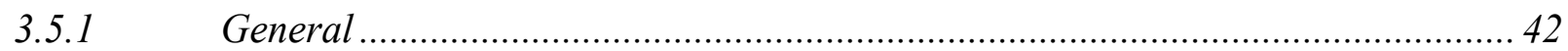

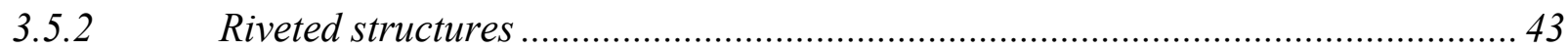

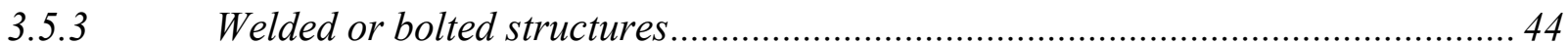

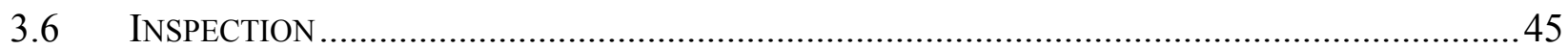

3.6.1 Causes and identification of fatigue cracks....................................................45

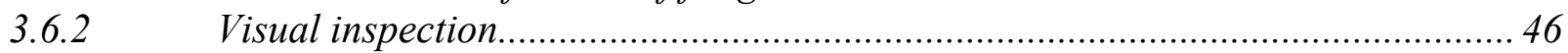

3.6.3 Non destructive testing (NDT) ……………….......................................... 46

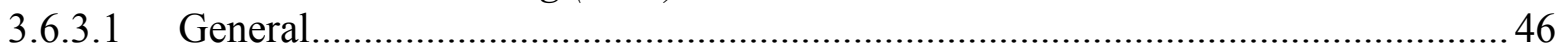

3.6.3.2 Applicable methods ..................................................................................... 48

4 INFORMATION ON LOADING AND LOAD EFFECTS ............................................54

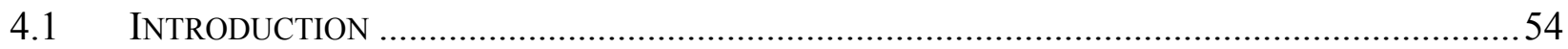

4.2 IDENTIFICATION AND MODELLING OF THE STRUCTURE...................................................5

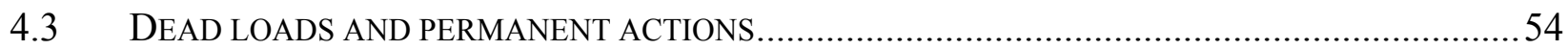

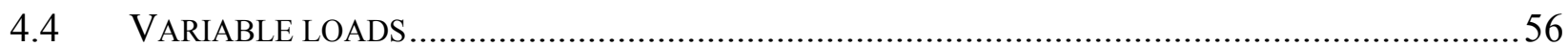

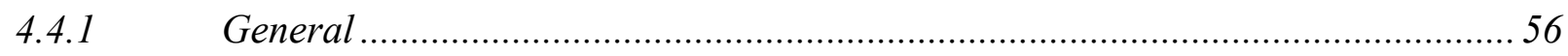

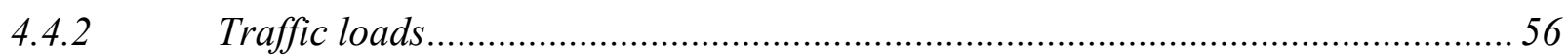




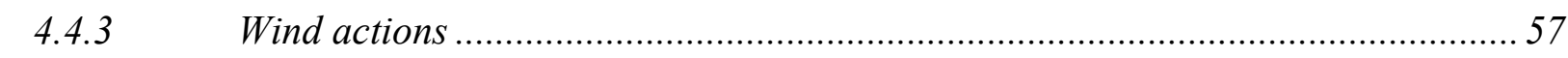

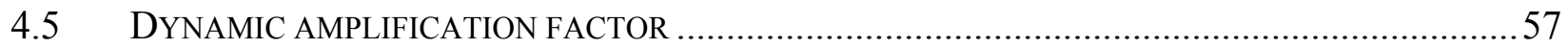

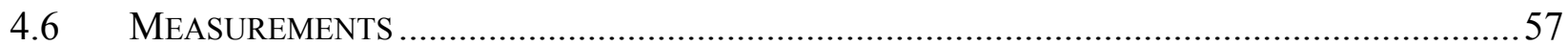

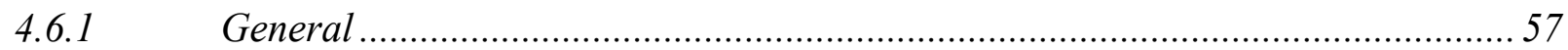

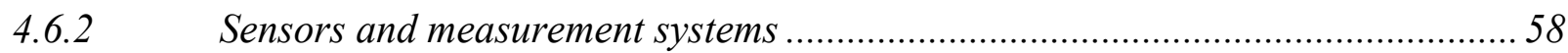

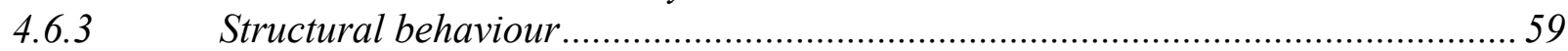

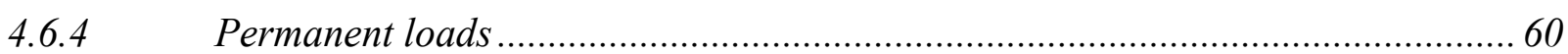

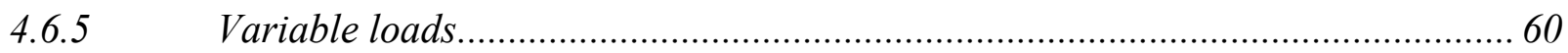

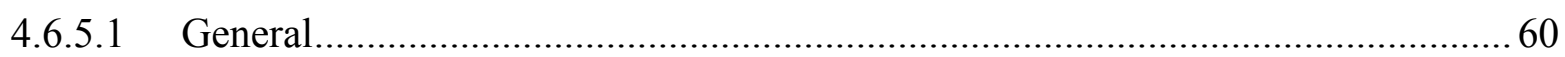

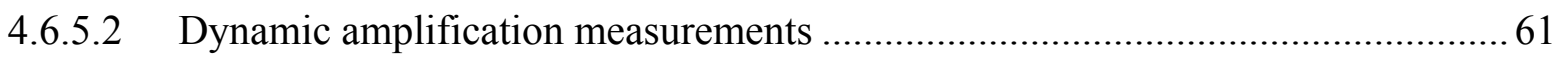

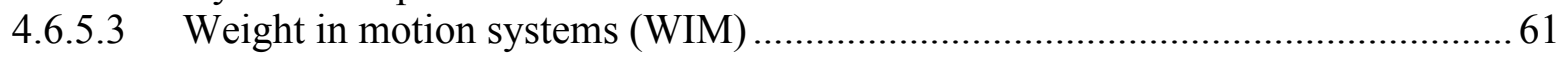

$5 \quad$ REMEDIAL MEASURES ................................................................................................63

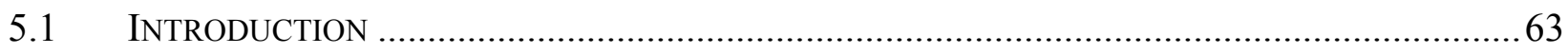

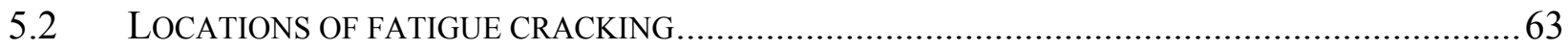

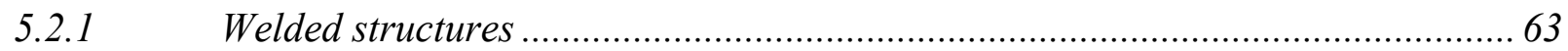

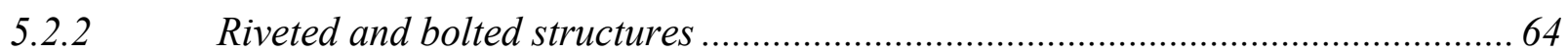

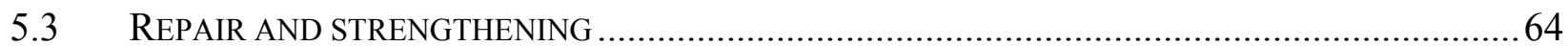

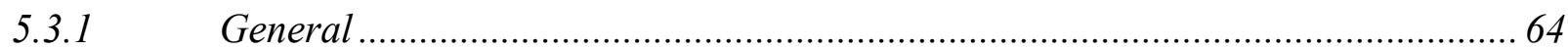

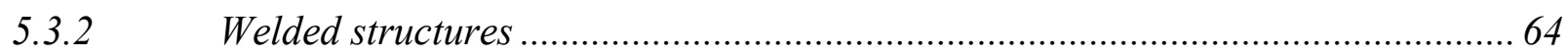

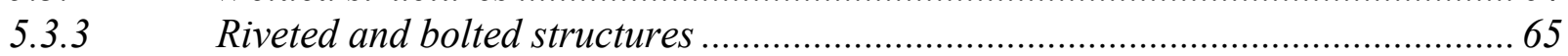

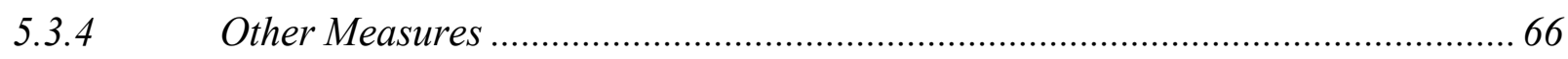

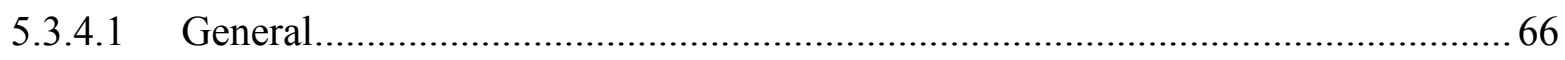

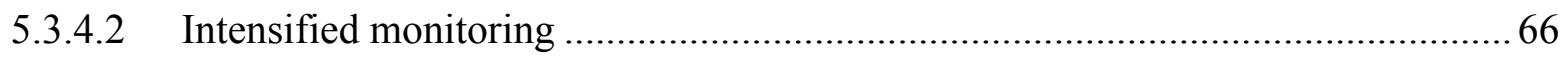

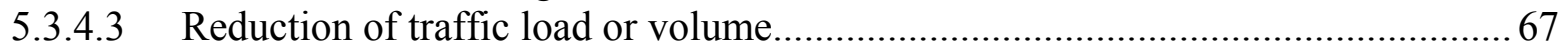

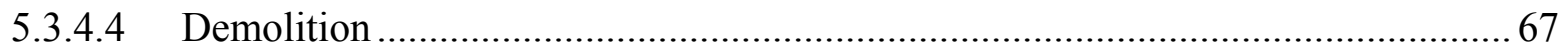

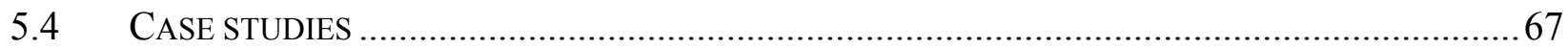

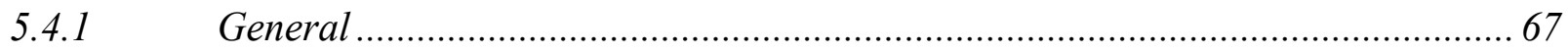

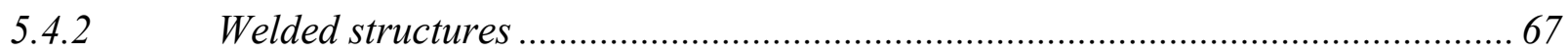

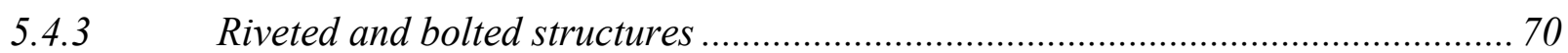

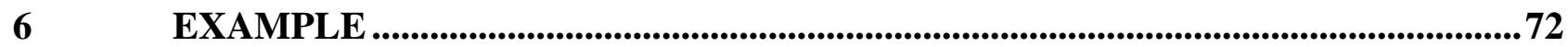

6.1 REMAINING FATIGUE LIFE OF A MAIN GIRDER OF A RIVETED RAILWAY BRIDGE ....................72

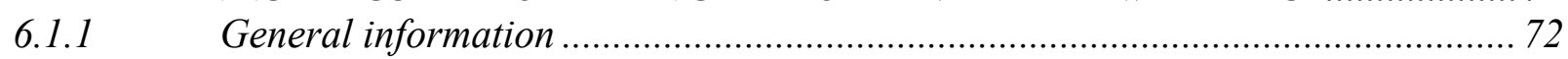

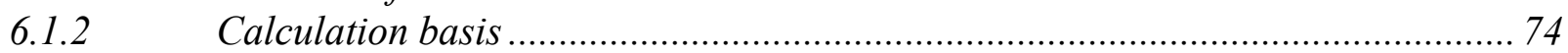

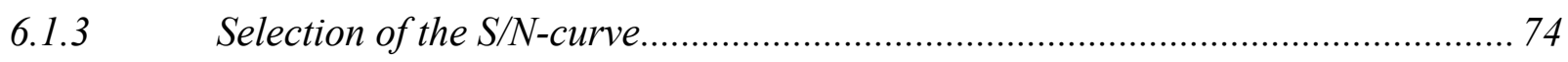

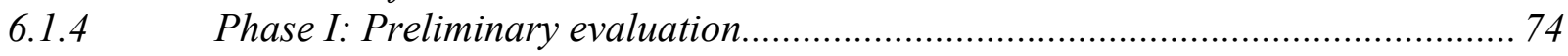

6.1.5 Phase II: Detailed investigation; Formation of the stress range spectrum ......... 74

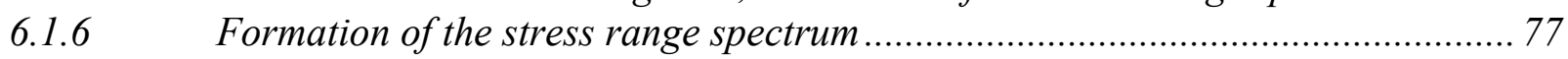

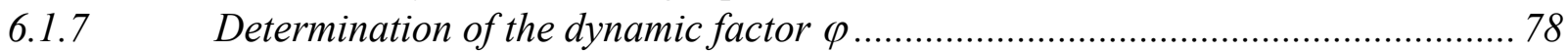

6.1.8 Taking into account secondary stresses ............................................................. 78

6.1.9 Stress range spectrum for the calculation of the remaining fatigue life ............... 79

6.1.10 Calculation of the remaining fatigue life ............................................................. 80

6.1.10.1 Accumulated damage during service life 1895 - today ..................................... 80

6.1.10.2 Conclusion Phase II: Remaining fatigue life................................................... 81

6.1.11 Phase III: Expert investigation and Phase IV: Further measures ....................... 81

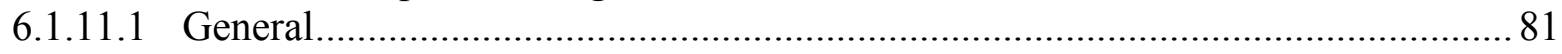

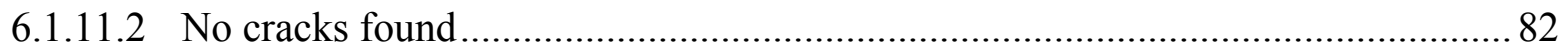

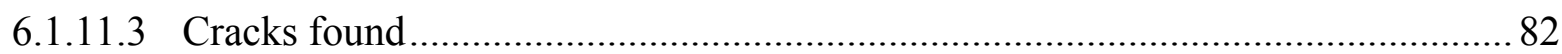

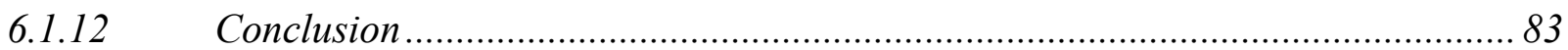




\section{INTRODUCTION}

\subsection{Main causes of in-service failures}

(1) Since the end of the $18^{\text {th }}$ century, first cast iron, then wrought steel and finally steel has increasingly been used as a construction material. Gradually, as industrial processes progressed, various steel products became available, such as rolled members and cold-formed elements. From the beginning, the fields of application of structural steel material included structures such as:

- Buildings,

- Bridges (first bridge made of cast iron and built 1777-1779 near Coalbrookdale (UK)) and - Industrial plants.

(2) At the beginning of the $19^{\text {th }}$ century, engineering design rules became more scientific as Navier, among others, developed the basis of modern static calculations. In this period, civil engineering saw a enormous development. This did not happen without problems, several dramatic collapses occurred, see for example Fig. 1-1 and Fig. 1-2. Steel structures were not exempted from serious failures and engineers had regularly to suffer setbacks. These setbacks contributed in many cases, however, to research and advancements in better understanding structural behaviour and developing new theories.

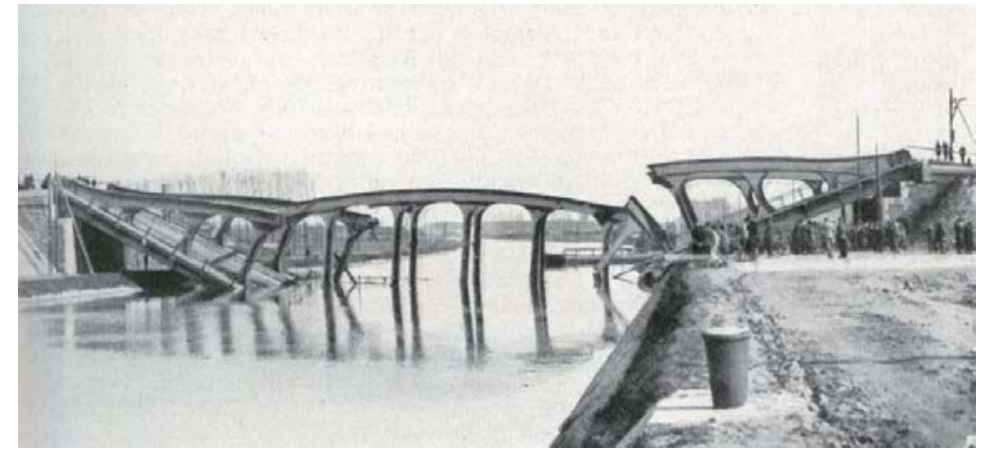

Fig. 1-1: $\quad$ Sudden collapse of the 1 year old roadway bridge over the Albert canal near to Hasselt due to brittle fracture, Belgium, 1938

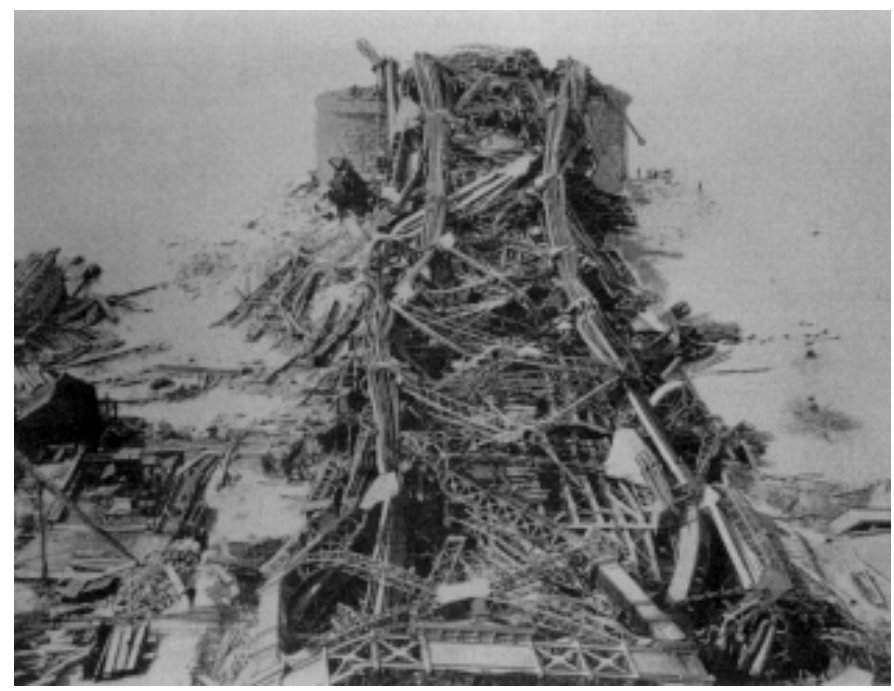

Fig. 1-2: Quebec bridge (Canada) after the first collapse due to buckling during the construction in August $29^{\text {th }} 1907$ 
(3) Considering only steel structures, P. Oehme [Lit. 1] made a study considering on the cause of damage and type of structures. This study is interesting because steel has been used in a wide variety of different structures. A total of 448 damage cases are reported. Approximately $98 \%$ occurred in the period of 1955 to 1984 and $62 \%$ in less than 30 years after erection. The damage cases can be assigned, according to Oehme, to the type of structure as follows:

- Buildings (including industrial buildings and crane supporting structures)

- railway bridges

- cranes

- road bridges

$8.7 \%$

- plant and big machinery used in surface mining

- masts and towers

- other steel structures

(4) As one can see, bridges (combining railway and roadway) are among the structures most often damaged. Another way of looking at the study is to separate by the cause, which leads to each of the damages, as it is presented in Table 1-1. From this table, one can see that fatigue is the third in the frequency of cause of all recorded damages; for bridges, fatigue ranks first.

\begin{tabular}{|l|c|c|c|c|c|c|c|c|}
\hline \multirow{2}{*}{$\begin{array}{c}\text { Damage cause } \\
\text { (Multiple denomination } \\
\text { possible) }\end{array}$} & \multicolumn{2}{|c|}{ Totality } & \multicolumn{2}{c|}{ Buildings } & \multicolumn{2}{c|}{ Bridges } & \multicolumn{2}{c|}{ Conveyors } \\
\cline { 2 - 9 } & No & $\%$ & No & $\%$ & No & $\%$ & No & $\%$ \\
\hline Static strength & 161 & 29.7 & 102 & 33.6 & 19 & 14.8 & 40 & 36.0 \\
\hline Stability (local or global) & 87 & 16.0 & 62 & 20.4 & 11 & 8.6 & 14 & 12.6 \\
\hline Fatigue & 92 & 16.9 & 8 & 2.6 & 49 & 38.3 & 35 & 31.5 \\
\hline Rigid body movement & 44 & 8.1 & 25 & 8.2 & 2 & 1.6 & 17 & 15.3 \\
\hline Elastic deformation & 15 & 2.8 & 14 & 4.6 & 1 & 0.8 & 0 & 0 \\
\hline Brittle fracture & 15 & 2.8 & 9 & 3.0 & 5 & 3.9 & 1 & 0.9 \\
\hline Environment & 101 & 18.6 & 59 & 19.4 & 41 & 32.0 & 1 & 0.9 \\
\hline Thermal loads & 23 & 4.2 & 23 & 7.6 & 0 & 0 & 0 & 0 \\
\hline Others & 5 & 0.9 & 2 & 0.7 & 0 & 0 & 3 & 2.7 \\
\hline Sum & 543 & 100 & 304 & 100 & 128 & 100 & 111 & 100 \\
\hline
\end{tabular}

Table 1-1: Detailed split up of the main causes, which led to the damage [Lit. 1]

(5) In the publication, "Collapse of Works, Part 1 Bridges" edited by Scheer in 2001 all known damages on bridges are analysed. His overview shows 8 categories of collapses of bridges made of all kinds of material in the past, see Table 1-2. 


\begin{tabular}{|c|c|c|c|}
\hline \multirow{2}{*}{ No } & \multirow{2}{*}{ Collapse } & \multicolumn{2}{|c|}{ Number of collapses } \\
\hline & & With detailed information & Without detailed information \\
\hline 1 & During erection & 93 & 20 \\
\hline 2 & $\begin{array}{l}\text { In service without external } \\
\text { influence }\end{array}$ & 86 & 35 \\
\hline 3 & Due to ship impact & 48 & 4 \\
\hline 4 & $\begin{array}{l}\text { Due to influence of traffic under } \\
\text { the bridge }\end{array}$ & 16 & 0 \\
\hline 5 & $\begin{array}{l}\text { Due to influence of traffic on } \\
\text { the bridge }\end{array}$ & 18 & 5 \\
\hline 6 & Due to high water level or ice & 32 & 10 \\
\hline 7 & Caused by fire, explosion, etc. & 15 & 2 \\
\hline 8 & Of the supporting framework & 48 & 14 \\
\hline & Total & 356 & 90 \\
\hline
\end{tabular}

Table 1-2: Analyses of all known damages on bridges acc. to Scheer

(6) During service in total 121 bridges collapsed (see Table 1-2, line No 2). In the case of steel bridges fatigue cracks have been induced by secondary stresses as well as by overload, but also because the assumed detail category used in design was too high and/or the workmanship was too poor, especially for welded structures.

A further detailed case study of failures in steel bridges was carried out by Fisher [Lit. 2].

(7) In Canada for example [Lit. 3], the causes of failures of structural components of bridges in the years 1987-1996 have been the following: overloads 8, fatigue 12, deterioration other than fatigue (corrosion, concrete cracking, ...) 18. In all these so-called "failures", only overloads resulted in complete failure of the component. Fatigue failures were rarely complete failures because redistribution between remaining elements occurred as the crack grew. This shows the importance of redundancy in the evaluation of safety when it comes to fatigue.

(8) The above mentioned reasons explain why the following recommendations will focus on the assessment of existing steel bridges.

(9) Especially in the field of fatigue assessment the word "failure" is widely used, but often has a different meaning. The explanation given below expresses the meaning used in these recommendations. Depending on the redundancy of the cracked element, a fatigue crack will grow in a different way. In a small non-redundant component the crack grows in an exponential manner, starting slowly and progressively accelerating. In a large redundant component the crack growth will show a long period of stable crack growth due to a redistribution of the load to the surrounding structure. Theoretically, the end of fatigue life is reached when fracture of the remaining net section occurs. In fact, defining failure, in particular in the domain of fatigue, is difficult. According to Carper [Lit. 3, Lit. 4], failure is an unacceptable difference between expected and observed performance. Therefore, the failure criterion for a fatigue crack can either be: an unacceptable change in the component stiffness, a given crack size, net section yielding or, in certain cases, brittle fracture which occurs after a critical crack length is reached. 


\subsection{Motivation}

(1) Transport systems experienced rapid development during the decades around the turn of the $19^{\text {th }}$ to $20^{\text {th }}$ century. A large number of riveted steel bridges were built at that time in many countries and these bridges are now approaching their hundredth birthday, see Fig. 1-3. Today, this is usually regarded as their design working life, which had not been estimated in the calculation when the bridges have been built. Many of these old bridges have undergone several phases of repair or strengthening after damages during the two World Wars or due to changes of service requirements. However, very often, there are no visible indications of deterioration or fatigue. Nevertheless, a profound rating of the bridges is advisable, at least before deciding about a new cost intensive repair, strengthening or protection systems. Because of the large number of these bridges, replacement - only as a consequence of approaching the "design life" - far exceeds the available funds. But, even if the funds existed, replacement of some of the bridges would be the last acceptable option, because some of them are historical and nice looking monuments, see Fig. 1-4.

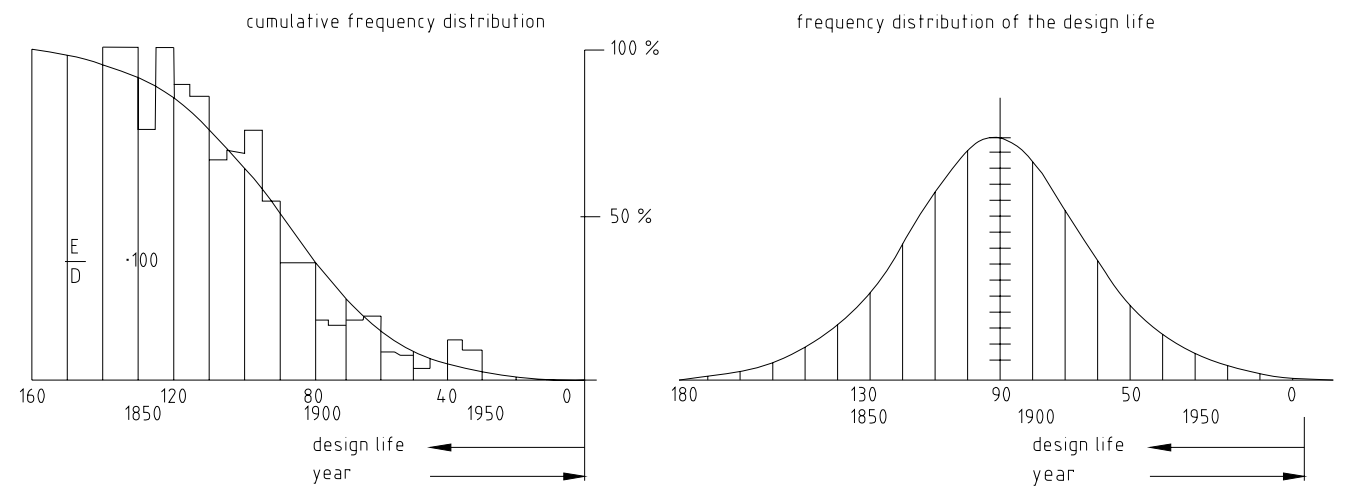

Fig. 1-3: $\quad$ Number of riveted railway bridges in Germany in relation to the year of erection according to [Lit. 5]

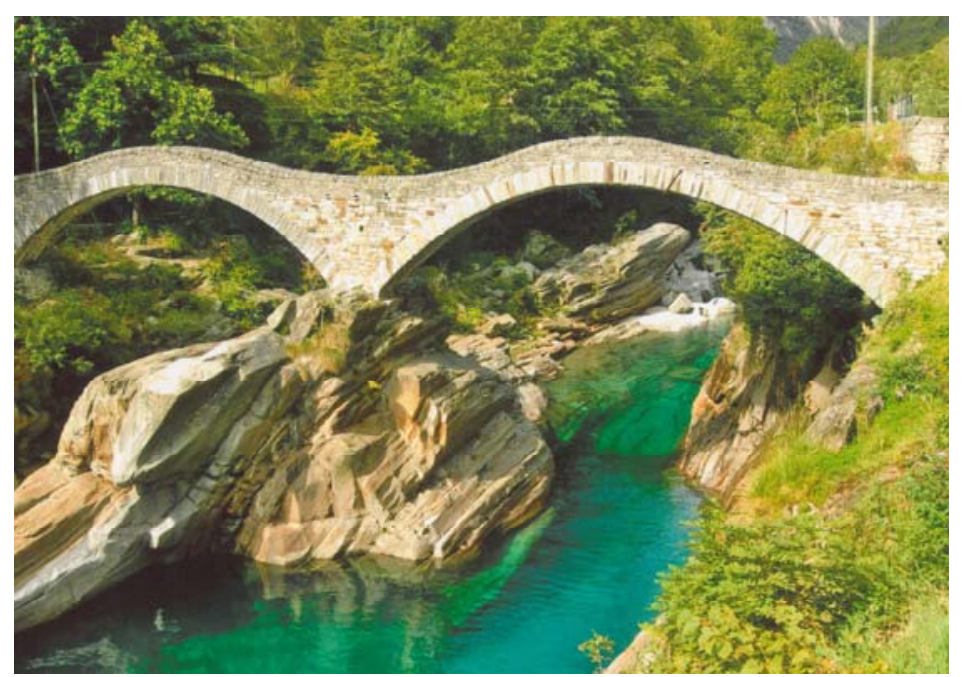

Fig. 1-4: $\quad$ Ponte dei Salti near Lavertezzo (CH, Verzasca, Tessin) built in $16^{\text {th }}$ century

(2) To make matters worse, engineers are becoming disenchanted with standard inspection techniques and conventional bridge analyses using design codes. Being confronted with the rating of old steel bridges, they prefer a comprehensive method, including advanced material testing, measurements on vital structural components and system identification.

(3) The influence of the economic aspects on the decision should not be underestimated. Although nowadays the financial assessment of a construction project lies more frequently in 
the hands of project managers instead of expert engineers, the engineers also should know something about the economic aspects of conservation measures. Despite of the innumerable, impressive proofs of the robustness of steel bridges, which are able to resist also the most corrosive environmental conditions for 90 and more years, it can happen that a renovation is uneconomical and the design life of a bridge is prolonged only provisionally. The engineer has to take into account all the economic aspects, the cost effectiveness of the actual investments and the future maintenance and conservation costs. E.g. Seemann et al. [Lit. 6] estimated these costs for a 91 year old road bridge with serious damages from corrosion in the year 2000 (http://europa.eu/

(4) Table 1-3). From the results of this estimation it is obvious that, considering the future maintenance cost, scenarios exist where a new bridge is more economic than renovating the old one.

\begin{tabular}{|l|c|c|}
\hline & Actual investment costs & $\begin{array}{c}\text { Actual investment costs + capitalised } \\
\text { future maintenance and conservation costs }\end{array}$ \\
\hline Renovation of old bridges & 0.56 to 0.97 Mio EUR & 0.97 to 1.58 Mio EUR \\
\hline Building new bridges & 1.18 to 1.79 Mio EUR & 1.33 to 1.99 Mio EUR \\
\hline
\end{tabular}

http://europa.eu/

Table 1-3: Actual costs (2000) acc. to Seemann et al. [Lit. 6]

(5) Apart for riveted bridges, these recommendations deal also with welded steel bridges, coming up around 1935, see Fig. 1-5. The majority of welded steel bridges have been built since 1950 and due to that they did not reach their design working life yet. Nevertheless a number of fatigue damages, which cannot be ignored and neglected, are known, especially in the field of orthotropic decks, due to the inexperience and the lack of knowledge about fatigue strength in the beginning of the welding techniques. Another cause is the unforeseen large traffic increase on these bridges.

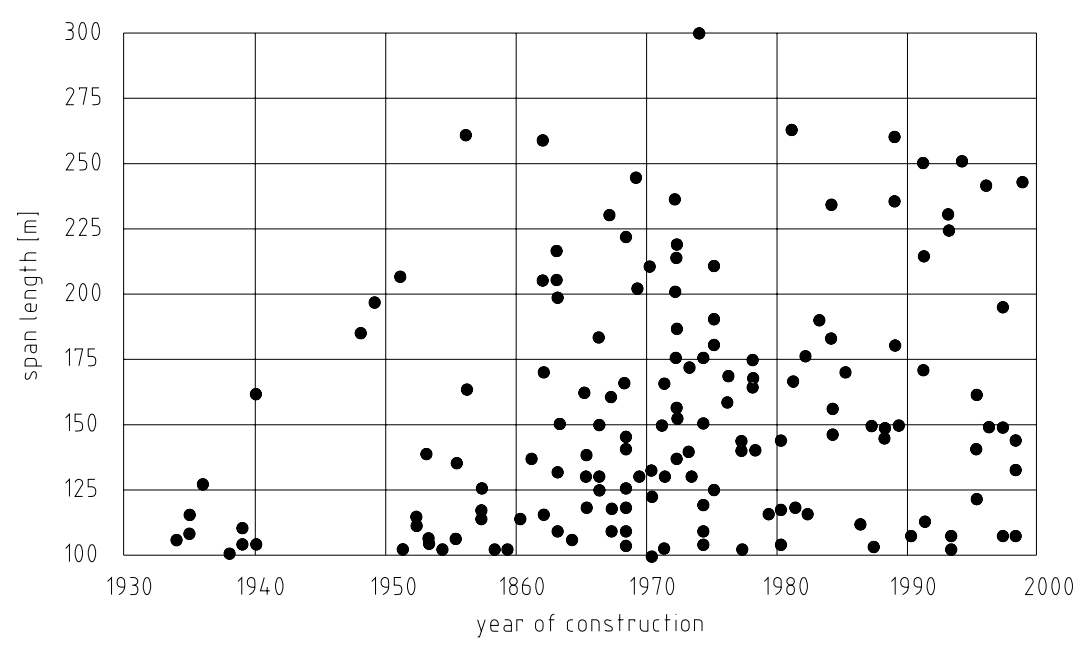

Fig. 1-5: The year of construction in relation to span length of welded girder steel bridges according to [Lit. 7]

(6) Therefore, the adequate evaluation of the stress ranges applied in the past, present and future on the structural component influences to a great percentage an adequate assessment of the remaining fatigue life of bridges. 


\subsection{Aims}

(1) The aims of these recommendations are the following:

- Presentation of a stepwise procedure, which can be generally used for the assessment of existing structures (see section 1.6)

- Presentation of a stepwise procedure in particular for the fatigue assessment of existing steel bridges (see chapter 2)

- Description of all factors to be taken into account on the resistance side and description of possibilities to get more detailed information on these factors (see chapter 3)

- Description of all factors to be taken into account on the action side and description of possibilities to get more detailed information on these factors (see chapter 4)

- Description of remedial measures which can be chosen after a fatigue assessment shows no or insufficient remaining fatigue life (see chapter 5)

- Presentation of examples explaining the use of the proposed fatigue assessment procedure (see chapter 6)

(2) The stepwise procedures are arranged in a way that with each step the input for the assessment fits more accurately to the structure assessed and the assessment itself becomes more realistic; however with each step also the effort in time and money is increased and also the knowledge necessary to carry out the assessment.

(3) These recommendations include only the most relevant information. For more detailed information references are given.

\subsection{Applicability}

(1) In general these recommendations are applicable to all existing structures, but it focuses mainly on existing steel bridges made of all grades of structural steels, including old steels, stainless steels and unprotected weathering steels. Therefore it is also applicable for the assessment of other existing steel structures than bridges. The general assessment procedure in section 1.6 is applicable for other existing structures exposed to cyclic loading made of concrete (except for bridge decks), timber or masonry.

(2) The application is limited as follows:

- Structures under normal environmental conditions and with adequate corrosion protection. In cases of insufficient corrosion protection, the loss of cross section due to corrosion has to be taken into account separately. Corrosion due to specific environmental conditions like seawater or industrial environment require special considerations where these recommendations do not deal with.

- The service temperature range is from $-40^{\circ} \mathrm{C}$ to $+150^{\circ} \mathrm{C}$. Special considerations are required for an assessment of structures in arctic regions or structures subjected to high temperatures during service; both are not included in these recommendations. Also not included are rules for an assessment following a fire.

Assessment following seismic actions are not covered.

Minimum wall thickness of components is $8 \mathrm{~mm}$ (as this components experience specific combined stability and fatigue problems or to be able to use detail categories from codes as well as this thickness is approximately the limit due to the change from plane stress to plane strain fracture mechanics).

- The elements which should be assessed must be inspectable. 


\subsection{Definitions}

(1) In this section only definitions of terms which are closely related to these recommendations are given. For more terminology definitions, references are given as follows:

- Fatigue assessment, see [Lit. 48]

- Actions, see [Lit. 49]

- Probabilistic methods, see [Lit. 8]

\begin{tabular}{|c|c|}
\hline $\begin{array}{r}\text { Keyword in: English } \\
\text { German } \\
\text { French } \\
\end{array}$ & Definition \\
\hline $\begin{array}{l}\text { Fatigue } \\
\text { Ermüdung } \\
\text { Fatigue }\end{array}$ & $\begin{array}{l}\text { The process of initiation and propagation of cracks through a } \\
\text { structural part due to action of fluctuating stress. }\end{array}$ \\
\hline $\begin{array}{l}\text { Fatigue life } \\
\text { Lebensdauer } \\
\text { Durée de vie (à la fatigue) }\end{array}$ & $\begin{array}{l}\text { The predicted period of time to cause fatigue failure under the } \\
\text { application of the design or assessment spectrum. }\end{array}$ \\
\hline $\begin{array}{l}\text { Remaining fatigue life } \\
\text { Restlebensdauer } \\
\text { Durée die vie restante }\end{array}$ & $\begin{array}{l}\text { The period between the date when the assessment is carried out and } \\
\text { the calculated end of fatigue life. The calculated period can be both } \\
\text { negative and positive where a positive values mean there is a } \\
\text { remaining fatigue life and a negative values mean there is no } \\
\text { remaining fatigue life with acceptable safety prediction. }\end{array}$ \\
\hline $\begin{array}{l}\text { End of fatigue life } \\
\text { Ende der Lebensdauer } \\
\text { Fin de durée de vie }\end{array}$ & $\begin{array}{l}\text { The end of fatigue life of a structural element is reached when a } \\
\text { failure in it leads to an unacceptable reduction of safety from the } \\
\text { ultimate limit state point of view and / or to an unacceptable limitation } \\
\text { of the serviceability. }\end{array}$ \\
\hline $\begin{array}{l}\text { Residual service life } \\
\text { Verbleibende } \\
\text { Nutzungsdauer } \\
\text { Durée de vie résiduelle }\end{array}$ & $\begin{array}{l}\text { The period between the date when the assessment is carried out and } \\
\text { the end of service life. Nowadays the service life is directly related to } \\
\text { the safety level chosen for the design and therefore it is somewhere } \\
\text { also named design life. It has to be kept in mind that a design } \\
\text { calculation carried out in the past was not related to a fixed service } \\
\text { life. The calculated period can be both negative and positive where a } \\
\text { positive values mean there is a residual service or design life and a } \\
\text { negative values mean there is no theoretical safety for a residual } \\
\text { service or design life. }\end{array}$ \\
\hline $\begin{array}{l}\text { Pig iron } \\
\text { Roheisen } \\
\text { Gueuse de fonte, fers crus }\end{array}$ & $\begin{array}{l}\text { Product of the blast furnace; iron without any after-treatment and a } \\
\text { carbon content of } 3-4 \% \text {; basic material for conversion into cast iron } \\
\text { or steel. }\end{array}$ \\
\hline $\begin{array}{l}\text { Cast iron } \\
\text { Gusseisen } \\
\text { Fonte }\end{array}$ & $\begin{array}{l}\text { Iron with a carbon content }>2 \% \text {; made by re-melting pig iron. It is } \\
\text { brittle and cannot be forged or welded, see section } 3.4 \text {. }\end{array}$ \\
\hline $\begin{array}{l}\text { Steel } \\
\text { Stahl } \\
\text { Acier }\end{array}$ & Every iron alloy, which is forgeable (carbon content $<2 \%$ ). \\
\hline $\begin{array}{l}\text { Wrought / Puddled steel } \\
\text { Schweißstahl / Puddelstahl } \\
\text { Fer puddlé }\end{array}$ & $\begin{array}{l}\text { Steel produced in the puddling furnace with a very small carbon } \\
\text { content of almost less than } 0.08 \% \text {. It has a high anisotropy and usually } \\
\text { contains slag layers, see section } 3.4 \text {. Usually also known as wrought } \\
\text { iron (Schweißeisen / acier puddle) even if the term is wrong in it's } \\
\text { metallurgical meaning (see definition of steel). }\end{array}$ \\
\hline
\end{tabular}




\begin{tabular}{|c|c|}
\hline $\begin{array}{r}\text { Keyword in: English } \\
\text { German } \\
\text { French } \\
\end{array}$ & Definition \\
\hline $\begin{array}{l}\text { Mild steel }\left(19^{\text {th }} \text { century }\right) \\
\text { Flussstahl }(19 . \text { Jhd.) } \\
\text { Acier doux (19. siécle) }\end{array}$ & $\begin{array}{l}\text { Low-carbon steel produced by blast process (Bessemer or Thomas } \\
\text { process) or hearth process (Siemens-Martin process), see section } 3.4 \text {. } \\
\text { Excess carbon and other impurities were oxidised from pig iron to } \\
\text { produce steel, which was normally un-killed (rimmed). In the } \\
\text { Bessemer process only low-phosphorus pig iron could be treated by } \\
\text { acid lining of the converter whereas in the Thomas process also pig } \\
\text { iron with a high content of phosphorus could be converted because of } \\
\text { a basic of the converter. In the Siemens-Martin process pig iron could } \\
\text { be melted together with steel scrap and/or iron ore. Metallurgical } \\
\text { treatment was possible in the hearth furnace. Siemens-Martin steel has } \\
\text { a lower content of nitrogen than Bessemer or Thomas steel. }\end{array}$ \\
\hline $\begin{array}{l}\text { Mild steel }\left(20^{\text {th }} \text { century }\right) \\
\text { Flussstahl }(20 . \text { Jhd.) } \\
\text { Acier doux (20. siécle) }\end{array}$ & $\begin{array}{l}\text { Low-carbon low-alloyed steel produced in the end of the } 19^{\text {th }} \text { and the } \\
\text { beginning of the } 20^{\text {th }} \text { century using the Thomas or Siemens-Martin } \\
\text { process. This kind of steel has properties close to those of modern } \\
\text { mild steels (S235, S355), see section 3.4. Depending on the degree of } \\
\text { deoxidation the steel can be un-killed (rimmed), semi-killed or killed. }\end{array}$ \\
\hline $\begin{array}{l}\text { Assessment spectrum } \\
\text { Beurteilungsspektrum } \\
\text { Spectre d'évaluation }\end{array}$ & $\begin{array}{l}\text { The total of all stress-range spectra in the remaining fatigue life of an } \\
\text { assessed structure, which are relevant to the fatigue assessment. }\end{array}$ \\
\hline $\begin{array}{l}\text { Fatigue strength curve } \\
\text { Ermüdungsfestigkeitskurve } \\
\text { Courbe de résistance à la } \\
\text { fatigue }\end{array}$ & $\begin{array}{l}\text { The quantitative relationship between the stress range and number of } \\
\text { stress cycles to fatigue failure, used for the fatigue assessment of a } \\
\text { particular category of structural detail. The fatigue strengths given in } \\
\text { these recommendations are lower bound values based on the } \\
\text { evaluation of fatigue tests with large scale test specimens. }\end{array}$ \\
\hline $\begin{array}{l}\text { Detail category } \\
\text { Kerbdetail, Kerbklasse, } \\
\text { Kerbfall } \\
\text { Catégorie de détail }\end{array}$ & $\begin{array}{l}\text { The numerical designation given to a particular detail for a given } \\
\text { direction of stress fluctuation, in order to indicate which fatigue } \\
\text { strength curve is applicable for the fatigue assessment. The detail } \\
\text { category number in these recommendations indicate the reference } \\
\text { fatigue strength } \Delta \sigma_{\mathrm{c}} \text { in } \mathrm{N} / \mathrm{mm}^{2} \text { related to a specific endurance }\left(2 \cdot 10^{6}\right. \\
\text { load cycles) as it is defined in Eurocode } 3 \text {, Part } 1-9 \text {, too. }\end{array}$ \\
\hline
\end{tabular}

\subsection{General assessment procedure}

(1) The assessment of an existing structure aims at producing evidence that it will function safely over a specified residual service life. It is mainly based on the results of assessing hazards and load effects to be anticipated in the future, and of assessing material properties and geometry taking into account the present state of the structure [Lit. 8]. Guidelines for existing structures exist in a large number of countries. Thereby many countries have presented documents for particular categories of structures. In Canada, Germany, the Netherlands, Switzerland, UK and USA such guidelines have been prepared at a detailed level. In any assessment, the problem of fixing risk acceptance criteria is difficult since it must be compatible to codes for new structures (limit state analysis, safety factor format, etc.), and with national determined parameters (generally partial safety factor values). The engineer has to think about risk acceptance criteria and is referred to section 1.7 for more information.

(2) The process of any structural assessment can be separated in the four phases, see Fig. 1-6 and for example [Lit. 8, Lit. 9, Lit. 124]. 
Phase I Preliminary Evaluation: the aim is to remove existing doubts about safety of the structure using fairly simple methods and identify critical parts or members in the structure. This is performed by gathering information on the structure from drawings and design computations, carrying out a site visit, etc. The assessment should be carried out by the engineer alone. Assessment is performed by using current codes and by making conservative assumptions where information is lacking or doubtful.

Phase II Detailed investigation: the aim is to update information and to carry out refined assessments only for those members where safety is not ensured. This is done by doing quantitative inspections (for example using easy to use, low tech NDT methods), the use of updated values for loads, resistance, as well as more accurate models (static system, structural behaviour). Here, in addition to the engineer, a specialised firm or agency or individual experts are generally called in.

Phase III Expert investigation: for problems with large consequences in terms of risks or of costs related to a decision, a team of experts should be called in order to check carefully the conclusions and proposals reached in Phase II. Discussions and further assessments using specific tools (high tech NDT methods, probabilistic methods, fracture mechanics, etc.) can also be carried out to help in reaching decisions.

Phase IV Remedial measures: the aim is to propose measures to have a fit for service structure with sufficient safety. Different measures can be taken, among them one can mention: intensification of monitoring, reduction of loads or change in use, strengthening, repair or rehabilitation. The choice of the measures to be taken will be function of the structure studied but in any case the proof of adequacy of the measures to insure safety must be shown.

(3) These phases will be further developed - with a focus on existing steel bridges and fatigue - in chapter 2 .

(4) The problem of existing bridges and of their assessment have recently increased. Indeed, the current low funding in the infrastructure sector of many European countries forces the owners as well as the operators to postpone investments in new road and railway bridges and consequently stretch the service life of their existing old structures. Therefore, the owner of the infrastructure nowadays sees itself facing two main challenges: need of a further continuing safe operation of the ageing bridges and of cost effective maintenance. Methods must be provided that enable engineers to offer safe and cost effective assessment and maintenance methods to their clients. 


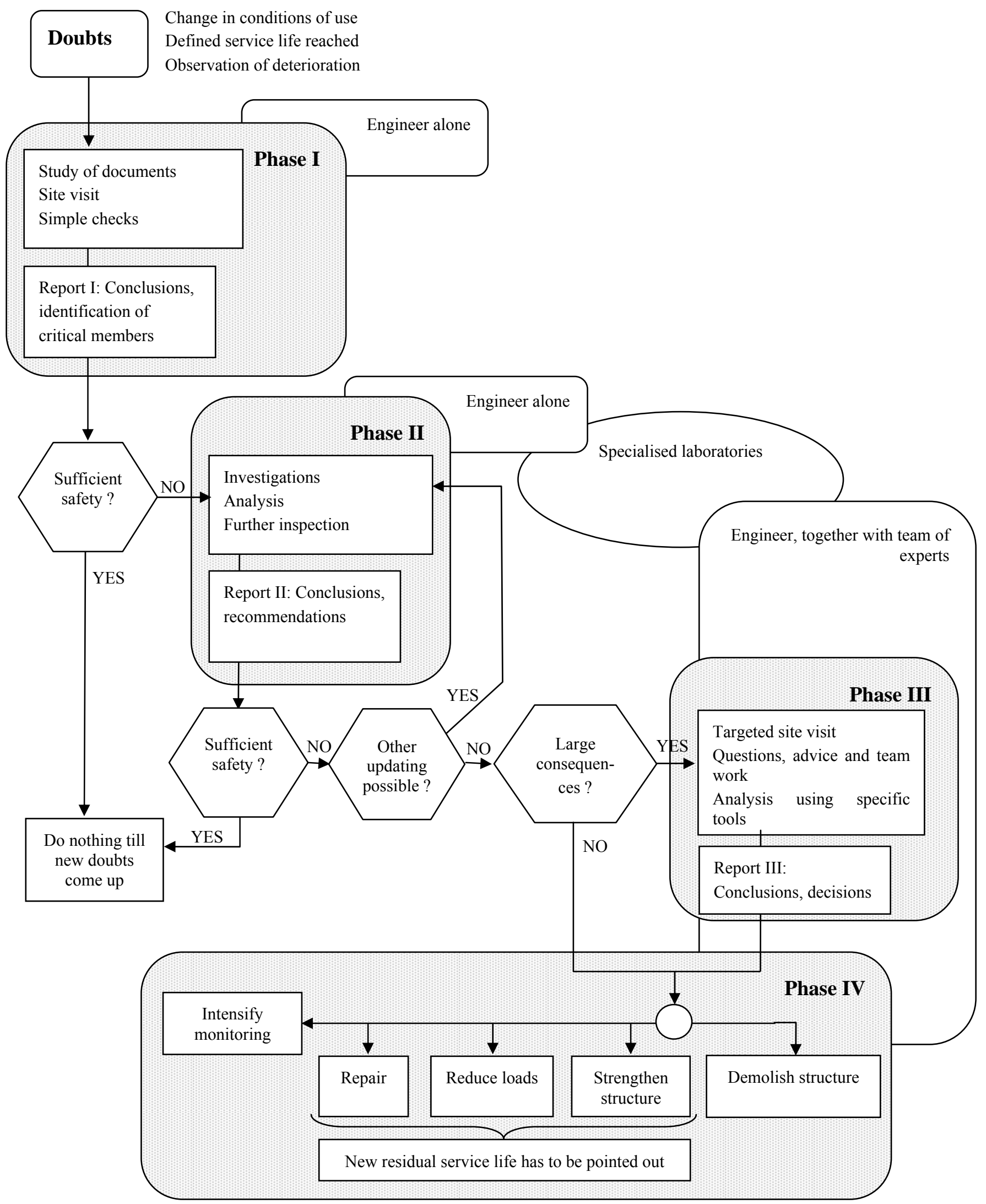

Fig. 1-6: Illustration of the four phases general assessment procedure. 
(5) In existing steel bridges, the connection technique most widely-used during the decades around the turn of the $20^{\text {th }}$ century was riveting. Afterwards, bolted connections followed and are still widely in use. Welding techniques started to be used in the middle of 1930's; nowadays welding is used for almost every steel bridge.

(6) The process for the assessment of structural safety can be initiated for different reasons and results in various measures. This process can be distinguished in the following steps (see Fig. 1-6 and for example [Lit. 9]):

1. Motivation for an assessment. The assessment may be initiated for different reasons:

- evolution of conditions of use: increase of the axle loads, increase of the distributed loads, changes in the traffic volume. In all these cases, an assessment of the load carrying capacity has to be performed prior to the fatigue safety assessment;

- exceptional incidents during use (such as impact of vehicles, earthquakes, flooding, etc.)

- legal reasons: the defined or presumed service life is reached;

- observation of deterioration: defects or damaged elements on the bridge, increasing in displacements or vibration characteristics, occurrence of corrosion, etc. Note that in many cases serviceability was not calculated, because the calculation procedure has not been standardized before the 1960's.

2. Identification of the critical details. At this stage, the bridge is assumed to be designed as new. This corresponds to Phase I and it involves:

- finding information about the bridge (drawings, design computations, former inspection minutes), use of a bridge management system (BMS) if any;

- site visit with visual observation and qualitative inspection, appraisal of the bridge (how has the bridge really been built, what is its actual state)

- way of classifying the criticality of the members.

3. If sufficient safety cannot be shown for every member, assessment according to Phase II is needed.

4. Depending on the results, different strategies can be proposed to the owner. It includes more updating, or remedial measures (Phase IV) such as monitoring, rehabilitation, or strengthening.

5. If needed or if the consequences of failure are large, collaboration with a team of experts as shown in Phase III can be in done. Again, the aim is to propose possible strategies involving remedial measures (Phase IV) such as monitoring, rehabilitation or strengthening to the owner.

6. Cost-benefit-analysis. The costs and the benefit of each measure on the residual service life and/or safety level, with reference to the "take no measure" state, can be evaluated and compared. The strategy for the optimal life-cycle costs has to be found.

\subsection{Risk acceptance criteria}

(1) The assessment of the reliability of an existing structure aims at producing the evidence, that it will function safely over a specified residual service life. In evaluating the reliability of an existing structure, the following questions arise,

- what are the consequences in accepting a lower safety level and thereby the accompanied risks

- how to define risk acceptance criteria and

- what are adequate safety goals for them. 
(2) In general the consequences in accepting a lower safety level and thereby the accompanied risks should be clarified and discussed between the client, the owner and the relevant authority in order to clarify who profits from the risks and who bears the consequences. This may be done by defining a List of Accepted Risks (LAR).

(3) The definition of risk acceptance criteria may in general be based on a safety class differentiation system covering various important items which are responsible for the reliability of structures. Typically risk acceptance criteria (important in evaluating the safety) are the following items:

- Redundancy. Many codes for existing structures (e.g. [Lit. 68]), and nowadays also many codes for new structures (e.g. [Lit. 73]), relate the probability of failure to the redundancy of the structure. Concerning redundancy, one may differentiate between the system behaviour or the component behaviour by considering the entire structure or only simple members and their type of failure, e.g. ductile or brittle failure, or in bridge structure, e.g. redundancy in longitudinal or transverse direction.

- Importance of structure and consequences of failure. This criterion depends on the socioeconomical and political importance of the structure itself, e.g. the risk acceptance criteria for a major motorway bridge may be more severe than for a local country road. An additional aspect may also be the consequence of failure of a structure considering safety of people in, on, under or near the structure. Large consequences of failure in general mean that the structure is of high socio-economical value and its failure will cause human life losses.

- Inspection level. An important feature in defining risk acceptance of existing structures should be the inspectability of structural components and the supposed inspection intervals. Concerning the inspectability it is obvious that for structural components that are not inspectable, e.g. hidden members such as interior webs, the acceptance criteria should be much more severe than for easily inspectable members. Concerning the inspection interval the higher the inspection interval the higher the accepted risks.

(4) Defining an adequate safety level for the risk acceptance of existing structures can be done by setting up target reliability indices $\beta$ taking into account the above mentioned classification items. Explicit values for target reliability indices are for example given in [Lit. 59, Lit. 68 or Lit. 124]. However, the definition of risk acceptance criteria based on target reliability indices in general needs knowledge about probabilistic assessment procedures, and should only be performed by experts. To overcome this problem, some codes propose a set of easy to apply safety factors that cover the main risk acceptance items such as the redundancy or the consequence of failure of structural elements [Lit. 73]. This procedure is therefore much easier for the assessment of existing structures, and is usually compatible with the limit state design of new structures.

A summary about the various ways in defining risk acceptance criteria and corresponding safety levels is given in [Lit. 69]. 


\section{FATIGUE ASSESSMENT PROCEDURE FOR EXISTING STEEL BRIDGES}

\subsection{Introduction}

(1) Fatigue is a specific case of deterioration that is of great importance in the assessment of existing steel bridges. In the following sections, the various phases of the fatigue assessment will be elaborated upon. From the general assessment procedure scheme in Fig. 1-6, the fatigue assessment procedure shown in Fig. 2-1 can be derived.

(2) In most cases the fatigue assessment of an existing steel bridge will occur after a similar assessment of the static strength is carried out in accordance with the general assessment procedure presented in section 1.6. Herein, it is assumed that the bridge has either passed this first assessment, or sufficient remedial measures have been implemented to ensure adequate static strength. 


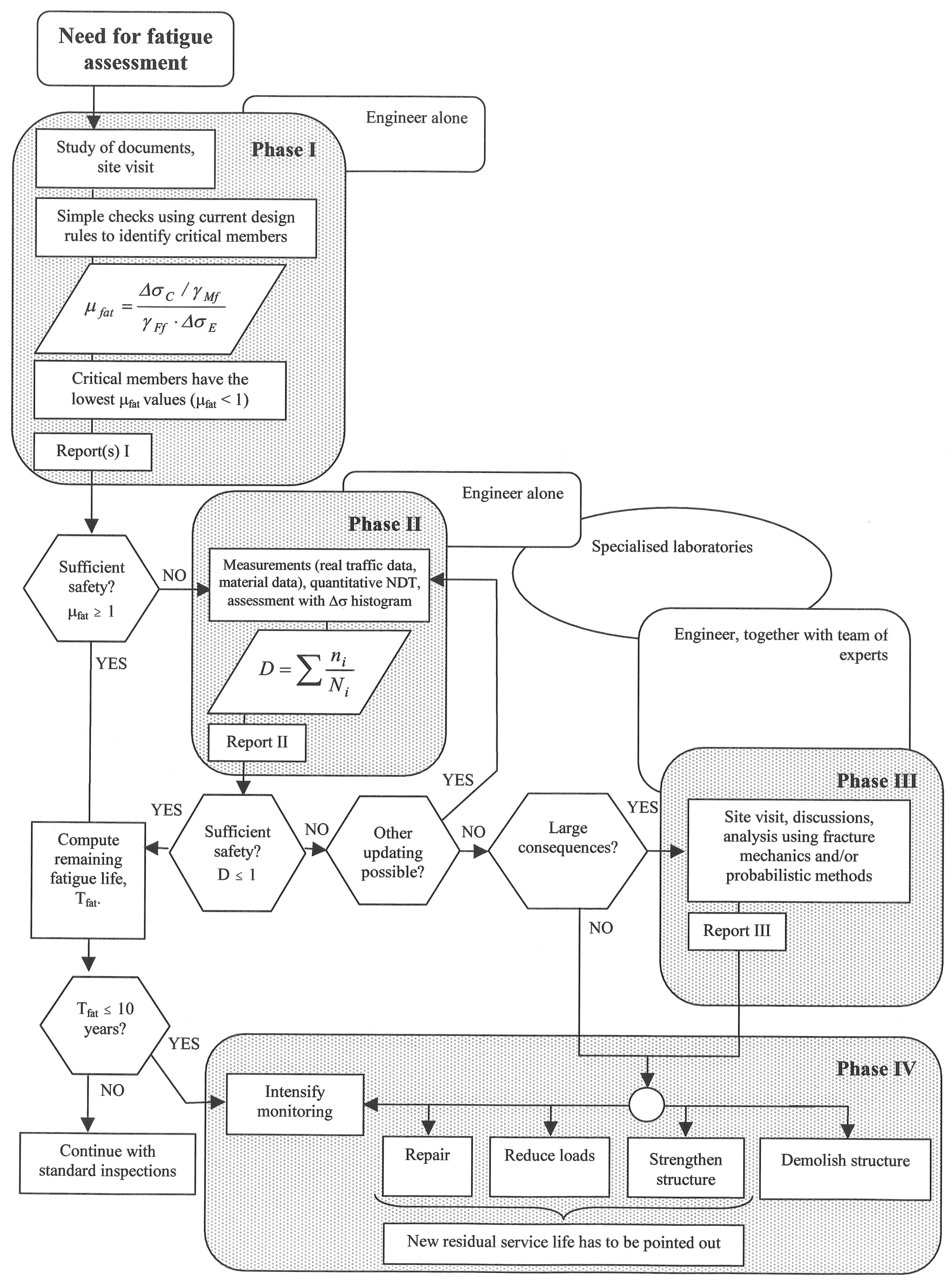

Fig. 2-1: $\quad$ Fatigue assessment procedure for existing steel bridges 


\subsection{Phase I: Preliminary evaluation}

(1) As mentioned in Section 1.6, the aim of the preliminary evaluation is to remove existing doubts about the safety of the structure using fairly simple methods and identify critical parts or members in the structure. At this stage, the assessment is carried out by the engineer alone. In order to identify critical members (fatigue critical construction details), it is necessary to carry out an intensive study of the available documents, along with a visual inspection of the structure (see Sections 3.2 and 3.6.2). Sometimes, the available documents are incomplete and it may also be determined that there were little (if any) fatigue calculations done at the time of design. In all cases, even when there is significant documentation available, it is important to perform an inspection of the bridge.

(2) One cannot rely solely on drawings and design calculations, but one must also obtain information about the bridge as it was built, and its maintenance. When performing this inspection, the following points must be checked (or checked further if they initiated the assessment):

- Does the actual bridge construction conform to the drawings? If not what are the differences?

- Has the bridge been modified (rehabilitated, strengthened, undergone changes in the static system, etc.)?

- Is there any visual evidence of degradation (damaged expansion joints, supports, corrosion, cracks, vibration or loose rivets etc.)?

(3) In this respect, inspection and maintenance reports can be particularly helpful. The most commonly used inspection method to detect bridge deterioration, even fatigue cracks, is the relatively elementary visual inspection (see Section 3.6.2). This explains why most cracks in steel bridges have been first detected in this manner.

(4) For Phase I, preliminary evaluation should be conducted as for design of a new structure, that is by using current codes and recommendations and making conservative assumptions where information is lacking or doubtful. In this manner, critical construction details can be identified. Calculations such as this are quick and give a good estimation of the safety level of each detail on the bridge. Most current codes are based on the classification method which employs S-N curves in conjunction with detail category tables (see [Lit. 48] or [Lit. 50]). For the fatigue limit state, the safety level can be expressed by:

$$
\mu_{f a t}=\frac{\Delta \sigma_{c} / \gamma_{M f}}{\gamma_{F f} \cdot \Delta \sigma_{E, 2}}=\frac{\Delta \sigma_{c}}{\gamma_{F f} \cdot \gamma_{M f} \cdot \Delta \sigma_{E, 2}}
$$

$\mu_{\text {fat }} \quad: \quad$ fatigue safety level

$\gamma_{\mathrm{Ff}} \quad: \quad$ partial safety factor for equivalent constant amplitude stress range $\Delta \sigma_{\mathrm{E}, 2}$

$\Delta \sigma_{\mathrm{E}, 2}: \quad$ equivalent constant amplitude stress range at $2 \cdot 10^{6}$ cycles

$\Delta \sigma_{\mathrm{c}} \quad$ : fatigue resistance at $2 \cdot 10^{6}$ cycles (detail category)

$\gamma_{\mathrm{Mf}}:$ partial safety factor for fatigue strength $\Delta \sigma_{\mathrm{c}}$

(5) This method is presented conceptually on a log-log scale in Fig. 2-2. Rules for the determination of $\gamma_{\mathrm{Ff}}, \Delta \sigma_{\mathrm{E}}, \Delta \sigma_{\mathrm{c}}$ and $\gamma_{\mathrm{Mf}}$ are given in current codes such as [Lit. 50]. For various structural details, the reference value of the fatigue strength at $2 \cdot 10^{6}$ cycles $\Delta \sigma_{c}$, also referred to as the "Fatigue strength", is normally presented (in tabular form) by a description of the detail and the applied nominal stress. 


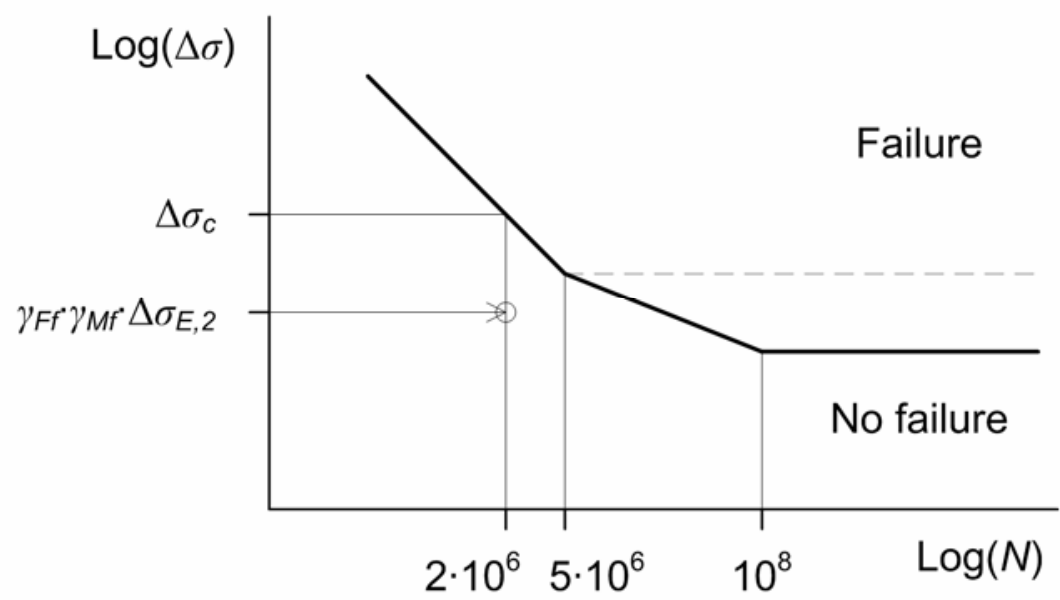

Fig. 2-2: $\quad$ Preliminary evaluation of fatigue safety level

(6) A variation of the classification method is the geometrical (hot spot) stress method. In this method, the value of the stress range is evaluated at the location of cracking (usually the weld toe) by appropriate means [Lit. 48, Lit. 50]. The design curve is then independent of the detail and there are only a few curves [Lit. 48].

(7) Many current codes require a structural assessment when significant changes to the structure are planned. If this is the case, or if the assessment has been initiated due to changes in the conditions of use (see Section 1.6), then these changes should be considered in the preliminary evaluation. A conservative way to do this would be to evaluate each structural element using the more severe of the two load cases (prior to or after change in structure or conditions of use).

(8) For $\mu_{\text {fat }} \geq 1$, the investigated element fulfils the fatigue safety requirements. For $\mu_{\text {fat }}<1$, the fatigue safety needs to be further assessed. Analysing the elements of the structure in this way, one can derive a list of priorities for subsequent, more thorough investigations. Once the critical construction details are known, that are the details with the lower $\mu$ fat values, a calculation of the remaining fatigue life can be made.

(9) At the end of the Phase I work at a given point in time, a report (Report(s) I in Fig. 2-1) should be prepared identifying the critical members, summarising the calculations conducted and the conclusions. This is an important step, as this report will provide the bridge owner and the engineers responsible for the following assessment phases with useful information as well as justification for possible further assessment or remedial action.

\subsection{Phase II: Detailed investigation}

(1) The aim of the detailed investigation is to update the information obtained in Phase I by carrying out refined assessments only for those members for which adequate safety was not confirmed by the preliminary evaluation. At this stage, in addition to the engineer, a specialised firm, agency or individual experts may be consulted. Once the critical construction details are known, e.g. the lower $\mu_{\text {fat }}$ values (including all details with $\mu_{\text {fat }}<1$ ), a calculation of the remaining fatigue life can be made.

(2) This calculation normally takes the form of a damage accumulation calculation (see Fig. 2-3). The most commonly used method is the linear Palmgren-Miner damage rule [Lit. 51] which can be simply stated as follows: 


$$
D=\sum \frac{n_{i}}{N_{i}} \leq 1
$$

$n_{i} \quad$ : number of cycles occurring at stress range magnitude, $\Delta \sigma_{i}$ of a stress spectrum

$N_{i} \quad$ : number of cycles corresponding to a particular fatigue strength at stress range magnitude, $\Delta \sigma_{i}$

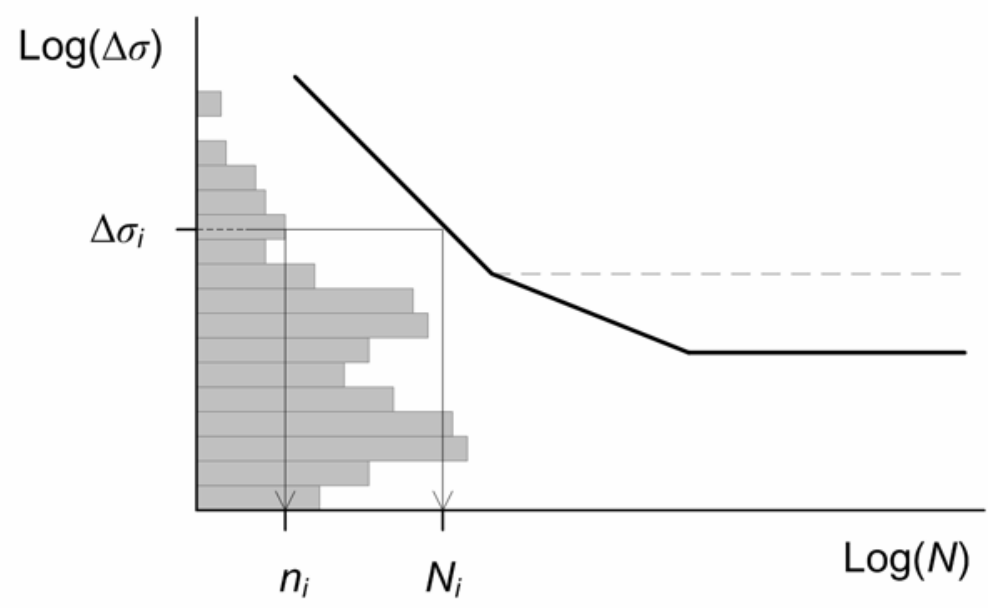

\section{Fig. 2-3: $\quad$ Damage accumulation calculation}

(3) In practice, the above equation may be applied at the simplest level to a single equivalent constant amplitude stress range (as may be the case for the code-based preliminary evaluation). For more detailed investigations, the equation can be applied to the multiple stress ranges comprising a design stress spectrum or histogram (see Fig. 2-3). $N_{i}$ in either case is determined using the S-N curve-based classification method. To improve the accuracy of such calculations, the information used in Phase I is to be updated.

(4) The loading can be superior or inferior to the design values. For design, conservative permanent load values, conventional load models and partial safety factors from codes are used. To insure safety, these are calibrated using rules, which consider that: 'the worst case is always possible, even if unlikely', and 'provisions should be made for future traffic load increases'. The same holds true for the strength (due to degradation). This normally involves the use of updated values for the various load and resistance parameters as well as the adoption of more accurate models (static system, structural behaviour, etc.), but can also involve quantitative inspections (i.e. NDT methods) when necessary (these latter concern rather Phase III).

(5) The following steps can thus be taken:

- Updating load information: in general, loading represents the greatest uncertainty compared to the other factors listed below and should be refined first. Instead of the current code-specified axle loads and traffic volumes, actual (measured) or more refined traffic models can be used. With these more realistic models, more reliable and in many cases extended predictions of the remaining fatigue life are possible. It should be kept in mind, however, that measurements at a given point in time have to be extrapolated into the past as well as into the future. Sometimes, especially for railway bridges, statistical data on the real traffic over the lifetime of the structure can be obtained and used to further improve the predictions. Chapter 4 discusses in greater detail the various possibilities for updating the load information. 
- Refining the model: the static model is often more conservative than needed. The primary stresses calculated can generally be 10 to $40 \%$ higher than the actual values in the structure, depending on the modelling method used for the assessment. For fatigue this means an extension of the expected service life by a factor 1.3 to 2.7 , assuming $\mathrm{m}=3.0$ (1.6 to 5.4 if $\mathrm{m}=5.0$ is assumed). On the other hand, apart from the primary induced stresses, the fluctuating loads can also induce secondary stresses, impact stresses, distortions, out-of-plane deformations and vibrations. These effects are not generally considered in the static model and are difficult to quantify. They - especially distortions and secondary stresses - are responsible for a large number of the fatigue cracks found in service. By suitable measurements on the bridge, uncertainties about stresses and stress ranges can be reduced (see Chapter 4). These uncertainties may also be reduced by using more refined structural models (i.e. plate or shell FE-models), possibly validated using the measured data.

- Updating resistance information: the characteristic values for the S-N fatigue resistance curves are often conservative. Perhaps the constructional detail on the bridge has not been properly categorised, and thus, a lower detail category had to be used in Phase I. The type of steel used on the bridge may not be known. Looking for the necessary information concerning similar cases in the available literature or performing material testing either on replaceable components or on sub-sized specimens removed from the bridge may help to improve the quality of the assessment (see Chapter 3).

(6) An illustration of the result of these steps is presented in Fig. 2-4 where assessment is needed because of an increase in traffic loads. Updating has shown that there was some conservatism in the strength, dead loads and permanent actions. The assessment shows that once the updated values are used, the structure can carry safely the new traffic loads, even if they are larger than the live loads for which the structure was originally designed.

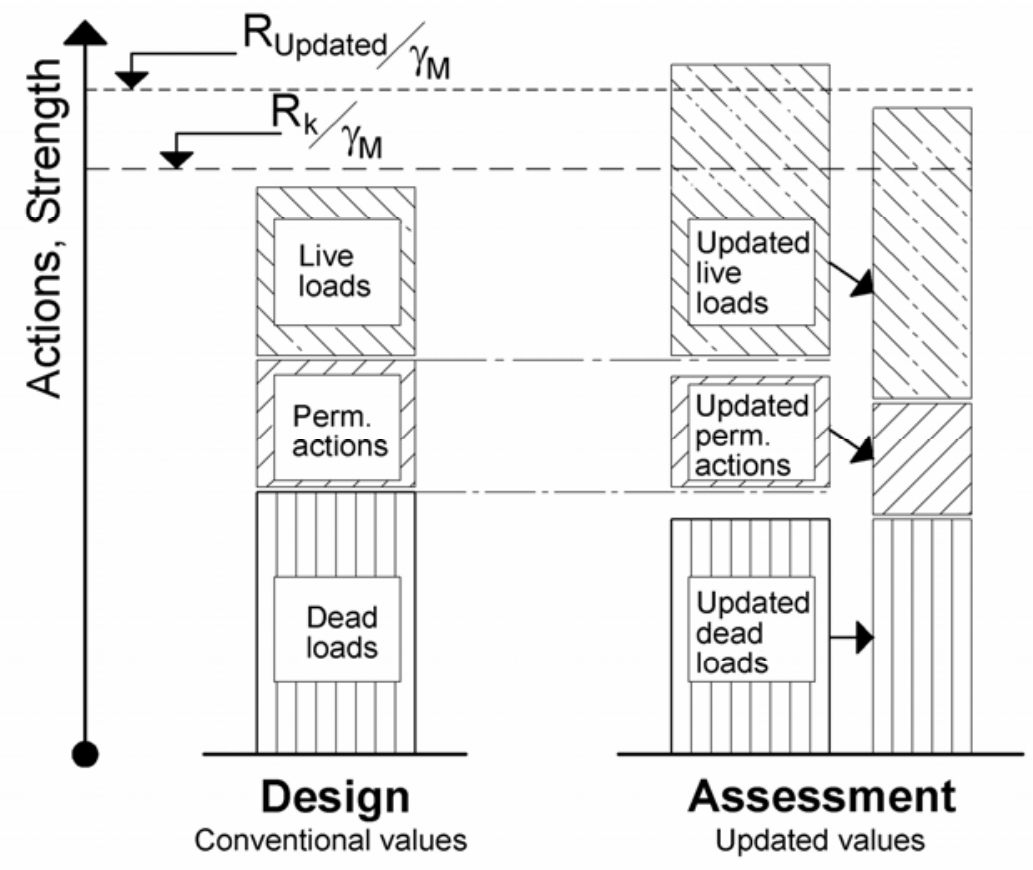

Fig. 2-4: $\quad$ Design and assessment conditions (loads including partial load factors too)

(7) If these steps do not lead to damage D less than 1, then the severity of the consequences of failure must be considered (see Fig. 2-1). Depending on the consequences of failure and/or the cost of remedial action, an expert investigation may be justified. 
(8) Importantly, at the end of the Phase II work, a report (Report II in Fig. 2-1) should be prepared identifying the critical members and summarizing the calculations conducted and conclusions.

\subsection{Phase III: Expert investigation}

\subsubsection{General}

(1) For problems with large consequences in terms of risks or of costs related to a decision, a team of experts should be called in order to carefully check the conclusions and proposals reached in Phase II. Discussions and further assessments using specific tools can also be carried out to help in reaching decisions. In this section these tools will be introduced and briefly discussed.

\subsubsection{Fracture Mechanics}

(1) Until this point, the discussion of fatigue assessment, either on a preliminary or a detailed level, has been limited to variations of the S-N curve-based classification method. This method has the advantages of being relatively simple and widely adopted by the engineering profession. Backing the method are large databases of small and large scale fatigue test results for various structural details. With this experience comes a certain degree of confidence, which can be of great value to the engineer either in assessment or in the design of new structures.

(2) Despite these advantages, the classification method has several disadvantages, the most important of which is the fact that the method cannot be used to provide information about crack size and anticipated crack growth rates at various stages of the service life of a structure. The use of fracture mechanics methods can be useful, where information about crack size is either known or needed. This may include situations where a fatigue crack has been detected, and information about the remaining fatigue life is needed.

(3) These methods can also be useful for determining inspection frequencies for example, and comparing the effectiveness of various inspection methods, for a given situation, as a function of their ability to detect cracks of a given size. Much information can be found about the various fracture mechanics methods in literature [Lit. 13, Lit. 14, Lit. 52, Lit. 53]. For more information, the reader is advised to refer to these sources. One limitation of fracture mechanics methods that should be noted here, is that their application for the assessment of "distortion-induced" fatigue cracking, due to secondary stresses, is rather complex. For this reason, it is recommended that extreme caution be exercised when employing these methods in situations where secondary stresses are expected to play a significant role.

(4) Simply stated, the basis for linear elastic fracture mechanics (LEFM) methods is the principle that the stress state very close to the tip of a crack can be uniquely described by a single parameter, referred to as the stress intensity factor $\mathrm{K}$, or under cyclic loading conditions, a stress intensity factor range $\Delta \mathrm{K}$. In general, $\Delta \mathrm{K}$ can be described by the following expression:

$$
\Delta K=Y \cdot \Delta \sigma \cdot \sqrt{\pi \cdot a}
$$

$a \quad: \quad$ crack size (i.e. depth or length)

$\Delta \sigma:$ applied cyclic stress range (often gross section stress for riveted structures)

$Y \quad$ : the product of various multipliers which account for the geometry of the crack, the geometry of the cracked body and (if necessary) the effect of non-uniform applied stresses - various detail/load specific formulations for $Y$ can be found in literature [Lit. 53, Lit. 75]. 
(5) Using the Paris law (see Fig. 2-5), the applied stress intensity factor range can be related to the rate of crack growth as follows:

$$
\frac{d a}{d N}=C \cdot \Delta K^{m}
$$

$C \quad$ : constant of the Paris law

$m$ : exponent of the Paris law

(6) Integrating the Paris law over the crack size, the fatigue life of a structural detail can be calculated:

$$
N=\int_{a_{0}}^{a_{c}} \frac{d a}{C \cdot \Delta K^{m}}
$$

$a_{0} \quad: \quad$ initial crack size (i.e. depth or length)

$a_{c} \quad$ : final or critical crack size (i.e. depth or length)

(7) Equations (2-3) to (2-5) provide the basis for conducting fracture mechanics calculations for a wide range of cases, including fatigue susceptible details on steel bridge structures. A fundamental assumption of LEFM-based fatigue calculations is that prior to loading, small initial cracks or defects are already present. Research has shown that this is (for practical purposes) an appropriate assumption for welded civil engineering structures [Lit. 76].

(8) Modifications to Equations (2-3) to (2-5) have been proposed in order to improve the accuracy of the basic fracture mechanics approach. A few of the more important ones are as follows:

- On a log-log plot of $d a / d N$ versus $\Delta K$, Paris law for stable crack growth results in a straight-line relationship, with a slope of $m$ (see Fig. 2-5). In reality, fatigue cracks in steel specimens are known to exhibit also non-linear behaviour, that is: as $\Delta K$ decreases it will approach a threshold value wherein the crack growth rate will decrease rapidly to zero. Ignoring this effect will generally lead to the underestimation of fatigue life (which is conservative), with the degree of underestimation depending on the number of stress cycles occurring near or below this threshold. In order to consider threshold effects, Equation (2-4) can be modified (for example) as follows:

$$
\frac{d a}{d N}=C \cdot\left(\Delta K^{m}-\Delta K_{t h}^{m}\right)
$$

$\Delta K_{t h} \quad: \quad$ threshold value of the elastic stress intensity factor range

$\Delta K_{\text {th }}$ can be set at a fixed value, however some researchers have suggested that $\Delta K_{t h}$ varies, in fact, with the stress ratio $R$, that is, the ratio of the minimum over the maximum applied stress. This phenomenon can be considered in the model with various expressions relating $\Delta K_{\text {th }}$ to the $R$-ratio, which can be found in literature [Lit. 53]. Alternatively, the $d a / d N$ versus $\Delta K$ relationship may be modelled using a 2-slope relationship. 


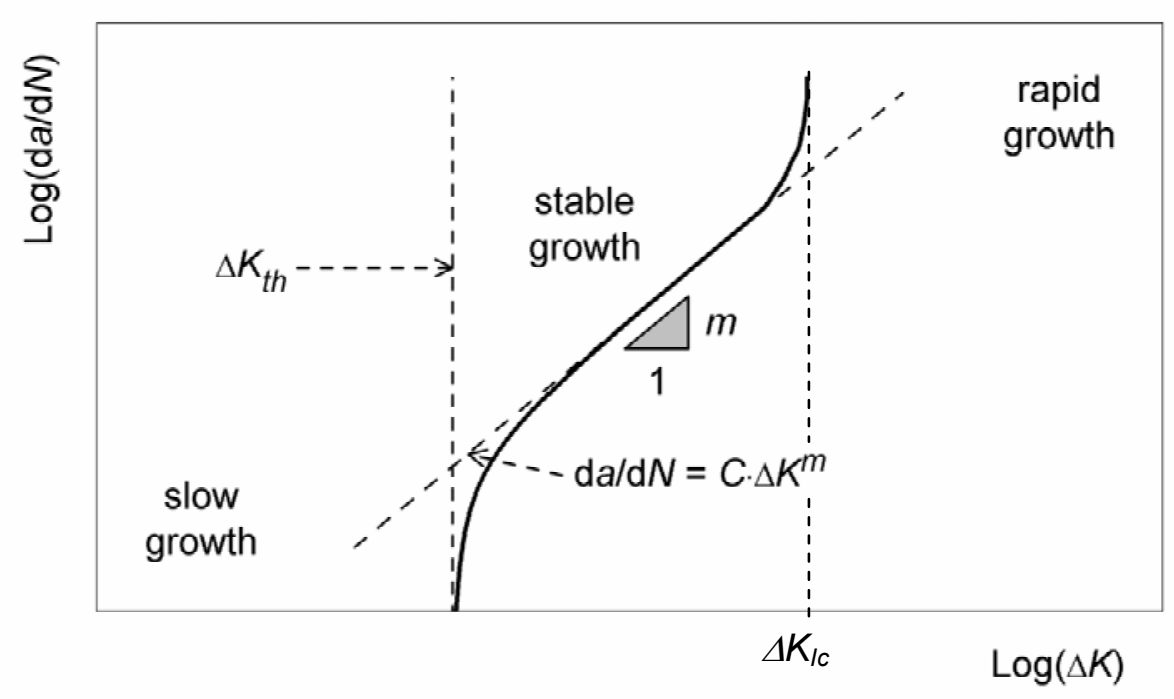

Fig. 2-5: $\quad$ Threshold stress intensity factor range, $\Delta K_{\text {th }}$.

(9) The following additional considerations on the da/dN- $\Delta \mathrm{K}$-relationship can be made:

- In the equations described above, the entire stress cycle, $\Delta \sigma$, is considered as contributing to crack growth. In fact, it is known that if the minimum applied stress intensity factor is negative (compressive), then only a portion of the stress cycle will be "effective". This effect is often (conservatively) ignored, however, as its significance may be reduced or even negated by the presence of tensile residual stresses at the crack location under investigation.

Residual stresses are known to be present in steel structures due to various elements of the fabrication process including hot-rolling, welding and possible lack of fit of the various elements comprising a larger structural assembly. In general, if these residual stresses are compressive, they will have a beneficial effect on fatigue life, and if they are tensile, they will have a negative effect. As an alternative to simply assuming that the entire applied stress cycle is effective (whether it's tensile or compressive), estimates or measurements of the residual stress field may be made, and the $\Delta K$ in Equation (2-4) may be replaced with an effective stress intensity factor range $\Delta K_{\text {eff }}$ which takes into account the effect of residual stresses using the principle of superposition. $\Delta K_{\text {eff }}$ is generally formulated in such a way that only the part of the stress cycle in which the stress intensity factor at the crack tip is positive will contribute to crack growth [Lit. 77].

- The previous point aside, some researchers have shown that even if the entire stress cycle is positive (tensile), it may not be entirely effective due to crack closure effects [Lit. 77, Lit. 78]. These effects may be a result of plasticity near the crack tip, roughness of the crack faces, or environmental aspects such as rust or fine particles collecting near the crack tip while the crack is open, which will inhibit (to some extent) full crack closure when the detail is "unloaded". Expressions also exist to take these phenomena into account, however, in general, it can be said that the effect of ignoring them is normally small, and will generally result in underestimation of the true remaining fatigue life.

(10) Once an appropriate model has been selected, values for the various input parameters must be determined. This can be a rather difficult task, as some of these parameters are known to vary significantly, and small changes in some of the input parameters can be shown to have a large effect on the calculated fatigue life. The following comments are made regarding the selection of appropriate input parameters for estimating remaining fatigue life using fracture mechanics methods: 
- The more complex the applied stress field is (secondary stresses, etc.) the more detail is needed in the model used to characterize this stress field (special boundary conditions, special element types, etc.).

- Where possible, input parameters should be based on field measurements (for detail and weld geometry and applied stress range) or materials tests (Paris $C$ and $m, f_{y}, \Delta K_{t h}, K_{I c}$ ) performed on the actual structure under investigation. If this is not possible, values for similar materials and fabrication procedures should be taken from the available literature. In general, when there is doubt, conservative values should be selected.

- A number of approaches exist for determining the applied cyclic stress range, $\Delta \sigma$, in Equation (2-3). Among the simplest of these is the equivalent stress range approach. According to this approach, the rate of fatigue damage due to the true, variable amplitude stress history is predicted using an equivalent constant amplitude stress range, $\Delta \sigma_{\mathrm{E}}$, which can be calculated using, for example, the following expression [Lit. 78, Lit. 85]:

$$
\Delta \sigma=\Delta \sigma_{E}=\left(\frac{\sum\left(n_{i} \cdot \Delta \sigma_{i}^{m}\right)}{\sum n_{i}}\right)^{1 / m}
$$

More elaborate methods exist for predicting the fatigue lives of details under variable amplitude loading conditions. These are discussed in a number of references, for example [Lit. 78].

- Several approaches exist for selecting an appropriate value for the initial crack size, $a_{0}$. These include: selecting a value based on actual measurements on the structure in question or on a similar structural detail, selecting a value which has been "calibrated" by back-calculation of the fatigue lives of test specimens similar to the details under evaluation, and/or selecting a value based on what is known to be the "minimum detectable crack size" for the method of NDT being employed.

- Likewise, several approaches exist for selecting the final or critical crack size $a_{c}$. This value may be taken as being equal to the thickness of the cracked element, or some percentage of this thickness. Alternatively, $a_{c}$ may be limited by appropriate brittle fracture or yield criteria like e.g. Failure-Assessment-Diagrams (FAD), see [Lit. 9, Lit. 13, Lit. 14, Lit. 17].

- Sensitivity studies should be conducted to determine the implications of the various assumptions made fore the values of the input parameters.

\subsubsection{Probabilistic Methods}

(1) Variations in some of parameters required for calculations based either on the classification method (or the similar geometric (hot-spot) stress method) or on the fracture mechanics method can be shown to have a significant effect on the calculated fatigue life. One way in which this uncertainty may be considered explicitly is through the use of probabilistic methods, which can be employed in conjunction with either the classification method or the fracture mechanics method. Normally, when these methods are used, the various "input parameters" (i.e. the detail category, the initial crack depth, etc.) are assigned deterministic values (i.e. $a_{0}=0.2 \mathrm{~mm}$ ). When probabilistic analysis is employed, these values are replaced with statistical distributions (i.e. $a_{0}=\mathrm{LN}\{0.2 \mathrm{~mm}, 0.045 \mathrm{~mm}\}$ ). The probability of failure is then determined, for a predefined limit state function.

(2) Much information can be found about the use of probabilistic methods in literature [Lit. 54, Lit. 55]. For more information, the reader is advised to refer to these sources.

(3) Probabilistic methods in the current context are primarily for determining the "probability of failure" $P_{f}$ or "reliability index" $\beta=-\Phi^{-1}\left(P_{f}\right)$ of a given structure or structural component, where $\Phi()$ is the standard normal cumulative distribution. In the case of fatigue, which is a 
deterioration process, $P_{f}$ and/or $\beta$ are usually presented as a function of some measure of time. Various codes and standards [e.g. a summary is given in Lit. 8] prescribe maximum $P_{f}$ (minimum $\beta$ ) targets for new and existing structures. Comparing the calculated $P_{f}$ and/or $\beta$ vs. time curves for a given structure or structural component with these target values, an estimate of the remaining fatigue life can be made.

(4) Fig. 2-6 presents sample $P_{f}$ and $\beta$ vs. time curves for a structural detail in a bridge. The different curves in this figure correspond with different assumptions for the critical crack depth, $a_{c}$. The first one corresponds with a limiting crack depth based on the so-called R6 yield/fracture criterion [Lit. 118]. The second and third correspond with arbitrary crack depth limits of 0.5 and 1.0 times the wall thickness of the cracked member.
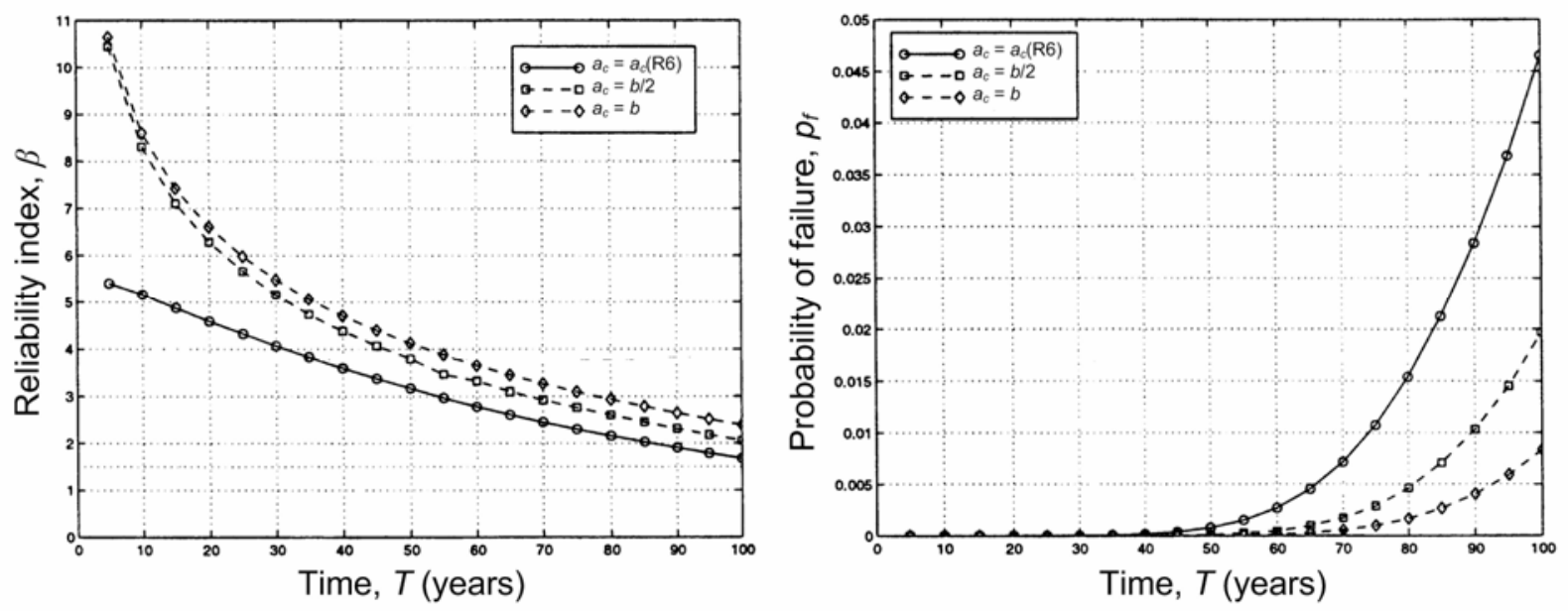

Fig. 2-6: $\quad$ Reliability index and probability of failure with time [Lit. 74]

(5) A necessary step in formulating the probabilistic model, whether it is based on the classification method or the fracture mechanics method, is to define a limit state function, $G\left(z_{i}\right)$, wherein $z_{i}$ are the $i$ probabilistic parameters characterizing either the "load" or the "resistance" of the structural element or detail. $G\left(z_{i}\right)$ is defined such that: $G\left(z_{i}\right)>0$ means the limit state is satisfied, whereas $G\left(z_{i}\right)<0$ signifies "failure". $G\left(z_{i}\right)=0$ represents the failure surface (see Fig. 2-7). Several criteria may be considered to define "failure". For the fracture mechanics method, these may include the exceedance of a critical crack size $a_{c}$, critical number of cycles $N_{c}$ or critical stress intensity factor $K_{l c}$. For the classification method, this may include surpassing a certain damage level, $D$ or fatigue safety ratio, $\mu_{\text {fat }}$.

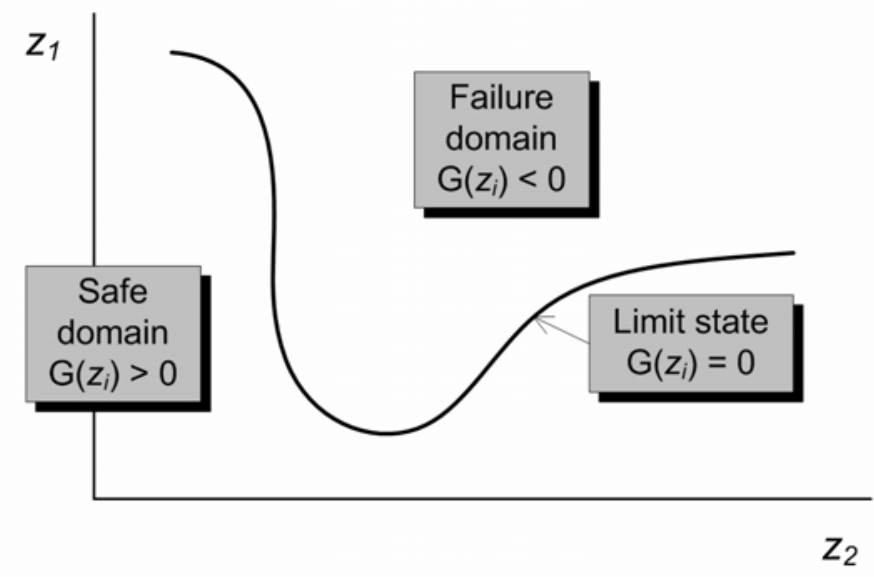

Fig. 2-7: $\quad$ Limit state function 
(6) The generic formulation for the limit state function of a structural problem wherein the "load" or "load effects" on the structure and its "resistance" are fully independent takes the following form:

$$
G\left(z_{i}\right)=\left.R\left(z_{i}\right)\right|_{i=1 \ldots j}-\left.S\left(z_{i}\right)\right|_{i=j+1 \ldots k}
$$

(7) The following is an example of a limit state function for a probabilistic model based on the fracture mechanics method, with failure defined as the exceedance of a critical number of cycles, $N_{c}$ :

$$
G\left(z_{i}\right)=N_{c}-N=\int_{a_{0}}^{a_{c}} \frac{d a}{C \cdot \Delta K^{m}}-N
$$

(8) In this expression, the first term on the right-hand-side can be roughly equated to a measure of the "resistance" of the structural detail (R), and the second term $N$ as a measure of the "load" or "load effects" (S). With the limit state function formulated, the next step is to replace the more important deterministic variables that occur in the function with appropriate probabilistic distributions. The "importance" of the various input parameters is determined by the extent to which their variation affects the result of the calculation. A sensitivity study is recommended to ensure that the most important parameters are treated in a probabilistic manner.

(9) Various methods exist for solving the limit state function. In general, the most common methods can be classified as either "reliability" or "simulation-based" methods. Reliability methods include the well known first- and second-order reliability methods (FORM and SORM, see Fig. 2-8), and variations thereof. The most well known simulation-based method is Monte Carlo simulation (MCS) which can be further subdivided into "crude" MCS or MCS with importance sampling. For more information on these methods, the reader is referred to the various specialized references on this subject [Lit. 54, Lit. 55].

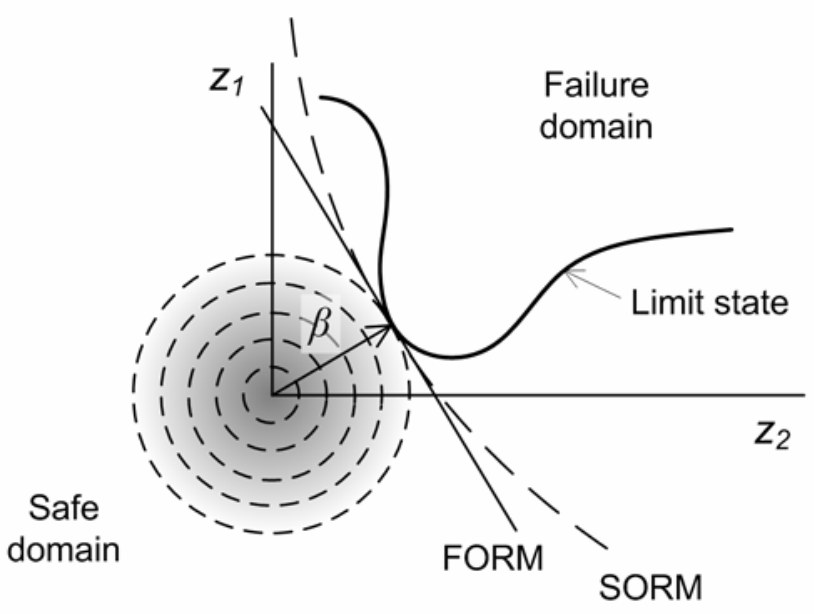

Fig. 2-8: $\quad$ Reliability methods

(10) Herein, the following additional comments are made, to provide some guidance in the application of probabilistic methods for the fatigue assessment of existing steel structures:

- [Lit. 8] discusses in some detail the interpretation of the results of probabilistic analyses such as the one described above. The most common interpretation of "probability of failure" is a "relative frequency that can be observed in reality". In the engineering of electronic or mechanical products wherein large databases of statistical data can be compiled for essentially identical components or systems, this definition may be appropriate. In civil engineering structures, however, [Lit. 8] suggests that "probability of failure" should be treated more as an estimate of the true probability of failure at best, 
which may serve as a useful tool for making comparisons and evaluating different scenarios, but should not be taken to mean anything more than this. The reason given for this is that civil engineering structures tend to be unique, and failures of civil engineering structures are considered to be extremely rare. Therefore, assertions regarding the probability of failure prove to be difficult if not impossible to verify.

- Although not elaborated on herein, many researchers have proposed probabilistic models that allow the engineer to see the effect that various inspection strategies will have on the probability of failure of a given structure over time (see Fig. 2-9). The minimum acceptable safety level referred to in this figure should be specified by a competent authority (some indications can also be found in different codes). As noted in [Lit. 8], only remedial actions will have an effect on the true probability of failure of the structure. What inspections offer is a means to reduce our level of ignorance of the actual state of the bridge, or in other words to modify the probabilistic distributions for the various input parameters based on new information.

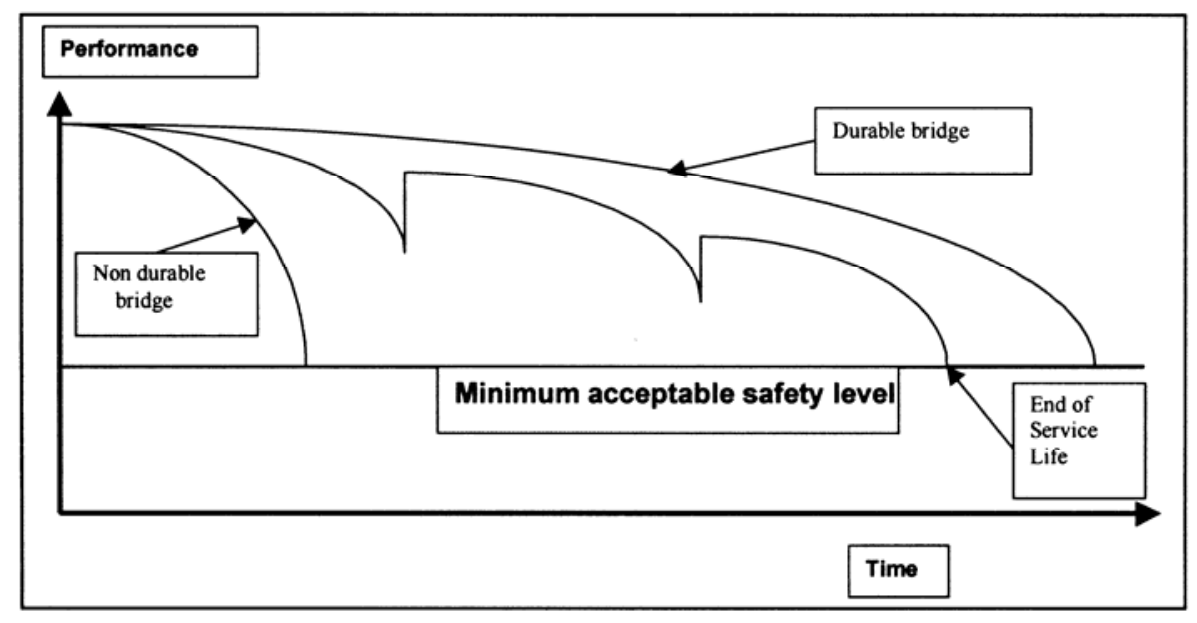

Fig. 2-9: $\quad$ Reliability re-evaluation [Lit. 57]

(11) Once again, at the end of the Phase III work, a report (Report III in Fig. 2-1) should be written identifying the critical members and summarizing the calculations conducted and conclusions.

\subsection{Phase IV: Remedial measures}

(1) If none of the assessments described in sections 2.2 to 2.4 provide ample justification for leaving bridge in service "as is" (i.e. continuing with standard monitoring, as per Fig. 2-1), then a suitable remedial measures must be implemented. The possibilities include strengthening, repair, intensification of monitoring, reduction of traffic loads or volume, and for the worst cases: demolition of the structure. These will be discussed in greater detail in Chapter 5. 


\section{STRUCTURAL AND MATERIAL INFORMATION}

\subsection{Introduction}

(1) In comparison to the fatigue assessment of a new structure, one of the biggest consequences of assessing an existing structure is that the structural and material information need not be estimated.

(2) This information can be determined from the structure itself. In particular for the structural information the assessing engineer should take profit from this fact (i.e. using as-built drawings or construction documents) in an early stage of the assessment like in the preliminary evaluation (Phase I).

(3) As mentioned in chapter 2 in phase I the engineer has to study first all available information of the structure. The engineer may also recall what the reasons for fatigue cracks are, where they can occur and how they can be identified. After investigation of drawings and all other available information the engineer should carry out the first site visit using the visual inspection to update drawings compared with the reality and to make a documentation on the state of the structure. In early stage of an assessment, but also for a detailed investigation (Phase II), the design values for material data and fatigue strength can be used, obtained from the available documentation about the structure, from national rules or taken as the values given in these recommendations.

(4) In cases where sufficient safety cannot be shown in the preliminary evaluation (Phase I), in Phase II (detailed investigation) one can take profit from a detailed measurement of the real cross section and, in cases where heavy corrosion can be observed, from the measurement of the remaining cross section.

(5) If sufficient safety cannot be shown in the preliminary evaluation (Phase I) and in the detailed investigation (Phase II) one can take profit from material data evaluated by destructive testing at a structure which can be more precise than lower bound values given in design codes or in these recommendations. For that the opportunity of material testing and/or measurements should be taken into account in an expert investigation (Phase III) and in some rare cases also in a detailed investigation (Phase II). Additionally one should keep in mind that by using NDT-methods, the outcome of detailed inspections can be improved qualitatively and quantitatively.

(6) Summarizing these, information about an existing structure and about the material (the assessed structure is made of) can be obtained from:

- Drawings and static calculations (see section 3.2)

- Measurements (see section 3.3)

- Material testing (see section 3.4)

- Non-destructive testing, on-site inspections (see section 3.6)

\subsection{Obtaining information from drawings and static calculations}

(1) In the evaluation of existing bridges, a comprehensive evaluation of all documents is needed. The assessing engineer must study all available information from static calculations, drawings, former inspections, publications, newspapers, etc. The engineer must be particularly attentive to indications of modification, repair or strengthening in the documents. Examples are: repair after a war, repair after an accident, modification during electrification of a railway line, setting up of new traffic signs system, widening of a bridge or installation of noise barriers. 
(2) The information obtained in former inspections is of interest. Some European countries have rules for regular inspection [Lit. 31]. All the same, each national highway or railways authority has its own rules for inspections and inspection reports, and generally international cooperation does exist on this topic. In the case of bridges, inspections have usually been performed every 5 to 6 years. More detailed information on inspections can be taken from section 3.6.

(3) Unfortunately, information on repair are often not documented, or sometimes wrong information is reported, and therefore the assessment of an old structure demands a detailed inspection of the actual state of the structure. Moreover, it is seen that strengthening and repair have sometimes been done by repair welding without care for the type of material. The rule is that all information obtained from drawings and static calculations must be compared with the structures during on-site inspections. Often it is an iterative process and more than one inspection must be carried out, each time finding and comparing other structural details.

\subsection{Measurements}

\subsubsection{General}

(1) The objective of measurements is always to gain information, either on the resistance or on the loading of the structure, in order to reduce the uncertainties associated with the static calculations made at the design stage or at the assessment (typically in phase I or phase II of the assessment) stage. The main areas of possible improvement of information on the resistance side (for loading side, see chapter 4, section 4.6) can be summarized as follows:

- carry out a campaign to measure real dimensions and thicknesses (see following section 3.3.2),

- obtain real material properties. This is dealt with in section 3.4,

- perform NDT tests. This is dealt with in section 3.6

- perform fatigue test on specific details, see section 3.3.3.

(2) After identifying the parameters where information gained by measurements has the largest influence on the assessment results, one must decide on the measurement aim and corresponding number of measurements needed. The aim can be to find a minimum or an average value, or to build the statistical distribution of a parameter. To guarantee an acceptable relation between data to be obtained and costs, the measurements have to be planned carefully.

(3) For measurements of loading and loading effects on a structure, the reader is sent back to section 4.6.

\subsubsection{Dimensions}

(1) In the case of real dimensions, possible parameters and ways of performing measurements are summarised below:

- Geometry: manual measurement, geodesic instruments, GPS, laser

- Reduction in thickness of a steel plate due to corrosion: manual measurements, ultrasonic methods, sampling by drilling (destructive).

- Bolt size and class in connections: manual measurement, sampling to perform material testing (destructive).

- Effective weld size: weld gauge.

- Effective weld penetration: NDT methods such as ultrasonic methods (UT).

- Size, number and location of reinforcing bars in concrete deck: cover-meter. 
Depth of concrete deck, of surfacing: Ultrasonic methods, impact echo, sampling by drilling (destructive). Note that, as an example, the depth of concrete deck affects both the strength (there is a reduction in strength if the real depth is inferior to the one accounted for in calculations) and the loading side (the same reduction in depth results in a reduction of the dead load).

\subsubsection{Fatigue tests}

(1) Apart from fatigue tests on the material, see information in section 3.4, fatigue tests on specific details can be carried out. However, since fatigue test are expensive, a cost benefit analysis needs to be carried out in order to compare this solution with alternative ones such as stress measurements, reinforced monitoring, etc.

(2) In the case of fatigue tests, one needs to distinguish between testing details taken out of the existing structure or details fabricated especially for testing purpose. In the latter case, the details shall represent as well as possible the existing details in terms of geometry and fabrication. It has to be noted here that it is very unusual to test a specific detail from an existing structure for an assessment due to a limited availability of elements for such use. It has been the practice when tests were carried out on riveted members to utilize members from structures that were replaced or taken out of service, which is not often the case. However, recommendations for the fatigue testing as well as for test results statistical analysis can be found in, for example the IIW recommendations [Lit. 50].

\subsection{Material}

\subsubsection{Material properties and identification}

(1) The most important material characteristics are:

- chemical characteristic values $C, S i, M n, P, S, N$

- yield strength $R_{e L}, R_{e H}\left(f_{y}\right)$

- tensile strength $R_{m}\left(f_{u}\right)$

- fracture toughness expressed in $K_{\text {Mat }}\left(K_{\text {Ic }}\right), J_{\text {Mat }}\left(J_{I c}, J_{c r i t}\right), \Delta K, \Delta K_{\text {th }}$

which either can be determined in single material tests or, if a sufficiently large database is available, expressed as a statistical values (mean value and standard deviation).

(2) The direct determination of the material properties using material tests always supplies the member-specific and thus the most exact material parameters. However, material tests should only be used in such cases, when statistically validated material characteristics, which are usually lower bound values, lead to too much conservative results. Thus the specific material tests on materials taken from old steel bridges can be reduced to few cases, see [Lit. 11].

(3) In the $19^{\text {th }}$ Century for old riveted bridges, wrought steel as well as mild steel were used. Chemical analysis or sulphurous prints can identify wrought steel, also called puddle iron, showing their characteristic lamellar microstructure consisting of ferrite matrix and slag layers. According to the research work done during the nineties of the $20^{\text {th }}$ century it was shown that the fatigue assessment using $\mathrm{S} / \mathrm{N}$-curves as well as fracture mechanics safety assessment are applicable.

(4) Mild steel has a totally different microstructure, which can be characterised by sulphuric segregation in the sulphurous (S) print. For more information see e.g. [Lit. 10 to Lit. 13].

(5) To distinguish specimens taken from riveted bridges on the basis of their original production method (see Table 3-1), by means of chemical and/or metallographical analysis, information 
are presented in Table 3-2. This scheme permits distinctions of steel produced by the puddling process developed in 1784 or mild steels produced since 1855 by the Bessemer, Thomas or Siemens-Martin process. The chemical analysis as well as the tension strengths of the steels described in table 3.1 have a high scattering. Therefore, the values given in table 3.1 have to be understood as tendencies. Other schemes are given in [Lit. 10, Lit. 11, Lit. 97].

(6) A rapid development of different kind of steel grades took place in the first three decades of the $20^{\text {th }}$ century. Not all of them can be considered in Table 3-1 and Table 3-2. In investigating old steel structures it has to be borne in mind, that - through low-alloyed steel to high strength steel (not included in Table 3-2) - the following steels had also been developed: chromium steel (since $\sim 1860$ ), nickel steel (since $\sim 1908$ ), high-carbon structural steel (since 1923), silicon steel (since 1926) [Lit. 13, Lit. 98]. If there are any doubts on the steel grade of the investigated steel structure, material tests are highly recommended especially with view on the strength, toughness and weldability.

(7) Furthermore, it has to be mentioned, that although the development of the steel grades increased during the first decades in the $20^{\text {th }}$ century the quality of the steels themselves might be low especially during the years of World War I (1914-1918), the great depression (19291939 ) and during and after World War II (1939-1950). Steel production had to be fast, and expensive alloys were not available. If a structure - built during one of these periods - has to be assessed, material tests are needed to be carried out.

(8) When investigating modern steel structures, it has to be considered that from the middle of the $20^{\text {th }}$ century the Thomas process was replaced by the oxygen blowing process and to the end of the $20^{\text {th }}$ century the Siemens-Martin process was replaced successively by the electric arc process.

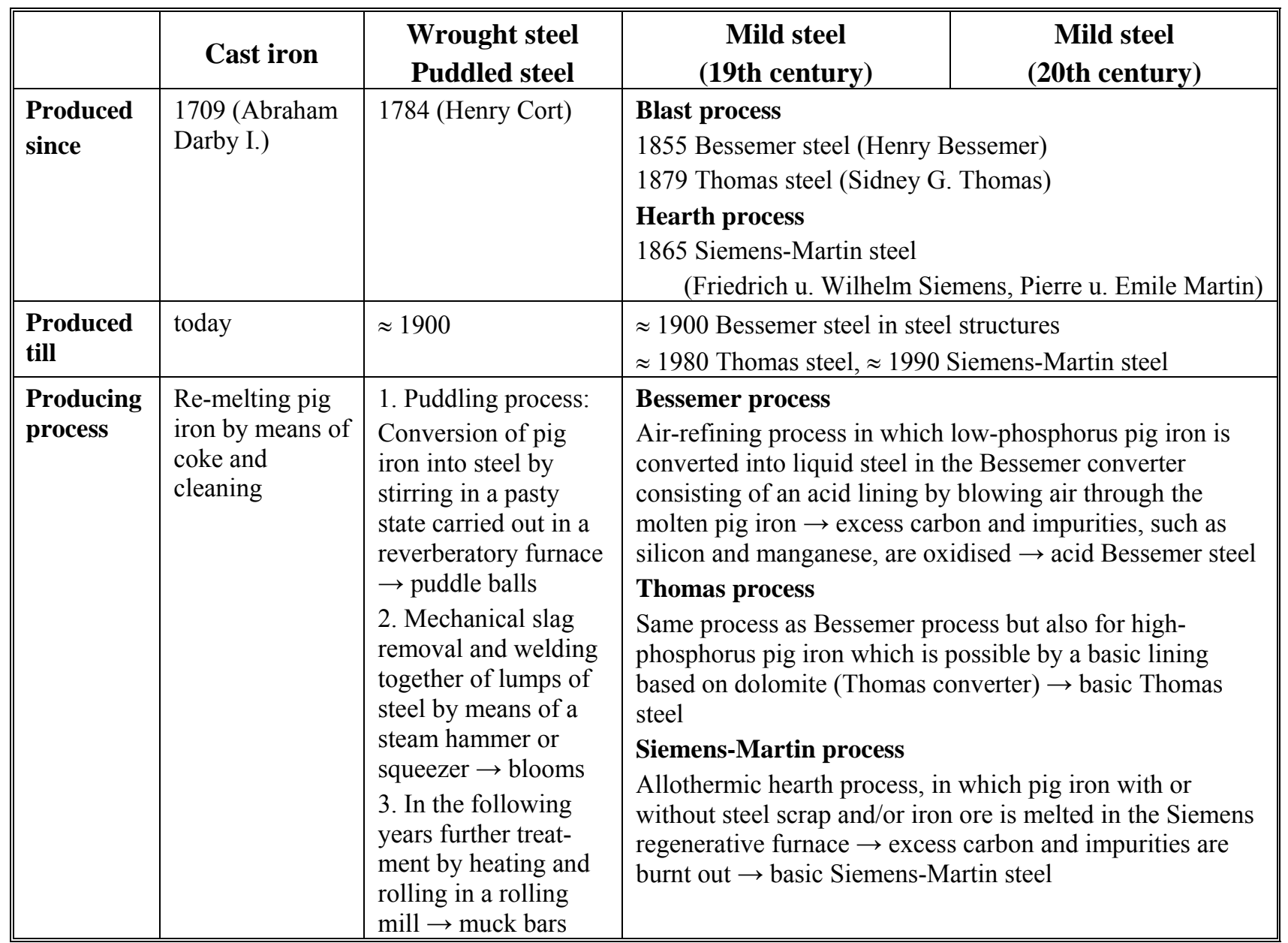

Table 3-1: Information on commonly used producing processes 


\begin{tabular}{|c|c|c|c|c|}
\hline & Cast iron & $\begin{array}{l}\text { Wrought steel } \\
\text { Puddled steel }\end{array}$ & $\begin{array}{c}\text { Mild steel } \\
\text { (19th century) }\end{array}$ & $\begin{array}{c}\text { Mild steel } \\
\text { (20th century) }\end{array}$ \\
\hline $\begin{array}{l}\text { Sulphur- } \\
\text { print } \\
\text { (Baumann- } \\
\text { print) }\end{array}$ & $\begin{array}{l}\text { Content of sulphur is } \\
\text { depending on coke } \\
\text { quality }\end{array}$ & $\begin{array}{l}\text { Slag segregation lines } \\
\text { containing phosphorus } \\
\text { and sulphur }\end{array}$ & $\begin{array}{l}\text { Core segregation containing } \\
\text { phosphorus and sulphur }\end{array}$ & $\begin{array}{l}\text { Low content of } \\
\text { phosphorus and sulphur }\end{array}$ \\
\hline \multirow[t]{2}{*}{$\begin{array}{l}\text { Micro- } \\
\text { structure } \\
\sim 1: 400\end{array}$} & & . & 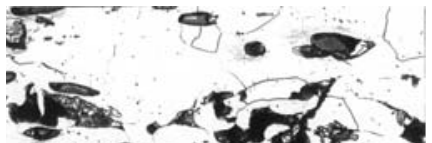 & 2 \\
\hline & $\begin{array}{l}\text { Cast iron with } \\
\text { lamellar graphite }\end{array}$ & $\begin{array}{l}\text { Ferritic, Inhomoge- } \\
\text { neous grain size } \\
\text { distribution, Oxide } \\
\text { inclusions, Slag lines }\end{array}$ & $\begin{array}{l}\text { Ferritic-pearlitic, Increasing } \\
\text { grain size from the edge to } \\
\text { the core, Oxide and sulphide } \\
\text { inclusions }\end{array}$ & Homogenous small grain \\
\hline \multirow[t]{3}{*}{$\begin{array}{l}\text { Chemical } \\
\text { analysis }\end{array}$} & \multirow[t]{3}{*}{$\begin{array}{l}\mathrm{C} \approx 2,0-4,0 \% \\
\mathrm{Mn} \approx 0,2-1,2 \% \\
\mathrm{Si} \approx 0,3-3,0 \% \\
\mathrm{~S}<\approx 1,2 \% \\
\mathrm{P}<\approx 1,0 \%\end{array}$} & \multirow[t]{3}{*}{$\begin{array}{l}\text { Very variable } \\
\mathrm{C}<\approx 0,08 \% \\
\mathrm{Mn}<\approx 0,4 \% \\
\mathrm{~S}<\approx 0,04 \% \\
\mathrm{P}<\approx 0,6 \%\end{array}$} & $\begin{array}{l}\text { Bessemer / Thomas steel } \\
\mathrm{C} \approx 0,02-0,1 \% \\
\mathrm{Mn} \approx 0,3-0,5 \% \\
\mathrm{~S}<\approx 0,1 \% \\
\mathrm{P} \approx 0,04-0,07 \%(\mathbf{B}) /-0,12 \%(\mathbf{T}) \\
\text { Siemens-Martin steel } \\
\mathrm{C} \approx 0,05-0,15 \% \\
\mathrm{Mn} \approx 0,2-0,5 \% \\
\mathrm{~S} \approx 0,02-0,15 \% \\
\mathrm{P} \approx 0,03-0,06 \%\end{array}$ & $\begin{array}{l}\text { Low-alloyed steel } \\
(\mathbf{T}, \mathbf{S M}) \\
\mathrm{C} \approx 0,1-0,2 \% \\
\mathrm{Mn} \approx 0,4-0,5 \% \\
\mathrm{Si} \approx 0,01 \%\end{array}$ \\
\hline & & & \multicolumn{2}{|c|}{ Blast Process: $N>\approx 0,01 \%$, Hearth Process: $N<\approx 0,01 \%$} \\
\hline & & & \multicolumn{2}{|c|}{ Bessemer steel: $\mathrm{Si}>\approx 0,08 \%$, Thomas steel: $\mathrm{Si}<\approx 0,08 \%$} \\
\hline \multirow[t]{2}{*}{$\begin{array}{l}\text { Tension } \\
\text { test }\end{array}$} & $\begin{array}{l}\text { Very brittle, almost } \\
\text { no plasticity }\end{array}$ & No local necking & local necking & $\begin{array}{l}\text { Local necking and shear } \\
\text { lips }\end{array}$ \\
\hline & $\begin{array}{l}\text { Old cast iron } \\
\mathrm{R}_{\mathrm{m}} \approx 90-135^{1)} \mathrm{N} / \mathrm{mm}^{2} \\
\varepsilon^{2)} \approx 0 \%\end{array}$ & $\begin{array}{l}\mathrm{R}_{\mathrm{e}} \approx 220-310 \mathrm{~N} / \mathrm{mm}^{2} \\
\mathrm{R}_{\mathrm{m}} \approx 280-400 \mathrm{~N} / \mathrm{mm}^{2} \\
\varepsilon \approx 5-20 \%\end{array}$ & $\begin{array}{l}\mathrm{R}_{\mathrm{e}}>\approx 220 \mathrm{~N} / \mathrm{mm}^{2} \\
\mathrm{R}_{\mathrm{m}} \approx 370-440 \mathrm{~N} / \mathrm{mm}^{2} \\
\varepsilon>\approx 20 \%\end{array}$ & $\begin{array}{l}\text { Low-alloyed steel } \\
\mathrm{R}_{\mathrm{e}} \approx 240-280 \mathrm{~N} / \mathrm{mm}^{2} \\
\mathrm{R}_{\mathrm{m}} \approx 370-450 \mathrm{~N} / \mathrm{mm}^{2} \\
\varepsilon \approx 15-25 \%\end{array}$ \\
\hline $\begin{array}{l}\text { Specimen } \\
\text { after } \\
\text { tension test }\end{array}$ & dichole & nethen & \multicolumn{2}{|c|}{ Local necking } \\
\hline
\end{tabular}

Table 3-2: $\quad$ Information on material characteristics of old iron and steels

${ }^{1)}$ Literature [Lit. 96] gives also higher values up to $260 \mathrm{~N} / \mathrm{mm}^{2} ;{ }^{2}$ elongation at rupture 
(9) Based on a statistical analysis (hypothesis testing) of the chemical and the microstructure properties of specimens from riveted bridges found in literature [Lit. 11, Lit. 12, Lit. 13, Lit. $124]$ it is concluded, that the obtained data for the strength and toughness of wrought steel can be treated as a statistical homogenous population. The statistical distribution of the material strength has been derived from an amount of 205 tests at $0^{\circ} \mathrm{C}$ and 283 tests at $-30^{\circ} \mathrm{C}$.

(10) The results of the statistical evaluation of old steels (except wrought steel) can be summarised as follows:

$\begin{array}{lllll}\underline{+10{ }^{\circ} \mathrm{C}} & R_{e L, 5 \%} & =229 \mathrm{~N} / \mathrm{mm}^{2} & \approx 230 \mathrm{~N} / \mathrm{mm}^{2} \\ \underline{0{ }^{\circ} \mathrm{C}} & R_{e L, 5 \%} & =248 \mathrm{~N} / \mathrm{mm}^{2} & \approx 240 \mathrm{~N} / \mathrm{mm}^{2} \\ & J_{\text {Mat, Modell, } 5 \%} & =30 \mathrm{~N} / \mathrm{mm}^{2} & & \\ & & & \\ \underline{-30{ }^{\circ} \mathrm{C}} & R_{e L, 5 \%} & =257 \mathrm{~N} / \mathrm{mm}^{2} & \approx 250 \mathrm{~N} / \mathrm{mm}^{2} \\ & J_{\text {Mat, Modell, } 5 \%} & =17.5 \mathrm{~N} / \mathrm{mm} & \approx 17 \mathrm{~N} / \mathrm{mm}^{2}\end{array}$

(11) Beside this, for wrought steel a tension strength of $R_{e L, 5 \%}=203 \mathrm{~N} / \mathrm{mm}^{2} \approx 200 \mathrm{~N} / \mathrm{mm}^{2}$ at $+10{ }^{\circ} \mathrm{C}$ was found.

(12) If material testing on specimens from the bridge are to be avoided, a conservative safety assessment for moderate climates may be carried out with the combination of $5 \%$ fractiles for $-30{ }^{\circ} \mathrm{C}$ for $\mathrm{J}_{\mathrm{Mat}}$-values and with the combination of $5 \%$ fractiles for $0{ }^{\circ} \mathrm{C}$ for $\mathrm{R}_{\mathrm{eL}}$-values.

(13) The modulus of elasticity (E) should be taken as $210.000 \mathrm{~N} / \mathrm{mm}^{2}$ for all kinds of steel.

(14) If fracture mechanics approach on a riveted structure is applied in an expert investigation (Phase III), the following lower limit (5\% fractile) for the threshold value of the cyclic stress intensity factor, $\Delta K_{t h}$, can be used in crack propagation calculation:

$$
\Delta K_{t h}=63 \mathrm{~N} / \mathrm{mm}^{3 / 2} \approx 2 M P a \sqrt{m} \text { (constantly for all R-ratios). }
$$

(15) The comparison of the threshold values found at other research institutes with the lower bound value mentioned above shows that a specific testing of the material characteristics of the examined bridge may also result in higher threshold values.

(16) According to BS PD 6493 [Lit. 14] the threshold value $\Delta K_{\text {th }}$ for modern steels can be estimated under consideration of a variable $R$-ratio using (3-1).

$$
\begin{aligned}
& -1<R \leq 0.5: \Delta K_{t h}(R)=170-214 \cdot R \text { in } \mathrm{N} / \mathrm{mm}^{3 / 2} \\
& 0.5<R \leq 1: \Delta K_{t h}=63 \mathrm{~N} / \mathrm{mm}^{3 / 2} \approx 2 \mathrm{MPa} \sqrt{\mathrm{m}}
\end{aligned}
$$

where $R$ is the ratio of the minimum stress $\sigma_{\min , i}$ to the maximum stress $\sigma_{\max , i}$.

(17) It has to be noted that a consideration of the relationship of the threshold value to the $R$-ratio, especially with a $R$-ratio smaller than 0.5 , can lead to noticeable more favourable results during the crack growth calculation. However in most cases it is rather difficult or sometimes even impossible to estimate the actual $R$-ratio of a structure [Lit. 63]. Referring to old steels the following quantitative assumptions can be made:

- Wrought steel has higher $\Delta K_{t h}$-values but the $d a / d N$-ratio is also higher in comparison to mild or killed steel.

- Thus, the slope of the Paris law, characterised with the below given material constants $C$ and $m$, is steeper for wrought steel than for mild steel, so at the end one should only carefully take profit from the higher $\Delta K_{t h}$-values for wrought steel. 
(18) If no other threshold value $\Delta K_{\text {th }}$ of modern steels used in welded structures is available this value should also be taken as:

$\Delta K_{t h}=63 \mathrm{~N} / \mathrm{mm}^{3 / 2} \approx 2 M P a \sqrt{m}$ (constantly for all $R$-ratios).

(19) The material constants of $C$ and $m$ (for old steel, if not determined in crack propagation tests) of the well known crack propagation equation according to Paris should be taken as follows:

$$
\begin{aligned}
& C=4 \cdot 10^{-13} \text { and } m=3 \text { (units in } \mathrm{N}(\mathrm{mm})^{-3 / 2} \text { and } \mathrm{mm} \text { ) or } \\
& C=1.3 \cdot 10^{-11} \text { and } m=3 \text { (units in } \mathrm{MPa}(\mathrm{m})^{1 / 2} \text { and } \mathrm{m} \text { ) }
\end{aligned}
$$

(20) Special attention should be paid on the question of the weldability of the old steels. Mild steel of the $19^{\text {th }}$ Century could fulfil the requirements of EN 10025 according to their analysis and hence may be classified as weldable e.g. for strengthening measures. However it is recommended that additional welding tests are performed to clarify the weldability. Components subjected to fatigue load, made in wrought steel or early old mild steel, neither should be welded, nor other thermal procedures (torch cutting or others) applied to the components. Only members predominantly under compressive loads could be excepted from this rule after applicability tests, which require however also a test of the weldability in each case (see also section 3.4.2.3).

(21) The killed steels normally used in the welded structures since 1966 are fully covered by the material characteristics given in the general technical delivery conditions of the Eurocodes (e.g. EN 10025 [Lit. 93] etc.).

(22) More information on material characteristics based on experience in the English construction market can be taken from [Lit. 10]

\subsubsection{Material testing}

\subsubsection{General}

(1) As described in the previous section the most important material characteristics:

- chemical characteristic values,

- fracture toughness,

- yield strength (higher and lower value) and

- tensile strength

have to be known for a proper assessment of existing steel bridges.

(2) It has to be taken into account that there is already a sufficiently large number of measured material data of most of the steels found in old steel bridges [e.g. Lit. 11, Lit. 12, Lit. 17 to Lit. 19]. In most cases an extensive and expensive investigation of the specific material characteristics of an old bridge is not necessary in Phase I and Phase II. In such cases material data given in section 3.4.1 should be used.

(3) Only if the static and/or fatigue safety assessment in Phase I or II shows no sufficient safety in Phase III and in some cases also in Phase II an investigation of the specific material data should be carried out. In such a case all available information and not only material tests should be investigated. Section 3.4.2.2 describes briefly the steps, which should be carried out for an investigation of specific material characteristics.

(4) Only the chemical and/or metallographical analysis should be carried out for each investigated bridge, to specify the existent steel and to ensure the weldability of the steel with regard to possibly necessary reinforcing of the structure. Due to the importance of the ascertainment of the weldability of old steels this will be separately explained in chapter 3.4.2.3. 


\subsubsection{Kind of test specimens, sampling and test procedure}

(1) For the determination of the actual material characteristics the kind of test specimens and test procedure is basically similar for old or for modern steels. Due to that, this chapter only briefly explains the most common material tests explains the size of adequate sampling and refers to more information to the relevant European standards.

(2) In connection with the determination of the material characteristics the most important difference between old and modern steels consists in the way of the sampling.

(3) Whereas the determination of the material characteristics of modern steels can be carried out during the production, in which enough material for sampling is available, for existing structures the sampling must be carried out on the structure itself. According to [Lit. 10], sampling in the first instance is needed only to confirm the nature of the material. More extensive and costly sampling and testing is best left until an initial appraisal has shown whether a scheme for re-use or alteration is feasible in principle.

(4) The following points must already be checked with high diligence, before sampling on an existing structure can be carried out:

1. Which material characteristics have to be determined?

2. How many tests should be carried out?

3. Which are the sufficient dimensions of the test specimens?

4. Which method can be used to cut out the samples?

5. Where in the structure the destructive sampling can be carried out without impairing the load capacity of the chosen component, or can the whole component be replaced?

(5) Regarding $1 \& 2$, the first two questions can be answered with the information given above. For most of the steels found in old steel bridges, a sufficiently large number of measured material data is available. Therefore, characteristic values of material characteristics can be used in the safety assessment instead of actual specific material characteristics of the examined structure, which have to be determined with an extensive, expensive and destructive testing. Conversely a well-documented, not grossly overstressed structure in a sound state may need little or no testing. Only for not well-documented structures a few samples are necessary to confirm these characteristic values. The number of samples and the material characteristics depends on the obtained information about the examined structure, which could be taken from drawings and/or other resources (see chapter 3.2).

(6) The following table gives an overview on the number of samples and tests should be carried out and which kind of tests. 


\begin{tabular}{|c|c|c|c|c|c|}
\hline \multirow[b]{2}{*}{ Obtained information } & \multicolumn{4}{|c|}{ Number of recommended... } & \multirow[b]{2}{*}{ Note } \\
\hline & samples & $\begin{array}{l}\text { tensile } \\
\text { test }\end{array}$ & $\begin{array}{l}\text { chemical } \\
\text { analysis }\end{array}$ & $\begin{array}{c}\text { fracture } \\
\text { mech. } \\
\text { test }\end{array}$ & \\
\hline $\begin{array}{l}\text { Steel grade, quality and producer } \\
\text { are known and the obtained } \\
\text { information is validated suffi- } \\
\text { ciently with on-site inspections or } \\
\text { by other documents }\end{array}$ & 0 & 0 & 0 & 0 & $\begin{array}{l}\text { Use of statistically } \\
\text { verified data }\end{array}$ \\
\hline $\begin{array}{l}\text { All members of a structure are } \\
\text { made of only one steel grade and } \\
\text { quality produced by only one } \\
\text { steel producer but it is not sure } \\
\text { from on-site inspection that the } \\
\text { obtained information is in } \\
\text { accordance with the actual } \\
\text { properties of the structure }\end{array}$ & 3 & 6 & 1 & 3 & $\begin{array}{l}\text { - position of } \\
\text { random sampling } \\
\text { can be chosen } \\
\text { freely } \\
\text { - after material } \\
\text { identification by } \\
\text { testing statistical } \\
\text { data can be used }\end{array}$ \\
\hline $\begin{array}{l}\text { The members of a structure are } \\
\text { made of different steel grades and } \\
\text { qualities produced by different } \\
\text { steel producers but it is not sure } \\
\text { from on-site inspection that the } \\
\text { obtained information is in } \\
\text { accordance with the actual } \\
\text { properties of the structure }\end{array}$ & $\begin{array}{l}1 \text { of each } \\
\text { kind of } \\
\text { member }\end{array}$ & $\begin{array}{c}2 \text { per } \\
\text { sample }\end{array}$ & $\begin{array}{c}1 \text { per } \\
\text { sample }\end{array}$ & $\begin{array}{c}1 \text { per } \\
\text { sample }\end{array}$ & $\begin{array}{l}\text { - position of } \\
\text { random sampling } \\
\text { can be chosen } \\
\text { freely } \\
\text { - after material } \\
\text { identification by } \\
\text { testing statistical } \\
\text { data can be used } \\
\end{array}$ \\
\hline $\begin{array}{l}\text { Lack of obtained information or } \\
\text { no information available or it was } \\
\text { found during on-site inspection } \\
\text { that the obtained information is } \\
\text { probably wrong }\end{array}$ & $\begin{array}{c}\geq 3 \text { of } \\
\text { each } \\
\text { kind of } \\
\text { member }\end{array}$ & $\begin{array}{c}2 \text { per } \\
\text { sample }\end{array}$ & $\begin{array}{c}1 \text { per } \\
\text { sample }\end{array}$ & $\begin{array}{c}1 \text { per } \\
\text { sample }\end{array}$ & $\begin{array}{l}\text { - position of } \\
\text { random sampling } \\
\text { can be chosen } \\
\text { freely but should } \\
\text { be located as } \\
\text { near as possible } \\
\text { at highly stressed } \\
\text { members } \\
\text { - after material } \\
\text { identification by } \\
\text { testing statistical } \\
\text { data can be used } \\
\text { or the measured } \\
\text { values }\end{array}$ \\
\hline
\end{tabular}

\section{Table 3-3: Number of sampling}

(7) Regarding 3, only a civil engineer who has knowledge in the field of the material science as well as in structural behaviour can answer the third question. With regard to the destructive sampling the following rule applies:

\section{“As large as necessary but also as small as possible!"}

E.g. according to [Lit. 10], a drilling swarf is adequate for chemical analysis whereas metallurgical examination will require a piece approximately 25 by $25 \mathrm{~mm}$.

(8) The samples must be large enough to cut out the test specimen for tensile test, chemical analysis and fracture mechanics test. In some rare cases the sample should also be large 
enough to cut out Charpy-V-notched test specimens. For an optimal assessment of sufficient dimensions of the samples engineers have to know the dimensions of standard tests as well as they have to know which kind of tests they will carry out.

(9) Table 3-4 includes the most commonly used material tests.

\begin{tabular}{|c|c|c|c|c|c|}
\hline \multirow{2}{*}{$\begin{array}{l}\text { Method on } \\
\text { Test }\end{array}$} & \multirow[t]{2}{*}{ Standard } & \multirow{2}{*}{$\begin{array}{l}\text { Determined } \\
\text { values }\end{array}$} & \multicolumn{2}{|c|}{ Dimension } & \multirow[t]{2}{*}{ Comment } \\
\hline & & & optimal & Minimal & \\
\hline $\begin{array}{l}\text { Sulphurous } \\
\text { print }\end{array}$ & & $\begin{array}{l}\text { Qualitative } \\
\text { analysis of } \\
\text { distribution of } \\
\text { sulphur }\end{array}$ & $\begin{array}{l}\text { Whole cross } \\
\text { section of } \\
\text { assessed } \\
\text { profile }\end{array}$ & $\begin{array}{l}\text { Section } \\
\text { from a } \\
\text { drilled } \\
\text { specimen }\end{array}$ & \\
\hline $\begin{array}{l}\text { Chemical } \\
\text { analysis (dry) } \\
\text { (Emission } \\
\text { spectroscopy) }\end{array}$ & & $\begin{array}{l}\text { Content of C, } \\
\text { Si, Mn, S, P, N }\end{array}$ & $\begin{array}{l}\text { Whole cross } \\
\text { section of } \\
\text { assessed } \\
\text { profile } \\
\end{array}$ & $6 \times 10 \mathrm{~mm}$ & $\begin{array}{l}\text { Not applicable on } \\
\text { wrought steel }\end{array}$ \\
\hline $\begin{array}{l}\text { Chemical } \\
\text { analysis (wet) }\end{array}$ & & $\begin{array}{l}\text { Content of C, } \\
\text { Si, Mn, S, P, N }\end{array}$ & \multicolumn{2}{|c|}{ Filings $(10 \mathrm{~g})$} & \\
\hline $\begin{array}{l}\text { Tension test } \\
\text { (shape E; flat } \\
\text { specimen) }\end{array}$ & $\begin{array}{l}\text { EN 10002, } \\
\quad \text { Part } 1\end{array}$ & $\mathrm{R}_{\mathrm{eH}}, \mathrm{R}_{\mathrm{eL}}, \mathrm{R}_{\mathrm{m}}$ & $\begin{array}{l}\text { Largest } \\
\text { possible } \\
\text { thickness }\end{array}$ & $\begin{array}{l}\text { Thickness } \\
4 \mathrm{~mm}\end{array}$ & $\begin{array}{l}\text { Length of } \\
\text { specimen follows } \\
\text { from thickness }\end{array}$ \\
\hline $\begin{array}{l}\text { Tension test } \\
\text { (shape B; } \\
\text { round } \\
\text { specimen) }\end{array}$ & $\begin{array}{l}\text { EN } 10002, \\
\quad \text { Part } 1\end{array}$ & $\mathrm{R}_{\mathrm{eH}}, \mathrm{R}_{\mathrm{eL}}, \mathrm{R}_{\mathrm{m}}$ & $\begin{array}{l}\text { Largest } \\
\text { possible } \\
\text { diameter }\end{array}$ & $\begin{array}{l}\text { Diameter } \\
5 \mathrm{~mm}\end{array}$ & $\begin{array}{l}\text { Diameter } \\
\text { restricted due to } \\
\text { ratio of thread to } \\
\text { material } \\
\text { thickness }\end{array}$ \\
\hline $\begin{array}{l}\text { Fracture } \\
\text { mechanic test }\end{array}$ & $\begin{array}{c}\text { BS } 6835 \text { or } \\
\text { ASTM E647 }\end{array}$ & $\mathrm{C}, \mathrm{m}, \Delta \mathrm{K}_{\mathrm{th}}, \mathrm{K}_{\mathrm{Ic}}$ & & $\begin{array}{l}\text { Width / } \\
\text { Thickness }\end{array}$ & \\
\hline
\end{tabular}

Table 3-4: Dimensions of the most commonly used material test specimens

(10) These recommendations advise to use the dimensions of material test specimens fixed in the respective standards [e.g. Lit. 36]. It is undisputed that tests carried out with standard samples deliver the most correct material data and only this data is comparable with other values.

(11) But in many cases it will happen during examination of an existing structure, that one cannot take samples from the structure as large as necessary for standard test specimens. According to [Lit. 11, Lit. 19], it has been proved that in such cases the most suitable kind of sampling are circular specimens (RCT-sample) in accordance with Fig. 3-1.

(12) It has to be noted that Charpy-V-notched test on specimen shown in Fig. 3-1 (left hand side) are only recommended for welded structures. In case of riveted structures e.g. SENB3 specimen for tests according to British Standard [Lit. 115] or others [Lit. 116] are recommended. 


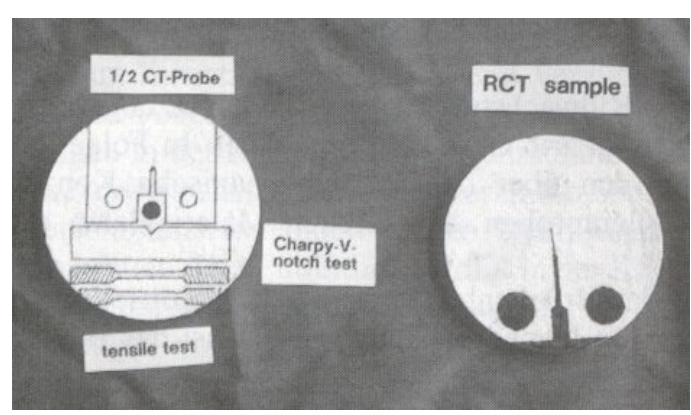

Fig. 3-1: Circular specimens (RCT-specimen) from a bridge structure with test specimens plotted on it [Lit. 19]

(13) In general these samples are taken from the members by drilling with a pod with an inside diameter of 60 to $76 \mathrm{~mm}$. After the circular specimen was drilled out, the different material test specimen could be cut out (Fig. 3-1). These small test specimens can also be used to determine the necessary information about the tension resistance, the toughness and the chemical properties. Especially the last point is rather important because the chemical properties can be used to estimate either the steel production process (see chapter 3.4) and the weldability of the examined steel (see chapter 3.4.2.3).

(14) For an expert investigation (Phase III) it should be stated, that also tensile tests can be carried out on round specimens with diameters thinner than the minimum diameter given in Table 3-4. An investigation carried out at the Bundesanstalt für Wasserbau (BAW), Germany, showed that the results obtained from tension tests with small test specimens are comparable with those obtained from standard test specimens (Fig. 3-2) [Lit. 20]. But it must be notified, too, that such tests are the responsibility of the expert in particular for old steels, because test on this kind of specimen are difficult and the results are not in all cases comparable like it was found in the BAW investigation.

a)

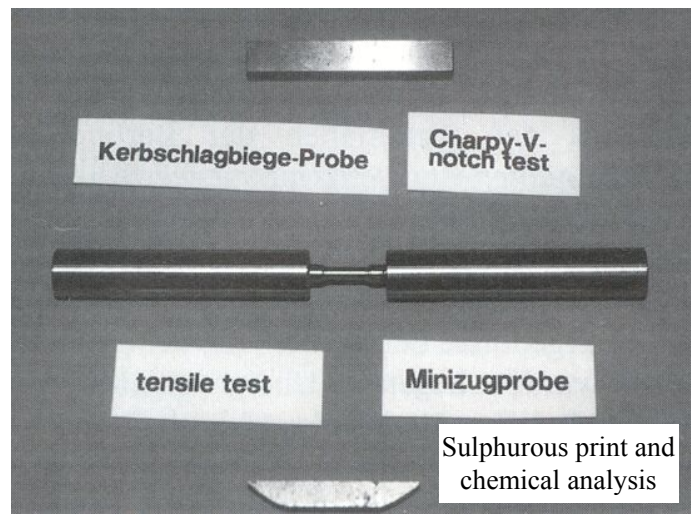

\section{Yield strength and tensile strength Wehrsteg Heidelberg}

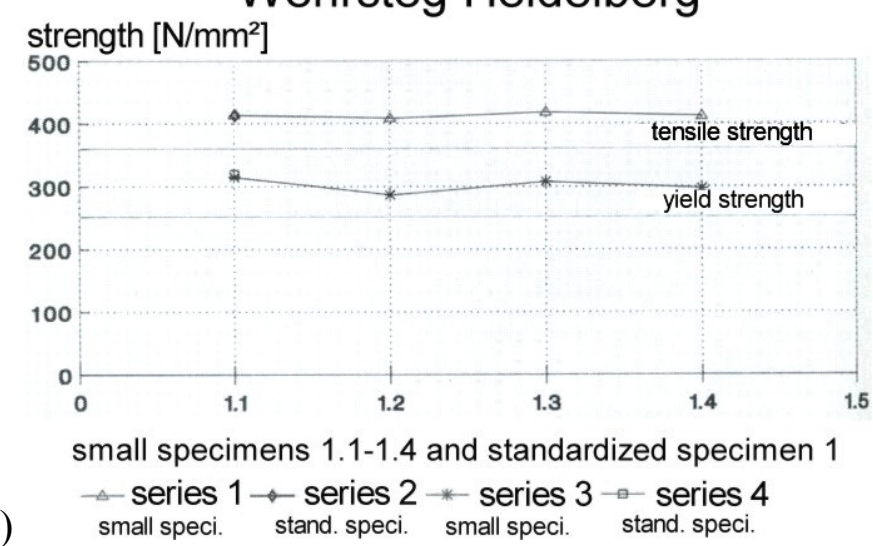

Fig. 3-2: a) Miniature specimen for tensile test with screwed on clamping support for the tensile test; b) Comparison of the results of standardized specimens for tensile test with those of small specimens [Lit. 20]

(15) Since the material specimens should principally be taken from the same element, but in low strengthened areas and never from the critical cross sections of an element, the area of sampling only has to be chosen by experienced experts.

(16) Moreover it has to be pointed out again that the material tests should be kept as small as possible to avoid impairing the bearing capacity of the examined member. For exceptional cases where a sampling with a pod diameter of $60 \mathrm{~mm}$ is still too large, a diameter $45 \mathrm{~mm}$ can 
be used instead. For that case a special procedure was developed at the RheinischWestfälischen Technischen Hochschule Aachen (RWTH) [Lit. 35], which allows the determination of material characteristics with rather small test specimens (Fig. 3-3).

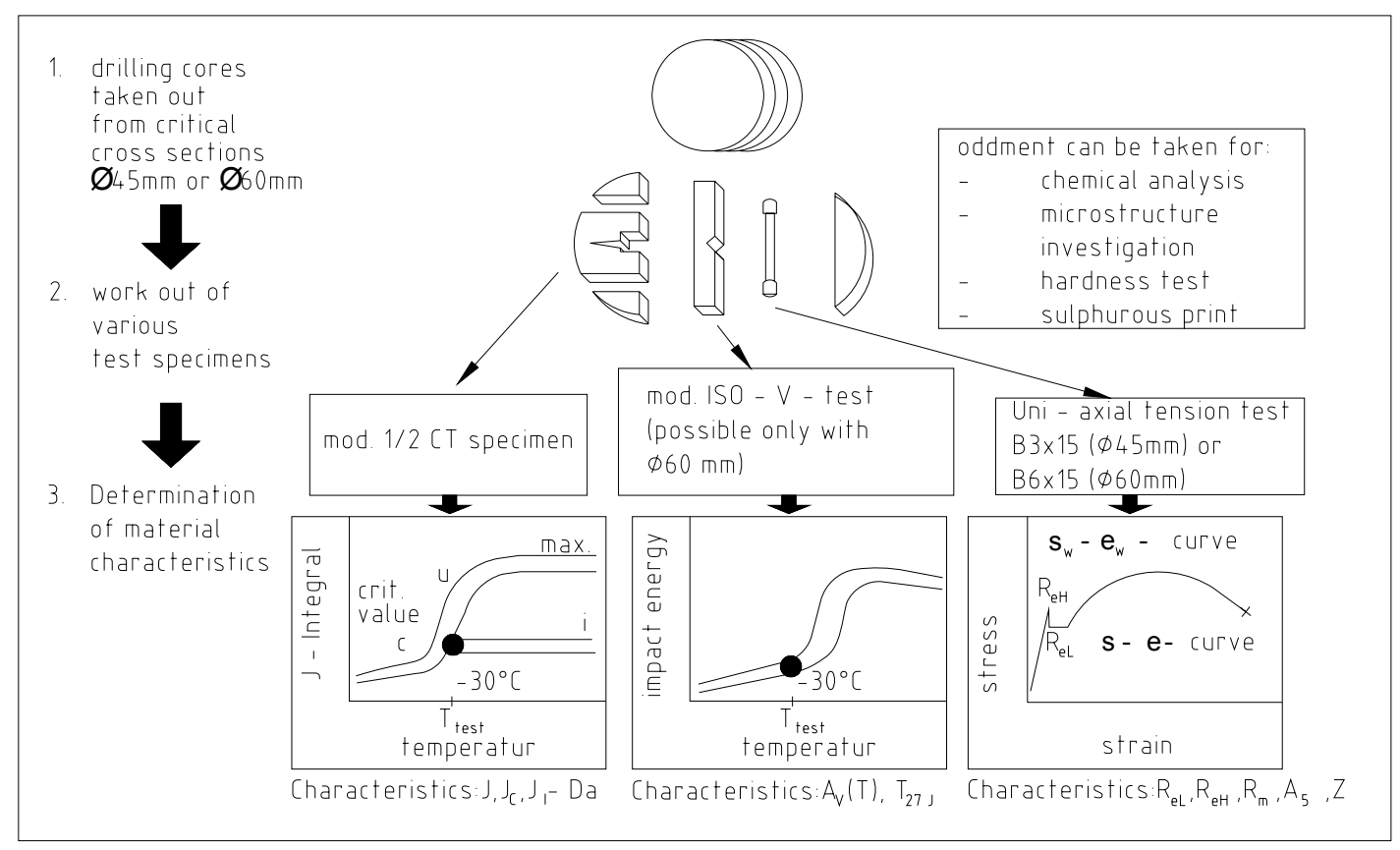

Fig. 3-3: Determination of material characteristics with small samples and from small test specimens [Lit. 35]

(17) The loading direction has to be marked on the sample so that the material tests will be carried out with regard to the actual crack orientation and loading direction in the examined member.

(18) Regarding 4, the fourth question of which cutting method to use can be answered easily. Because of the high risk of hardening and concentration of impurities in the heat-affected zone the examined material flame cutting has to be avoided. This can be done by sawing or drilling samples from redundant parts of the existing steel.

(19) Regarding 5, the last question of where at the structure the destructive sampling can be carried out without impairing the load capacity of the chosen member is also the most difficult one, which cannot be answered in general terms. In fact the answer to this question depends from the examined steel structure, the loading, the accessibility and the necessity to examine the critical cross section.

(20) It is obvious that the area of sampling has to be chosen by experienced experts, who are familiar with the structure because a wrong choice could lead to an undesirable reduction of the bearing capacity of the examined member.

(21) Fig. 3-4 gives some examples. Another sufficient area is an unloaded edge of a rolled profile at the end of a connection.

(22) The only general recommendation is that the sampling should be carried out in highly loaded components, but away from the most loaded section where the exploitation is as low as possible. If all critical cross section are highly loaded than chose a non-critical and lowly loaded cross section.

(23) But keep in mind that rolled profiles, for example often built in non-critical bracings, can have another steel quality as plates of main girders. 

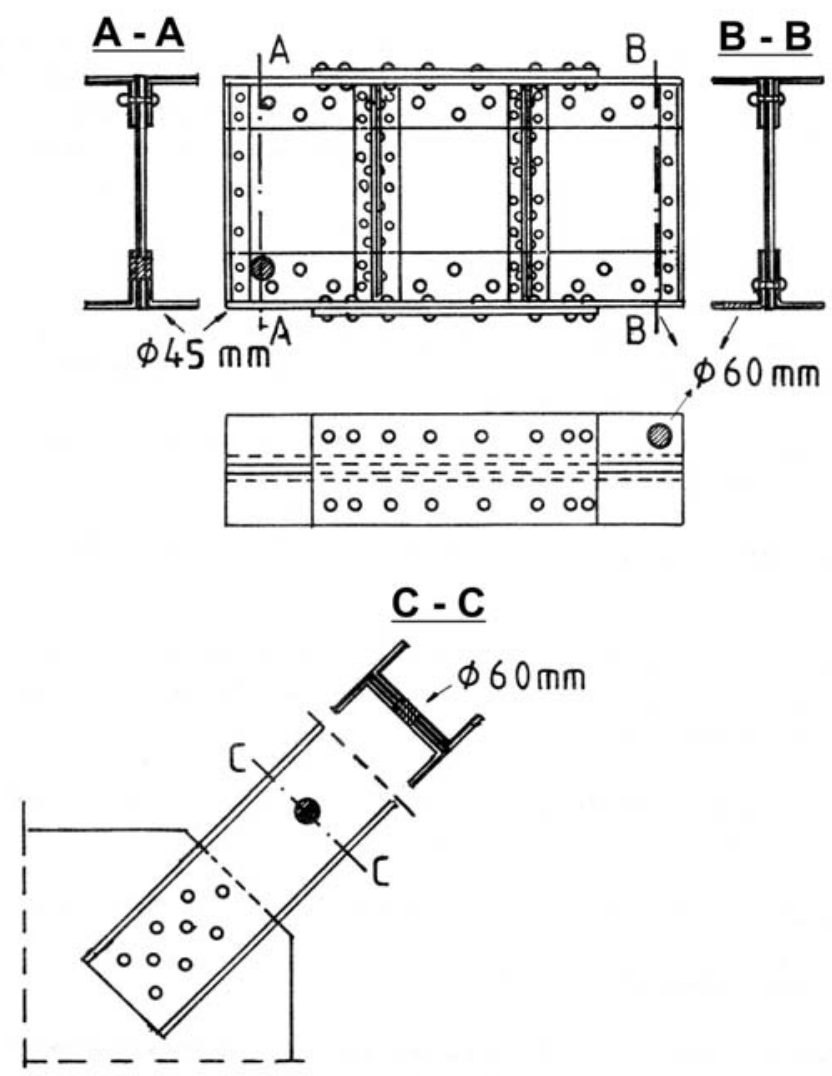

Fig. 3-4: Examples of sufficient areas for sampling acc. to [Lit. 17]

(24) It is of course important to discuss all these questions with the relevant authority at an early stage. According to [Lit. 10] some authorities are dubious about the usefulness of testing as an indication of typical strengths in the actual structure, but this may be understood by considering the relatively wide scatter of results, particularly for cast and wrought steel, previously quoted.

(25) Quality control in the $19^{\text {th }}$ century was very much cruder than it is today, as was recognized by the generous factors of safety applied. There is thus no guarantee that sampling for testing will give results that can be confidently regarded as "average", still less as "lower-bound", for the elements as a whole. In such cases it is more sensible and relevant to appraise the structure using (albeit conservative) permissible stresses or the statistically evaluated values given in section 3.4.1. Hints on sufficient interpretation e.g. of material test results can be found in [Lit. 10, Lit. 11].

(26) It is strongly recommended to prepare a report on the sampling of material test specimens carried out. It should include

- where exactly the material samples have been removed,

- why a region was chosen for sampling,

- who has chose the region and who has carried out sampling and when,

- the loading direction of the member of which the sample was cut out and where and in which way the loading direction was marked on the samples

- name of the samples

\subsubsection{Proof of the weldability of old steels}

(1) According to [Lit. 23], by 1900, steel had almost completely replaced wrought steel as a building material, although the latter continued to be used for certain applications mainly associated with its relative insensibility to atmospheric corrosion. Cast iron, once a popular 
material for columns and the fittings used in heavy timber construction, was fast dying out. Steel became the dominant building metal.

(2) Prior to about 1910, there was little standardization in the industry. Each steel producer used his own recipe and rules. This resulted in a wide variety of chemical and mechanical properties.

(3) Some of this early steel has good weldability and some does not. Wrought (puddle) iron is very inhomogeneous and shows a lot of slag inclusions (see Table 3-2), which makes it nearly impossible to weld such steels.

(4) Another example, the mild steel $\left(19^{\text {th }}\right.$ Century)s often have high contents of Nitrogen, which causes strong ageing effects, especially when reaching temperatures of $250^{\circ} \mathrm{C}$. This temperature is reached during the welding in the heat-affected zone (HAZ), what causes a remarkable rise of the risk of brittle fracture. Also due to riveting aging can occur when by bad workmanship the snap-tool penetrates into the parent material. In this situation the above mentioned conditions to aging (temperature and deformation) are present and brittle cracks can appear, too.

(5) Due to the fact, that the chemical composition of old steels varies in a very wide range (see Table 3-2), it is not possible to use results from one part of a structure for another. Even for parts with same cross sections this is not possible because one cannot be sure that they were made out of the same charge [Lit. 42]. Also, the fact that they have been produced after 1910 does not automatically guarantee their weldability.

(6) Weldability is not easy to define. In general, a material is called weldable if a connection can be realized which has sufficient ductility regarding the planned purpose and load situation.

(7) The obvious first test for weldability is to examine the existing steelwork to see if welding was used during the original fabrication and erection or if the structure has been successfully welded onto previously considering weldability tests and chemical analysis. Using dye penetration inspection, the old welds should be checked for surface cracks.

(8) Any steel whose weldability cannot be confirmed by such positive evidence, or whose chemical and mechanical properties are unknown, should be tested. This can be done by cutting or drilling samples from redundant parts of the existing steel (see section 3.4.2.2) and having them tested mechanically for ductility and chemically.

(9) The chemical analysis should include a minimum of the carbon-, manganese-, silicon-, phosphorus-, sulphur- and nitrogen-content. The laboratory analysis report should be required to list the quantities of each of the elements, even if the percentage reported is zero. The following four ingredients of structural steel which have considerable effect on its weldability are: carbon, -where too much carbon results in high hardening effect and eventual loss of ductility-, excess of phosphorus which increase brittleness, high sulphur which often results in porous welds [Lit. 24] and nitrogen responsible for aging effects, accelerated by higher temperature (e.g. due to welding) and deformations.

(10) Therefore on the basis of the results of the material tests a first proof of weldability can be done according to Fig. 3-5. 


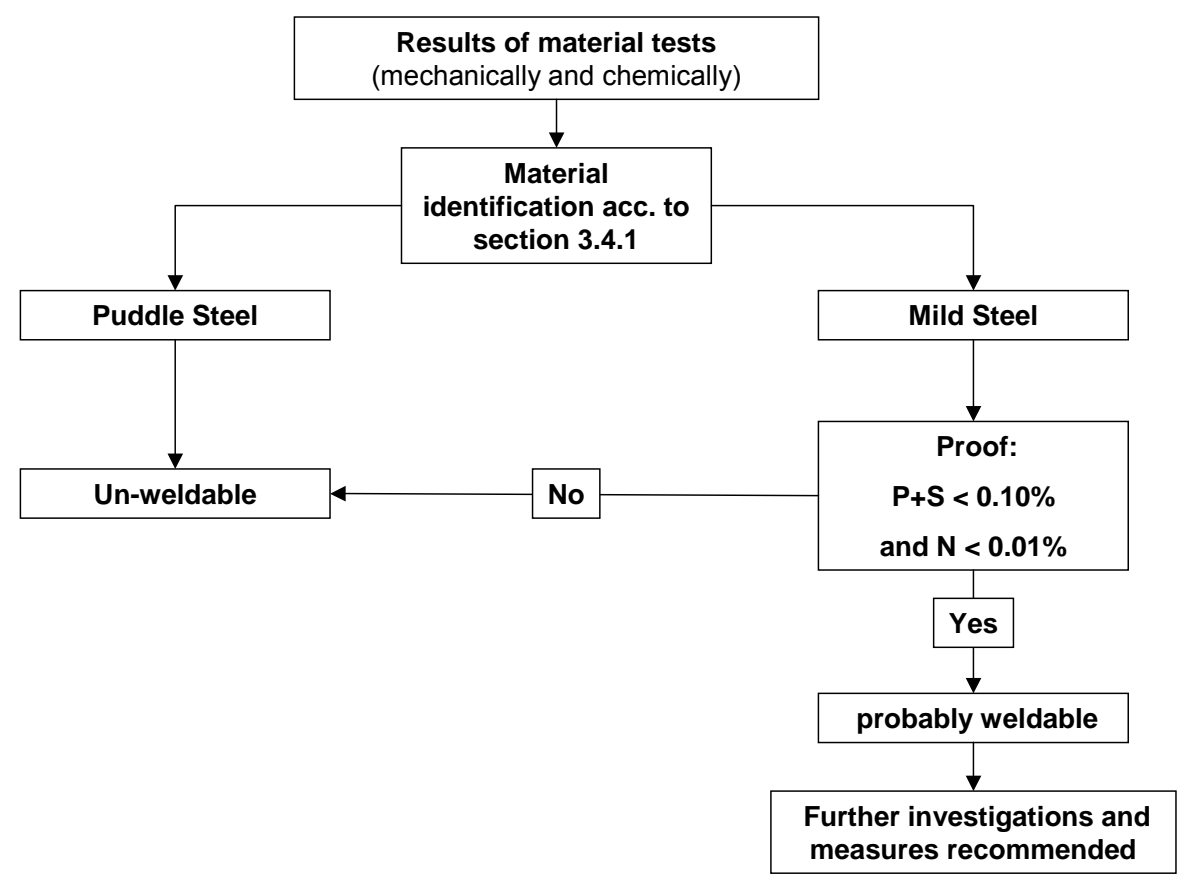

Fig. 3-5: $\quad$ First proof of weldability of old steels

(11) As mentioned in Fig. 3-5 puddle steel generally should be taken as un-weldable. Only in rare exceptional cases the weldability of puddle steel can be proofed, e.g. acc. to [Lit. 99, Lit. 100] etc.

(12) In the case of mild steel further investigations and measures are recommended in the case the first proof shows that the material maybe weldable. From the foregoing, it should be evident the higher the carbon content the less adaptable is the steel to welding.

(13) It should be kept in mind that it is not recommended to use common carbon equivalent formulas e.g. according to International Institute for Welding (IIW) [Lit. 25] or others [Lit. 27], because they were developed for the proof of weldability of modern steels (see also [Lit. 114]). Of course for modern steels, if the chemical composition of the steel is known, the weldability can be determine by these formulas.

(14) For un-weldable situations other repair methods should be considered (see chapter 5).

(15) As one further investigation, weldability tests are recommended to be carried out before welding.

(16) According to [Lit. 23], a simple on-site test can be done by welding a lug of weldable steel to an existing member or base metal specimen and beating it with a hammer (Fig. 3-6). Refer to the Fillet-Welded Bend Test as described in AWS Spec. D1.1, paragraphs 5.38.3 and 5.39.3 [Lit. 30]. If the weld deforms without fracturing, the steel can be considered weldable. If the weld separates from the base metal at the junction of the weld and base metal it indicates that the base metal is subject to hardening, often the result of high carbon content. The separation will then exhibit a grey granular surface, which usually follows the profile of the heat-affected zone, appearing as a shallow crater in the base metal. This is not a very sophisticated test (about as refined as the hammer test on welded shear studs), but it is better than nothing and is useful in emergencies or when a testing agency is not readily available. It is not recommended if other methods of determination are available. 


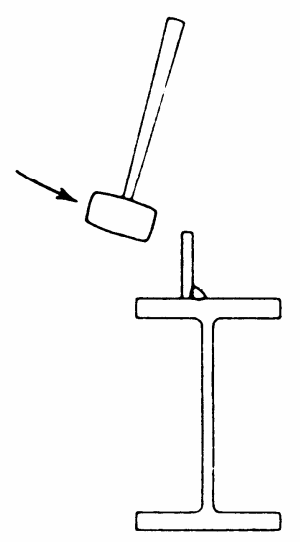

Test for weld ductility

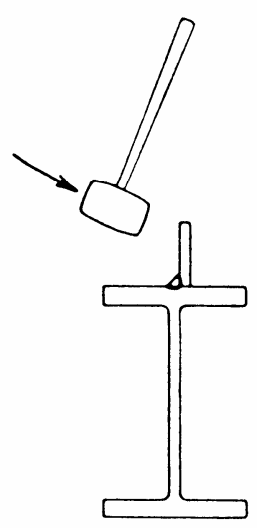

Test for hardening of base metal

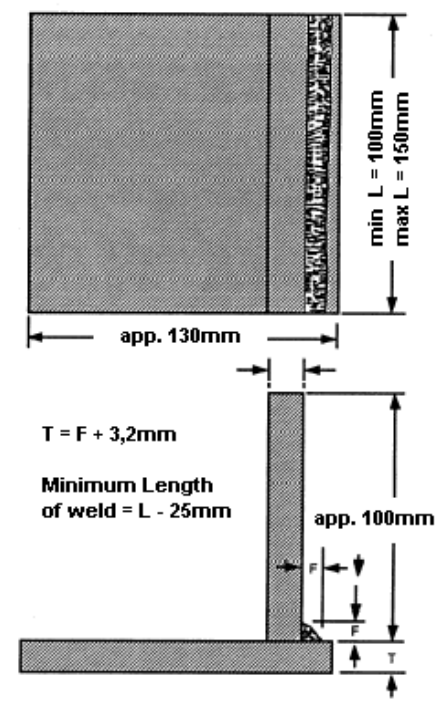

Fig. 3-6: Simple on-site test acc. to [Lit. 23] (left hand side) and dimensions of the test specimen according to AWS Spec. D1.1 [Lit. 30] (right hand side)

(17) Other methods for an improved classification of the weldability of steel are the so called coldcracking tests. For these destructive tests, samples made from the existing structure are necessary. For practice, the most common cold- cracking tests are the modified Tekken test [Lit. 27], the CTS test [Lit. 28] and the Implant test [Lit. 94], which are shown in Fig. 3-7. In both first mentioned tests, the load necessary to cause cracking comes from cooling down the weld. An useful compilation of the available cold-cracking tests can be taken from [Lit. 29].

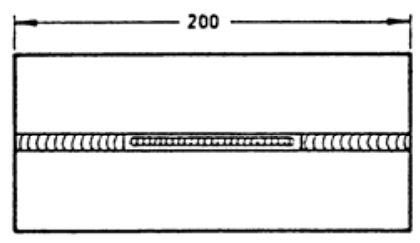

Modified Tekken test
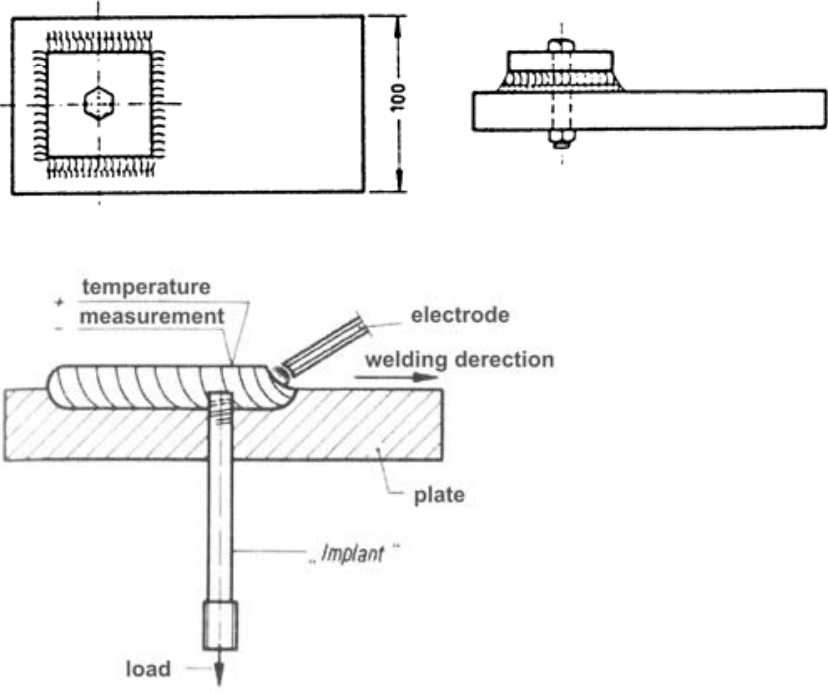

Fig. 3-7: $\quad$ Common cold-cracking tests
Controlled Thermal Severity (CTS) test

$\underline{\text { Implant test }}$ 
(18) It is recommended that both the evaluation of the material tests as well as of the weldability tests are carried out only by experts experienced with old steels. In the exceptional case that an old steel shows in all the above recommended investigation its weldability, an expert experienced with welding on old steels needs to define specific welding conditions, e.g. acc. to [Lit. 99 to Lit. 101].

(19) The following "rules-of-thumb" should be taken into account:

1. Welding and flame-cutting on existing structures should be avoided if possible.

If welding is mandatory and cannot be avoided, then:

2. The weldability must be established positively by the above mentioned methods, before welding on old steel structures.

3. The quality of the characterisation of the weldability increases according to the following listing in the same way as the effort for testing:

- simple on-site test

- material tests

- cold-cracking tests

4. If possible, test the specific members on which the welding is to be performed.

5. Specific welding conditions has to be defined by experts common with welding on old steels.

\subsection{Fatigue strength curves}

\subsubsection{General}

(1) To carry out an assessment of the remaining fatigue life of an old steel bridge and crane structures, critical structural details have to be identified and categorised. For the fatigue assessment of such detail categories the quantitative relationship between the stress ranges, which are the algebraic differences between the two extremes of a particular stress cycle derived from a stress history, and number of stress cycles to fatigue failure have to be known. Thus, fatigue strength curves should be used on the basis of doubly snapped off S/N-curve as it is used in Eurocode 3. In [Lit. 48] the main characteristics of fatigue strength curves for normal strength steel are defined in a diagram as given in Fig. 3-8. 


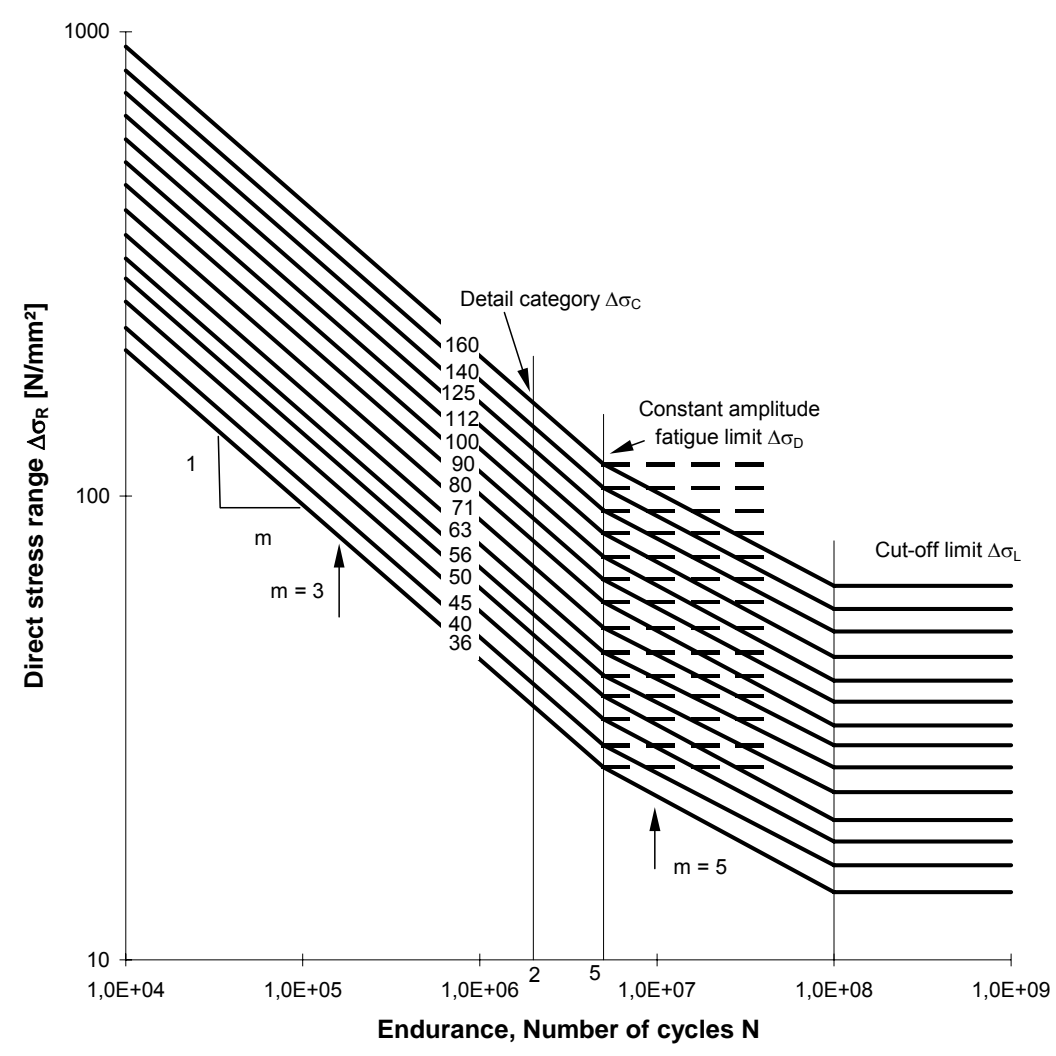

Fig. 3-8: $\quad$ Fatigue strength curves for nominal stress ranges

(2) The recommended detail categories are given in the following two sections.

\subsubsection{Riveted structures}

(1) For riveted structures, detail category 71 should be used, see Fig. 3-9, where the nominal stress $\Delta \sigma$ has to be calculated on the net cross-section (gross cross-section minus section of rivet holes in the critical section).

(2) Fig. 3-10 shows this curve and an additional S/N-curve according to ORE [Lit. 15] in comparison to more than 125 full scale fatigue test results. The full statistical analyses of these test data can be taken from [Lit. 12]. Other statistical analyses can be found e.g. in [Lit. 119].

(3) It should be noted that the evaluated test data also consider riveted beam elements with a loss of clamping force.

(4) Furthermore it should be noted that only few investigations on the constant amplitude fatigue limit exists, e.g. [Lit. 110 to Lit. 112]. 


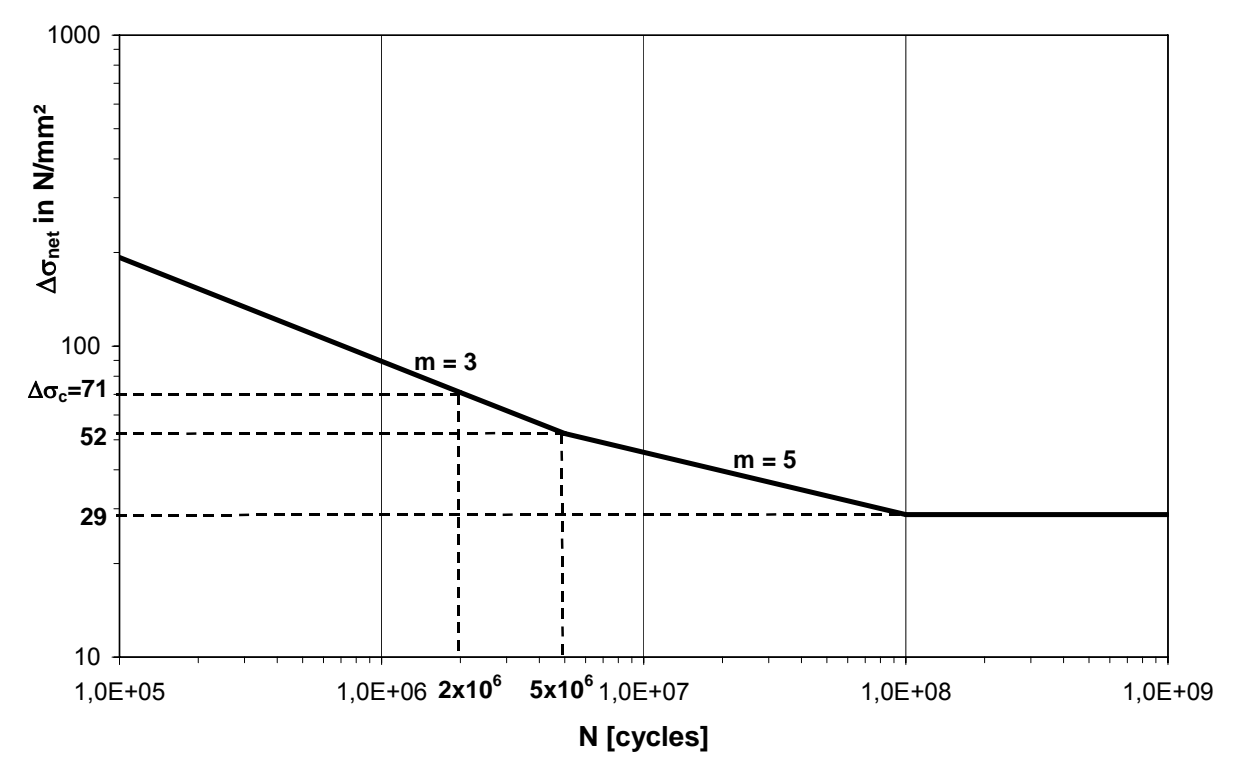

Fig. 3-9: $\quad$ S/N-curve for the fatigue assessment of old riveted steel bridges

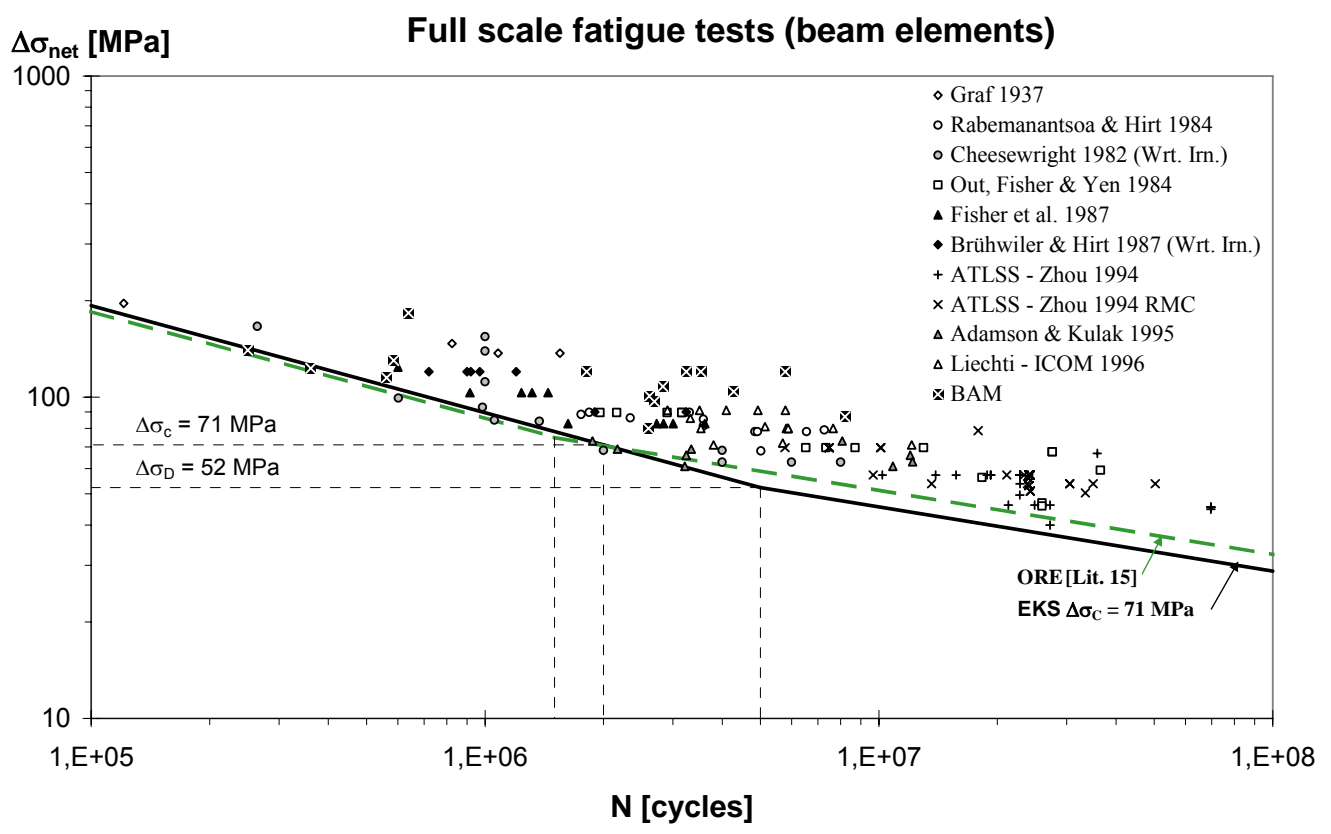

Fig. 3-10: $\quad$ Two different S/N-curves in comparison to more than 125 fatigue test results on riveted large scale tests found in literature

\subsubsection{Welded or bolted structures}

(1) For the fatigue assessment of existing welded or bolted steel structures the detail categories given in Eurocode 3, Part 1-9 [Lit. 48] should be used. But it has to be shown that the weld geometry on the structure is close to the ones produced today by manual arc welding. If not, specific fatigue tests need to be carried out. 


\subsection{Inspection}

\subsubsection{Causes and identification of fatigue cracks}

(1) Fatigue damage appears in the form of fatigue cracks and can occur in primary loaded or secondary elements. Since fatigue failure is depending - besides detailing or environmental conditions - on the load spectra over the service life, consequently, existing steel structures suffer more from fatigue and accumulate more damage the older the bridges are.

(2) The analysis of the reasons of detected fatigue failures often needs a detailed assessment of the existing steel structure. In particular, it is important to distinguish between unloaded defects and cracks resulting from the original fabrication process (with no crack propagation and remaining harmless throughout the structures life), and propagating cracks when subjected to cyclic loading. Thus, if one can observe an opening and closing of a crack under cyclic loading it is likely to be a fatigue crack.

(3) Another aspect is the acceptability of a fatigue crack with regard to the consequence of failure related to the main structure. This is the aspect of redundancy. A fatigue crack, initiated in a secondary element, e.g. caused by restraint, is usually not of major importance for a hazard scenario of a structure. Fatigue cracks in main elements, as longitudinal, cross and main girders, may be of high risk for a break down of a structure and for the safety of people being on or in these structures.

(4) All damages need be listed and considered for deciding on special remedial measures, see chapter 5 . The following reasons can be responsible for fatigue crack initiation:

1. Defects included during fabrication, as

- During welding (inclusions, imperfections, poor weld, lack of fusion, cold cracking) or

- During riveting (low clamping force, radial cracks due to low temperature during clamping, inadequate riveting e.g. penetrating of snap-tool in the material),

- Initial damage due to handling and shipping

2. Not good design with regard to fatigue

- Inappropriate structural details with a low fatigue strength chosen,

3. Stresses and deformations unforeseen in design in joints between components

- Eccentricities

- Restraint due to frozen or corroded bearings or structural joints

- Restraint due to secondary stresses and/or distortion induced stresses, caused by unforeseen interaction between longitudinal and transverse members, too high stiffness, or temperature,

- Overload of structures by trailers with higher axle load than permitted, as often recorded during bridge measurement

4. State of knowledge insufficient

- the structure behaving in a manner not expected in design, such as due to vibration (web breathing or galloping) or load contribution not anticipated in design (earthquake).

- Stiffness higher than foreseen during design.

(5) A damage study requires in general two main tasks:

- identification of a crack during inspection or detailed inspection,

- identification of the cause of the crack. 


\subsubsection{Visual inspection}

(1) In Phase I of the recommended assessment procedure (Fig. 2-1), a visual inspection of the structure is included. All studied documents and drawings have to be updated on-site.

(2) Some European countries have rules for regular visual inspections of bridges, e.g. in bridge management systems (BMS) or in recommendations of the bridge owners. Bridge management systems for existing structures require a detailed visual inspection of the actual state of the structure. Usually, the inspections are performed regularly every 5 to 6 years. Only specialist engineers together, when necessary, with experienced experts (such as welding specialists) should be responsible for regular inspections.

(3) During visual inspections, all deviations from existing documents, defects and fatigue failures must be determined and documented. In many cases cracking of the original corrosion protection, e.g. in shear splices or gusset plates may be a signal for potential crack locations on the surface of the components.

(4) At least the visual inspection should be used to evaluate the corrosion state. If huge corrosion was found, the remaining thickness of the particular cross section has to be measured and considered in the following static checks.

(5) To be well prepared for a visual inspection, the following items should be checked

- permission to access the bridge, e.g. safety requirements of the relevant authority (linesman)

- accessibility to the structure itself and to all members and joints, e.g. need of ladder, special inspection platforms

- power supply e.g. for enough light or measurements

(6) For the visual inspection the following things should be taken on-site:

- copies of previous inspection reports and of existing drawings for documentation of inspection results

- camera and list to document the position and number of photographs taken on site

- hammer, broom, wire brush, spatula, flashlight, length and thickness measuring devices, calliper rule, magnifying glass and water resistant colours for marking,

- safety clothes, helmets, gloves and magnifying glass

\subsubsection{Non destructive testing (NDT)}

\subsubsection{General}

(1) In order to detect fatigue cracks, the inspection focuses on details critical to fatigue. These are details, where fatigue failures are expected due to high load cycles or cross sections with identical details to such details, where fatigue damages occurred in the past, Non-Destructive Testing methods (NDT) can be applied. Measurements, e.g. of strains or deflections, give valuable hints on the locality, where NDT has to be applied. Thereby, the number of evaluated cross sections can be reduced to the most urgent cases.

(2) Quantitative NDT inspection is planed in Phase II of the assessment procedure, see chapter 2. The NDT evaluation can be intensified in Phase III, if the use of fracture mechanics approach is recommended. The idea of using a fracture mechanics approach for the calculation of a service life interval is based on the theory that all structures contain small defects. Since the application of fracture mechanics is based on the assumption of an initial crack size, NDT methods are best appropriate to help characterise the value of the initial fatigue crack size. 
(3) NDT-methods should be always considered prior to considering destructive testing methods. Each NDT-method has limits with regard to its application and level of accuracy under different testing conditions. The level of accuracy of the NDT- methods depends on:

- Chosen evaluation procedure

- Evaluated materials

- Qualification of the personnel (training is essential for the analysis of measurements)

- Quality of the used equipment and its calibration

- Position of the assumed damage and the environment in which the procedure is completed.

- Applied acceptance criteria (more research is needed for characterizing acceptance criteria and probability of detection in old materials).

(4) In each non-standardised NDT-inspection the required accuracy with reference to the measured physical values must be validated. All obtained data must be analysed, quantified and documented.

(5) The evaluation by means of qualitative non-destructive testing requires probabilistic methods (see section 2.4.3) for final expression of accuracy. In [Lit. 43] a reliability concept is introduced, using Receiver operating method (ROC), where the probability of detection (POD) of flaws of certain size or type versus probability of false indication (PFA) gives an indication for different thresholds or sensitivity in non-destructive evaluation.

(6) The Table 3-5 describes NDT-methods, which can be applied to riveted steel bridges by specialists, who have enough experience in evaluation of measured signals and possibly necessary precautions. The information given below does not focus on inspection of welds, since testing and acceptability of flaws in welds are well investigated and standardised (e.g. EN 12062 "Non-Destructive testing of welds-General rules for metallic materials", 2002, EN ISO Welding - General tolerances for welded constructions - Dimensions for length and angles; shape and positions, 1996, BS 7910 Guide on methods for assessing the acceptability of flaws in metallic structures, BSI, 1999).

(7) The probability of crack detection increases by purposeful loading of the examined cross section with a high but still admissible load on the bridge, which causes an opening of possible cracks in the highly loaded cross sections.

(8) With the applied procedures, using standard tests, the smallest detectable crack size should be examined, which is detectable with the applied method under the given test conditions. The method for testing is to choose in comparison with the acceptability of flaws

(9) The following specification gives a more detailed description and some hints for use of the available NTD-methods. The method is also dependent on the environmental conditions on site.

(10) In many countries, only experienced and trained inspectors are allowed to perform Nondestructive testing. In Germany, e.g. the German Society for Non-Destructive Testing (DGZfP) organises courses for professional skill with certificate.

(11) For more information about inspection in particular about NDT, too, see [Lit. 122, Lit. 123]. 


\begin{tabular}{|c|c|l|l|l||}
\hline \hline $\mathbf{N}^{\circ}$ & $\begin{array}{c}\text { Short } \\
\text { cut }\end{array}$ & \multicolumn{1}{|c|}{ Method } & \multicolumn{1}{|c|}{ Application } & $\begin{array}{l}\text { Costs of } \\
\text { equipment }\end{array}$ \\
\hline 1 & MT & Magnetic particle inspection & Surface cracks & low \\
\hline 2 & PT & Colour penetration test & Surface cracks & low \\
\hline 3 & RT & Radiographic inspection & $\begin{array}{l}\text { Surface and subsurface cracks also in } \\
\text { sandwiched elements }\end{array}$ & moderate \\
\hline 4 & UT & Ultrasonic inspection & $\begin{array}{l}\text { Material thickness, in some special cases } \\
\text { crack detection possible: } \\
\text { in riveted sections using low-angle } \\
\text { sound transmitter } \\
\text { in rolled sections, e.g. between flange } \\
\text { and web }\end{array}$ & moderate \\
\hline 5 & ET & Eddy current technique & $\begin{array}{l}\text { Crack detection in rivet holes after rivets } \\
\text { were removed, cracks in thin plates }\end{array}$ & moderate \\
\hline $6 *$ & AE & $\begin{array}{l}\text { Acoustic emission } \\
\text { techniques }\end{array}$ & $\begin{array}{l}\text { Surface cracks, subsurface cracks, } \\
\text { identification of "active" cracks only }\end{array}$ & $\begin{array}{l}\text { not fully applied } \\
\text { and approved }\end{array}$ \\
\hline 7 & FOS & Fibre optical sensors & Monitoring during the crack propagation & high \\
\hline
\end{tabular}

* Range of applicability not evident. Large testing, particularly in field tests is necessary.

Table 3-5: $\quad$ Available NDT-methods, applicable to steel bridges

\subsubsection{Applicable methods}

\section{Magnetic particle inspection (MT)}

(1) Magnetic particle inspection, see Fig. 3-11, uses magnetisation of questionable cross sections in electrically conductive materials. For visualization of the magnetic field, a suspension usually with fluorescent steel splinters is used. A damage or fatigue crack discontinue the formation of the magnetic field. Ultraviolet light (UV) visualises the alignment of the field, see Fig. 3-12.

(2) This inspection method can be used for detection of surface cracks in ferromagnetic materials only. Cracks in nonmagnetic material or in sandwiched elements cannot be detected. The method can be applied as quality control of precise setting of drilled holes to stop active fatigue cracks, see Fig. 3-13. 


\begin{tabular}{|ll|}
\hline Accuracy: & The method has a high accuracy, very small surface cracks on accessible \\
& surfaces, to up to a width of $0.2 \mu \mathrm{m}$ and length of $0,5-2 \mathrm{~mm}$ with use of \\
& reference samples (EN ISO $9934-2$, Non-destructive testing - Magnetic \\
& particle test), can be detected. New equipment can detect cracks below layers \\
& $<40 \mu \mathrm{m}$. Round robin tests are recommended. \\
Adaptation on site: & The surface has to be cleaned, for instance with wire brush, (loose colour \\
& would bridge the possible cracks). Site application is easy to handle using \\
& hand magnet (230 V) and UV-light. The magnetic field should be oriented \\
& perpendicular to the presumed crack. Magnetic powder suspension as \\
& Magnaflux or Fluorflux with particle size $\sim 3$ mm is sprayed on the magne- \\
& tised surface and creates the magnetic field, visualised under UV-light. \\
& The personnel are easy to train and the material expenditure is low. Exact \\
Advantages: & results are obtained for locally limited area. The method is convenient for \\
& inspection of target oriented small areas. \\
& The procedure should not be applied during direct sun exposure. Not usable \\
for non-ferromagnetic material. Photographic documentation is to be made \\
Disadvantages: \\
without flash. Not applicable method for subsurface damage. Surface has to \\
be protected after testing. Investigation on structures painted with aluminium \\
paint can lead to insufficient results.
\end{tabular}

\section{Fig. 3-11: $\quad$ Characteristics of Magnetic particle inspections}

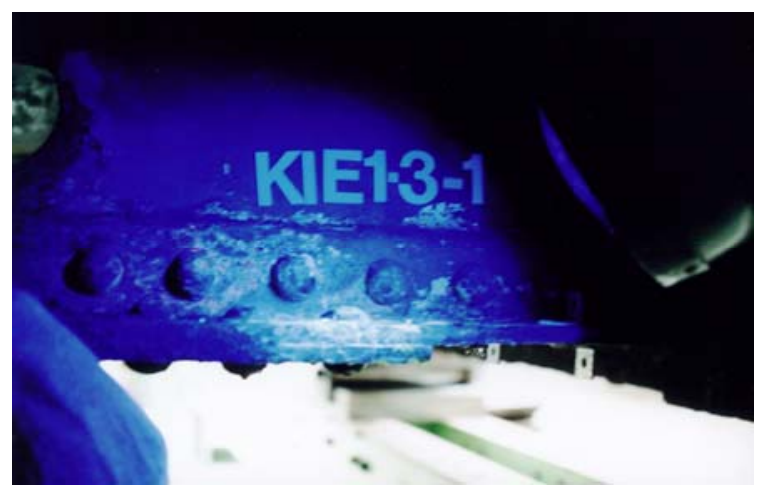

Fig. 3-12: $\quad$ Detection of fatigue crack in a wrought steel bridge [Lit. 13]

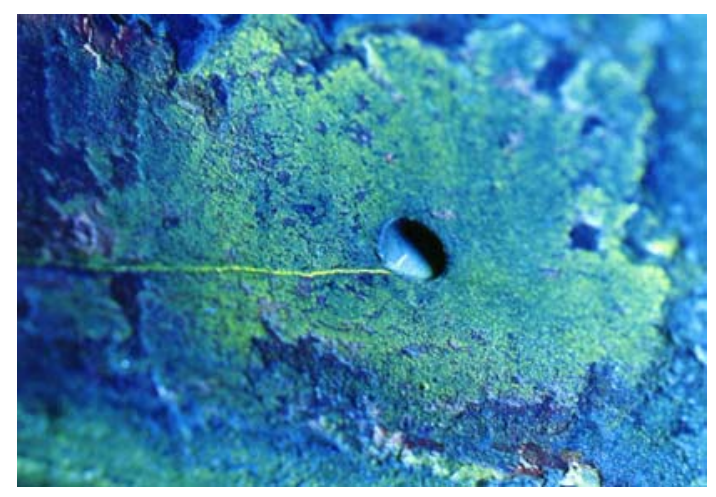

Fig. 3-13: Quality control after stop hole drilling using MPE [Lit. 13]

\section{Dye penetration inspection (PT)}

(3) Fatigue cracks in structural members made also of nonmagnetic materials can be detected with dye penetration method, see Fig. 3-14. The surface is cleaned and than a developer is applied to reveal locations were the dye has penetrated. The dye needs about 30 minutes to develop. 


\begin{tabular}{|ll|}
\hline Accuracy: & The method has a high accuracy (EN 571 Non-destructive testing - Penetrate \\
& testing, 1997), very small surface cracks with a minimum depth of 3 times \\
& surface roughness can be detected, if the surface preparation is diligent. \\
& Round robin tests and reference samples are recommended. \\
Adaptation on site: & Site application is very easy. The surface has to be cleaned, for instance with \\
& wire brush, (loose colour would bridge possible cracks). Don't use \\
& sandblasting, grind carefully, since the grinding process or sandblasting \\
& refuses may close the cracks. The detection accuracy can be reduced. \\
Advantages: & The personnel are easy to train and the material expenditure is low. Exact \\
results are obtained. & \\
Disadvantages: & Not applicable method for subsurface damage. Surface has to be cleaned and \\
& protected after evaluation
\end{tabular}

Fig. 3-14: $\quad$ Characteristics of Dye penetration inspection

\section{Radiographic evaluation}

(4) Radiographic inspection (x-ray, $\gamma$-ray, e.g. with Iridium source) is applied to detect cracks and flaws in built-up sections to evaluate sandwiched members, see Fig. 3-15.

(5) The radiographic source is located on one side of the built-up element, the radiosensitive film, detector or digital storage unit on the other side of the inspected cross section.

(6) The radiographic or $\gamma$-ray inspection is the only method with validated feasibility during laboratory tests and on-site for detection of internal failure or of cracks in the middle of sandwiched elements. The inspection follows EN 435, Non-destructive testing of welds Radiographic testing of welded joints, 2002.

(7) Fig. 3-16 shows a radiograph of a fatigue crack in the tension chord of a wrought steel web girder bridge section after fatigue testing [Lit. 31]. The example in Fig. 3-17 visualises a fatigue crack in the sandwiched gusset plate of a truss girder bridge [Lit. 13].

\begin{tabular}{ll|}
\hline Accuracy: & This method significantly depends on the characteristic and half-life age of \\
the source, of the education of personnel, materials characteristics and \\
thickness. Validation and assessment of the probability of detection is \\
needed in each application, when old steels should be investigated. Under \\
laboratory conditions a crack of $1 \mathrm{~mm}$ in length in the middle of $56 \mathrm{~mm}$ \\
thick built up section was detected. Analysis using advanced image data \\
processing increases the accuracy of the results [Lit. 45]. \\
Adaptation on site: Site application is possible using lightweight Iridium radiation source and \\
traditional radiation film. The accuracy and the remote control area depends \\
on the used source and its half-life age. It has to be measured in each single \\
application. The detectability can be increased by loading the structure to \\
open the cracks. [Lit. 95] \\
Applicable method for subsurface damage. Good detectability of cracks in \\
hidden members of typical built-up sections as was common practice in old \\
steel bridges. Detected cracks can be evaluated on films or digital foils. The \\
removal of paint and corrosion protection is not necessary. \\
Only educated specialists are allowed to work with radiation sources. Access \\
to both sides of the inspected member is necessary. Films are not re- \\
writeable. Films must be developed in a movable laboratory on-site. Source \\
is aging and thus the radiation time is longer for old sources. \\
Disadvantages:
\end{tabular}

Fig. 3-15: Characteristics of the radiographic evaluation 


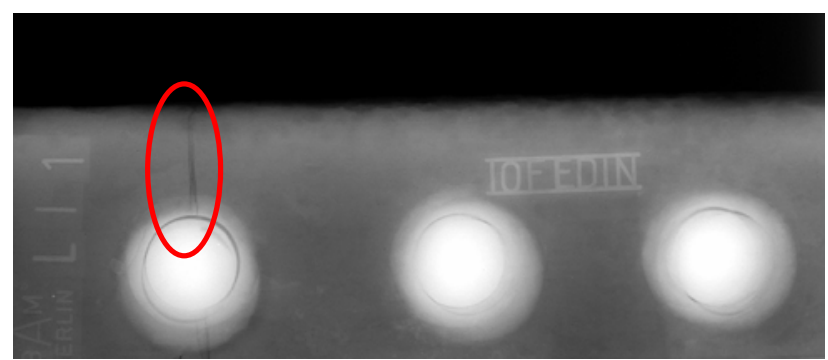

Fig. 3-16: $\quad$ Radiograph of a wrought steel detail in Fig. 3-17 [Lit. 13]

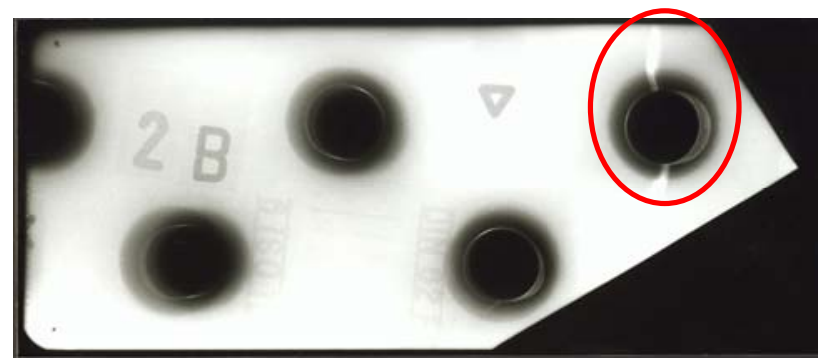

Fig. 3-17: $\quad$ Fatigue crack in the last connected rivet of a tension diagonal to a sandwiched gusset plate of a rimmed steel bridge [Lit. 13]

\section{Ultrasonic inspection (US)}

(8) The characteristics of Ultrasonic inspection are given in Fig. 3-18.

(9) Depending on the material, an ultrasonic signal propagates with a characteristic run time of the ultrasonic wave (velocity), which is different in each material. The back face of an element or damage inside the material is reflecting the signal.

(10) The characteristic velocity must be calibrated with material from the structure accessible from both sides or a drill hole. By means of the calibrated velocity and the run time, the remaining thickness of a corroded member can be determined. Inhomogenities, cracks or flaws inside the materials can be detected. Possible is hand scan or automatic scan (e.g. for rails). Specialists must do differentiation of the size and kind of flaw depending on characteristics of the assessed member.

\begin{tabular}{ll|}
\hline Accuracy: & The method has a high accuracy in homogeneous material to detect flaws \\
perpendicular to the surface and the depth of these flaws. With calibration of \\
the wave propagation velocity of the inspected material, the thickness can be \\
evaluated, too. Crack depth of a perpendicular crack can be assessed by \\
sending US-signals under a certain angle. The detectable size is depending \\
on the conditions especially in welds. \\
Adaptation on site: The surface has to be grinded, to get a good coupling effect. The assessed \\
member need only be assessable from one side. Commercial ultrasonic \\
equipment with adapted ultrasonic sensor and oscilloscope for use in \\
homogeneous steel are available. \\
The material expenditure is small. Exact results are obtained immediately for \\
one measurement point (thickness). Single point US measurement is \\
relatively cheap, scanning methods moderate \\
Not applicable method for wrought steel because of its layered texture [Lit. \\
13]. The size of cracks with unknown direction can be given only with low \\
accuracy, depending on the special conditions. Sandwiched elements cannot \\
be evaluated on-site due to multiple reflections at each surface interface.
\end{tabular}

Fig. 3-18: $\quad$ Characteristics of Ultrasonic inspections 


\section{Eddy Current inspection (ET)}

(11) Eddy current tests, see Fig. 3-19, are techniques well used in other fields of application, e.g. aircraft industry. There, the tests can be performed using hand scan or automatic scan.

(12) Welded details are investigated by ET with reference to EN 1711, Non-destructive evaluation of welds - Eddy current examination of welds by complex plane analysis, 2000.

(13) For the purpose of evaluation of old steel bridges ET is not applied yet. A feasibility study for application of the method to old structures to detect fatigue cracks in built-up sections of a truss girder after laboratory fatigue test has been realised [Lit. 13].

(14) The eddy current probe, used in hand scans is in direct contact with the surface. Eddy current inspection is applied to measure changes in magnetic fields preferably in thin plates. If magnitude and phase of the induced current flow change, a discontinuity is indicated. An application is using rotating eddy current sensor to investigate cracks in sandwiched layers of built up elements after educated guess. After rivets have been removed the sensors can indicate whether there is a crack in the rivets hole in one of the layers or not.

(15) The method is not introduced and needs further development. A feasibility study has been performed (see Fig. 3-20 and Fig. 3-21). The cracks and their position are visible on the display.

\begin{tabular}{|ll|}
\hline Accuracy: & No statistics have been performed. The information bases on [Lit. 13]. \\
& Accuracy of the qualitative depth of the plate (number of plate) with notch or \\
& fatigue crack can be given. Notch and deeper cracks, also 1 mm long cracks \\
& can be distinguished. The absolute crack length cannot be estimated. \\
Adaptation on site: Adaptation not validated and introduced yet. & \\
Advantages: & The specialist can analyse hidden fatigue failure in sandwiched elements \\
& after rivets are removed in case of qualified doubt or before strengthening \\
Disadvantages: & The application is necessary in each single rivet hole after the rivet is \\
& removed. Evaluation of one hole cannot be generalized. Specialized low \\
& sensitive probes, adjusted for each rivet diameter must be developed. A \\
permanent record is not possible. Reading of scans needs specialist \\
knowledge.
\end{tabular}

Fig. 3-19: Characteristics of Eddy current inspection

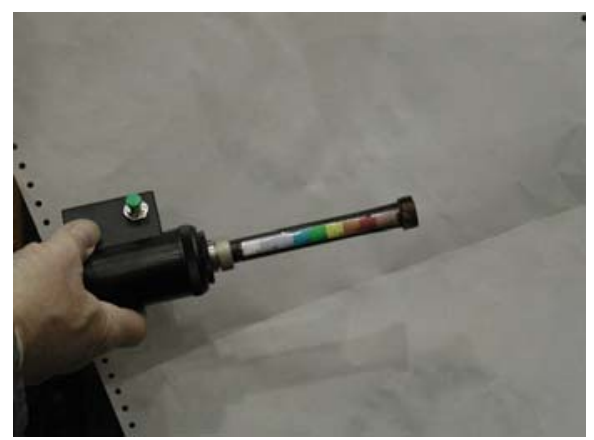

Fig. 3-20: $\quad$ Probe used in BAM feasibility test for crack detection in rivet holes. The depth of the probe (see colours) in the rivet hole is a hint for the depth of the failed member 


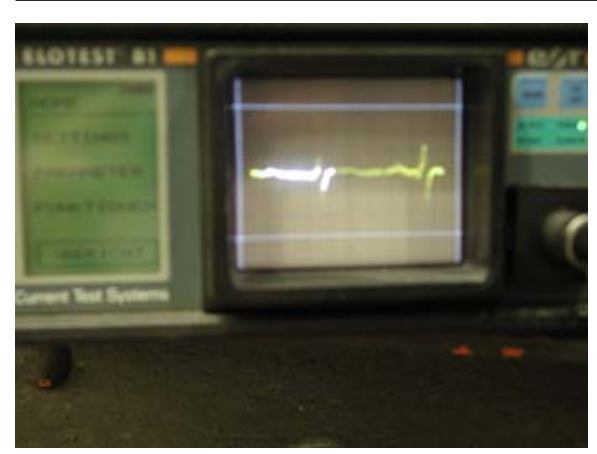

Fig. 3-21: $\quad$ Photograph of the display with signals from two fatigue cracks in the rivet hole.

\section{Acoustic emission techniques}

(16) "Active" growing cracks cause "a sound" under traffic load. The sound, emitted in characteristic frequencies can be received. Monitoring of the sound emission data, collection, filtering and analysing can give information about growing cracks.

(17) Additionally sound data, measured in some cross sections can be compared regarding to the travel time of the sound. The differences give hints about the position of the active cracks.

(18) The analysis is complicated and the system is not yet prepared for application. In [Lit. 33] a modified acoustic emission analysis is presented. Some railways supervise known cracks by acoustic emission, AE was not used for crack detection.

(19) However recent investigations of Boström [Lit. 33] have shown that this method, under consideration of special modifications, is even quite suitable to detect subsurface cracks.

(20) Till now the method is only recommended for applications where cracks were found and crack propagation shall be checked. Data evaluation is laborious and impossible on site. Additionally the equipment is expensive. An example of application of acoustic emission technique for monitoring crack growth is given in [Lit. 102]. 


\section{INFORMATION ON LOADING AND LOAD EFFECTS}

\subsection{Introduction}

(1) In phase II (see Fig. 2-1), a detailed investigation calls for the use of updated values in different areas related to actions, action effects and response of structures to actions, such as :

- Identification and modelling of the structure and its elements

- Loads and Actions (dead loads, permanent loads or variable actions)

- Response of the structure (e.g. secondary moments, dynamic behaviour)

(2) Improvements can be made by finding more precise information (in recent codes, from authorities, etc.) or by measurements. One must identify the parameters where information gained has the largest influence on the assessment results, keeping an acceptable relation between data to be obtained and costs. The different possibilities to update values on loads and load effects are reviewed in this chapter or can be taken from [Lit. 124].

\subsection{Identification and modelling of the structure}

(1) In order to determine correctly the action effects (e.g. internal forces, stresses, etc) resulting from the actions, a proper modelling of the load path from its origin to the supports must be made.

(2) In design, the structural behaviour is usually separated into a primary load carrying system and secondary load carrying system. For assessment, the modelling of the structure is first taken as for the design, where for example a $2 \mathrm{D}$ model of the primary load carrying system was used. Then, it must be improved, by modelling more precisely the primary load carrying system.

(3) In cases of a special structural behaviour, a model in $3 \mathrm{D}$ is advisable. This is for example the case for skewed bridges.

(4) It may also be necessary to include the secondary load carrying elements in the model if there is a strong interaction between these elements and the primary load carrying elements (e.g. secondary beams including connection supporting a concrete slab).

(5) The modelling of the joints is also a large source of difference between expected and real structural response of a structure. The level of partial end fixity, for example in a riveted truss, has a large influence on stresses in the joint and in the components attached to it. This is of particular importance when performing a fatigue assessment.

(6) One way to identify the behaviour of the structure and of its joints is to perform measurements as explained under section 4.6.3.

\subsection{Dead loads and permanent actions}

(1) In Phase I (see Fig. 2-1), the partial safety factors for the design of new structures were used in the assessment.

(2) In Phase II, one idea is to update the values used in the verification by updating the geometry values and the partial safety factors values. The first step is always to study the design notes, the plans and compare it to the structure effectively built. Then, as already mentioned, more realistic values for dead loads and permanent actions can be used in assessment since the uncertainties on these actions can be narrowed down. 
(3) It can be shown [Lit. 37], that keeping the safety level constant, the relationship between variance (= standard deviation / mean value) and value of the partial safety factors on dead and permanent loads can be expressed as shown in Fig. 4-1 and Fig. 4-2. For comparison, the relationships for both concrete and steel-concrete composite bridges are shown on the figures. One therefore sees that concrete bridges can benefit more from such an updating than steelconcrete composite bridges. In the case of steel dead loads, there is no updating possible, except if members found in structure are different from the one taken into account at design stage.

(4) It can be seen that design values, - e.g. the value 1.3 from the Swiss code SIA 160 [Lit. 79] have been used here -, correspond to relatively high variance coefficient values (e.g. values of 0.1 and 0.25 for the variance coefficients on dead load, respectively permanent actions). As a first estimate, one can see from the figures that the partial safety factors for a steel-concrete composite bridges can be reduced by 5 to $10 \%$ (e.g. (G,akt can for example be lowered from a value of 1.3 to 1.2). In order to show that such a reduction of the partial safety factors is possible, it is advisable to carry out a measurement campaign to gain information on real geometry and therefore variance coefficients (see section 4.6.4).

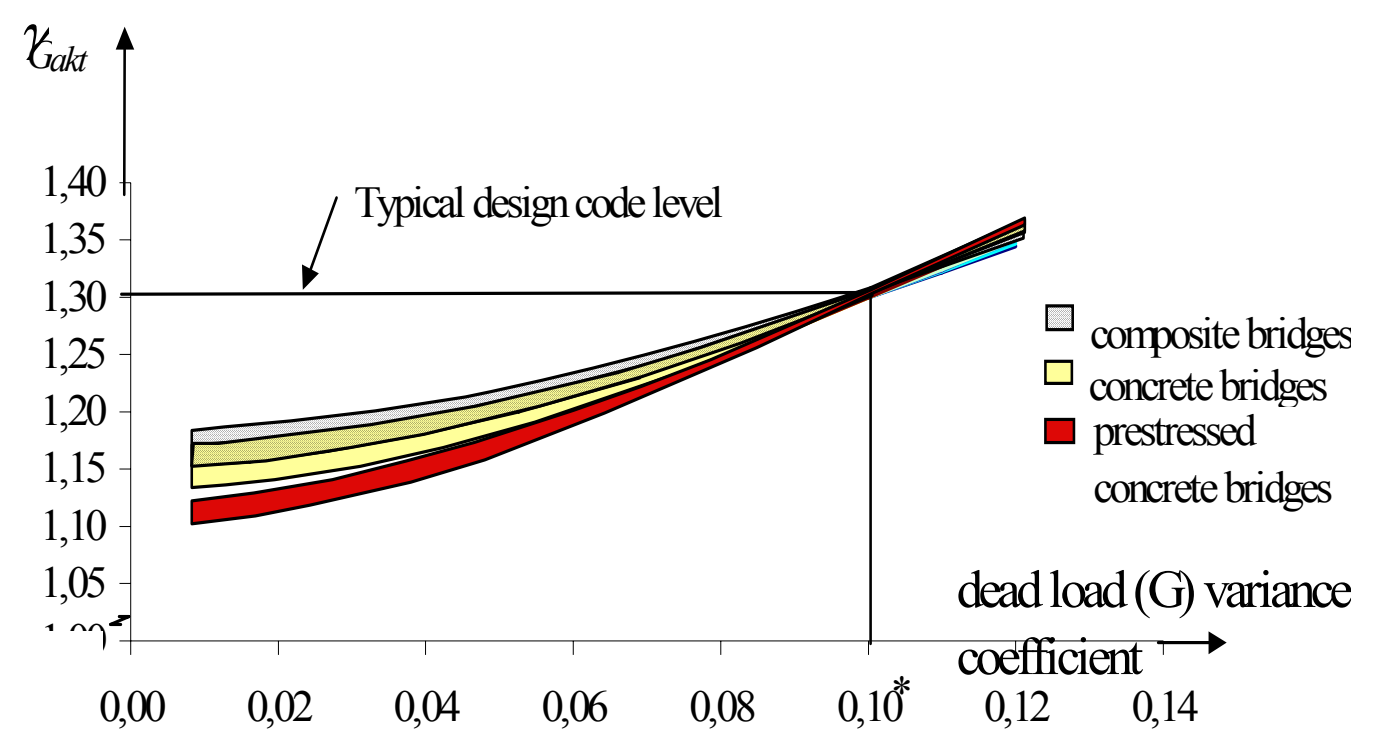

Fig. 4-1: Updated partial safety factor relationship for dead loads (concrete deck)

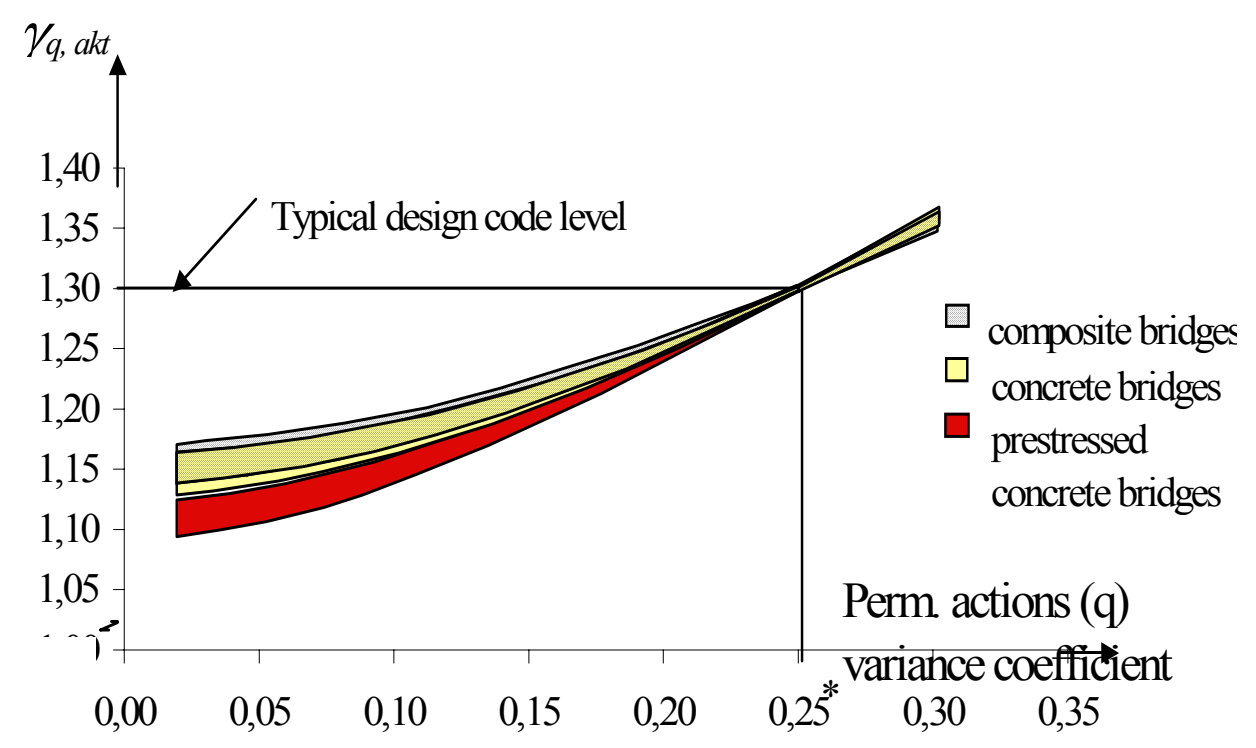

Fig. 4-2: Updated partial safety factor relationship for permanent actions (surfacing) 


\subsection{Variable loads}

\subsubsection{General}

(1) In the case of fatigue limit states, fatigue load models and values given for the damage correction factor in the codes are based on the worst case scenarios for each road category (secondary road, main road, highway, etc.).

(2) In the fatigue damage process, the extreme loads (stresses) or their high upper-fractiles (above 90 to $95 \%$ ) only have a small influence on the damage sum, because the number of cycles is very limited. In bridge engineering, using the shape of the usual stress range histograms, it can be shown that the largest contribution to fatigue is made by the 50 to $75 \%$-fractile of the stress range distribution.

(3) However, even small percentages of stress ranges above the CAFL, as low as $0.01 \%$, in the spectra will initiate the damage process and thus result in a finite fatigue life [Lit. 117]. It shall be noticed that since the CAFL is not a well known value, only a reliability analysis can demonstrate that a given number of stress ranges above the CAFL can occur without initiating a fatigue crack.

(4) The engineer shall seek whether information is available from the authorities. In particular, in the case of railways, data on past and present traffic can be extracted from the railways authorities records, timetables, etc., in the form for example of tonnage per year on a track.

(5) In the case of roads, permanent truck weighing stations, or toll stations can supply some information.

(6) All the same, information on wind speeds, wave heights, etc. over a given period, can be obtained from different authorities (meteorological office, air control tower, harbour office). If not, or if information on the variable loads of interest is too scarce, it can be obtained by different measurement means as explained in 4.6.5.

\subsubsection{Traffic loads}

(1) In phase I (see. Fig. 2-1), the stress range is obtained using a code load model and a damage equivalent factor.

(2) In phase II, a more detailed load model is necessary. This load model shall be composed of the different types of trucks or trains crossing the bridge. One example of such a load model for road bridges is given in EN 1991-2, fatigue load model 4 [Lit. 60]. This model is composed of 5 different lorries with different geometry, axle weight and percentage (traffic type).

(3) Other load models exist and can be found in national codes or specific regulations. The traffic to be used with this load model is function of the traffic type and volume and can be either taken from a code, or given by the proper authority.

(4) In EN 1991-2, three types of traffic, namely long or medium distance or local traffic, giving the percentage of each lorry are defined. These are used with traffic volume for which four different road types are defined and give the total number of lorries per year.

(5) In case insufficient information is available to define traffic type or volume, one should consider performing measurements (on traffic type and/or volume) as described in section 4.6.5. 


\subsubsection{Wind actions}

(1) In phase I (see Fig. 2-1), wind actions are not accounted for in fatigue verifications. Therefore, in phase II, the first step is to determine the susceptibility of the bridge or some of its components to stress variations induced by wind.

(2) Three main cases can occur:

- fatigue resulting from stresses induced by wind action spectra,

- fatigue resulting from stresses induced by vortex excitation or other aerodynamic excitation mechanisms (under constant wind action),

combination of both.

(3) Typical wind action spectra can be found in literature, for example in [Lit. 80] [Lit. 81]. In case insufficient information is available, one should consider performing wind speed or pressure measurements as described in section 4.6.

\subsection{Dynamic amplification factor}

(1) In addition to quasi-statically effects due to a slowly varying load, there are also some dynamic effects due to the rate of the change of load. For example, in the case of traffic on a bridge, due to the speed of the lorries moving on the bridge parameters such as inertia, road surface, passage on expansion joints, etc. influence the load effects.

(2) For phase I, these dynamic effects are accounted for by multiplying the static loads with a socalled dynamic amplification factor which value is always superior to one. This factor is specified in codes for new structures as either a constant or a function of different parameters, such as influence line length.

(3) For phase II, it is advisable to search for diminishing the conservative value given in the codes. To do so, the engineer can use values given in literature, in particular those given in U.S. recommendations for fatigue evaluation of existing steel bridges [Lit. 59]. It is also possible to evaluate dynamic effects through measurements of either loads effects or stresses in a member, see section 4.6.

\subsection{Measurements}

\subsubsection{General}

(1) During the design, the assumptions made simplify the real conditions. Therefore, for example, the static system used in design may differ significantly from the real existing structure. Measurements can be used for verification of the expected static system, if the structural safety or fatigue safety cannot be guaranteed by calculation using the design model. Measurements also often used to determine stresses at places on members where cracks could occur but the stresses cannot be calculated sufficiently.

(2) Fatigue assessment have not been carried out in many existing bridges, since fatigue design specifications did not exist at the time of their design and erection. Often when measurements are carried out, they show that stresses are lower than used in assessment. But, in some details, higher values can be measured. Usually these points are not in the main structure, but in secondary components. The underestimation of stress ranges in some details may result in early fatigue cracking. 
(3) Fatigue critical details may suffer from fatigue failure as result of secondary effects as bending moments, e.g. in connections. It also results from the interaction between main and secondary system (e.g. cross-beams and lateral wind bracing system, or the influence of the track system on the lateral distribution of the loading).

(4) The objective of measurements of loads or loads effects is to gain information on the real structural system, the static and dynamic loading of the structure in order to reduce the uncertainties associated with the static calculations made during design or at the assessment phase I. The main areas of possible knowledge improvement can be summarised as follows:

- Verification of the real structural system and system details: type of connection, real bearing conditions, sensitivity to fatigue, etc. The calculation model will be updated for recalculation.

- Dynamic behaviour of a structure (estimation of dynamic amplification due to traffic and/or other effects, e.g. wind).

- Changes in structural response after local damage (e.g. dents in members after collision influencing the buckling strength of those members).

- Estimation of unforeseen secondary stresses.

- Dysfunction of bearings or elements because of deterioration.

\subsubsection{Sensors and measurement systems}

(1) To guarantee an acceptable relation between data to be obtained and costs, the measurements have to be planned carefully. The information needed is important for the choice of number and type of sensors. Table 4-1 lists most commonly physical values and corresponding sensors to measure them. Information about sensors and their characteristics can be found for example in [Lit. 82, Lit. 83]

\begin{tabular}{|c|c|c|}
\hline No. & Physical value & Sensors \\
\hline 1 & $\begin{array}{l}\text { Strain, } \\
\text { Transverse load distribution }\end{array}$ & $\begin{array}{l}\text { Strain gauges } \\
\text { Fibre optic sensors, Mechanical strain devices }\end{array}$ \\
\hline 2 & Position of the neutral axis & Strain gauges \\
\hline 3 & Rotation & Inclinometer \\
\hline 4 & $\begin{array}{l}\text { Horizontal or transverse deflection, } \\
\text { displacements, stiffness }\end{array}$ & $\begin{array}{l}\text { Geodesic instruments, Laser, } \\
\text { Inductive position encoder }\end{array}$ \\
\hline 5 & Settlement of supports & $\begin{array}{l}\text { Hydrostatic levelling system, } \\
\text { Geodesic instruments }\end{array}$ \\
\hline 6 & $\begin{array}{l}\text { Dynamic response, vibration, } \\
\text { damping, natural frequencies }\end{array}$ & Accelerometers, strain gauges \\
\hline 7 & Static and In-service loading & $\begin{array}{l}\text { Weight-in-motion (WIM) system } \\
\text { Strain gauges calibrated using defined traffic } \\
\text { load }\end{array}$ \\
\hline 8 & Wind speed & Anemometer, wind pressure gage \\
\hline
\end{tabular}

Table 4-1: Physical values and commonly used corresponding sensors

(2) Strain gauges are the most precise system to obtain local strains needed in the fatigue assessment of fatigue critical details. The result is strongly depending on the right choice of the sensor position.

(3) For evaluating dynamic effects on the stress distribution of the structure, strain gauges are recommended. Preliminary assessment and previous experience, resulting from full-scale testing and fatigue failure analysis of comparable detected damages shall be analysed and 
included in the assessment. The choice of cross sections for the measurements should be based on this analysis.

(4) Different types of data acquisition are used:

- Static measurements are used to obtain information on load distribution under well known vehicle configuration in well defined positions on the bridge

- Measurement under service load is made to get real-time information for the assessment of the fatigue resistance of structural elements or connections, estimation of dynamic amplification factor, etc.

- Monitoring is a time dependant permanent (long term) measurement, usually with automatic data acquisition and data pre-processing. The measurements were carried out under service load. The pre-processed data can be used to get the specific actual load spectra of a bridge which furthermore can be used as fatigue load.

(5) For long-term measurements (monitoring), depending on the purpose of the physical value measured, a data sorting, a data computing or a triggering system may be profitable to reduce the amount of data to be collected and transferred. More information on applicability and aims of monitoring as well as detailed information on monitoring systems can be found for example in [Lit. 88, Lit. 125] or in various ISO-Standards [Lit. 90 to Lit. 92] (partially under development).

(6) In general measurement systems consist of the following main components:

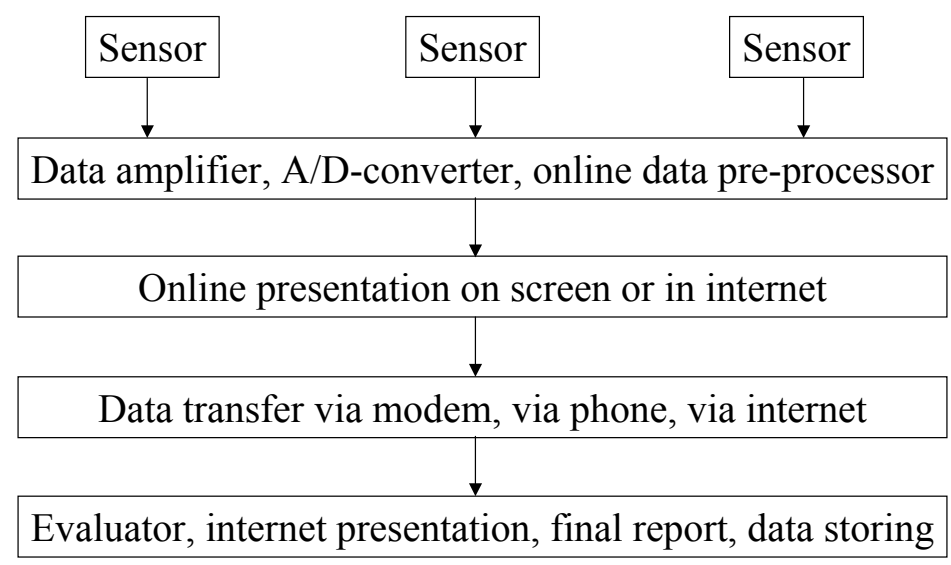

Fig. 4-3: Main components of a measurement system

(7) Data transfer is usually done via cable. The data can be either amplified close to the sensors or in the central-data acquisition unit. Amplification makes the data less sensitive to uncertainties caused by long cables but than the number of cables is high, because local amplifier need energy supply $( \pm 15 \mathrm{~V})$. In the recent research, wireless sensors are under development. In some cases data classing or triggering my be useful to reduce the amount of data to be transferred. It should be kept in mind that some measurement systems or components of measurement systems can not be used in areas with high electric fields as it is found at electrified railway tracks. In general measurements should only be carried out by specialised experts.

\subsubsection{Structural behaviour}

(1) Measurements can explain differences between model and real behaviour, differences between static and dynamic behaviour and therefore help improving the modelling, for example in the following cases [Lit. 59]:

- Unintended composite behaviour, unforeseen load distribution

- Contributions to strength from non-structural elements, such as parapets 
- Unintended partial end fixity at abutments

- Tension forces due to "frozen" expansion joints or rigid end supports

- Longitudinal distribution of moment or forces, unintended continuity at intermediate supports

- Direct transfer of load through the deck to supports in truss bridges

- Improper modelling of transverse load distribution

- Chord continuity and stiffness of joints in truss bridges, partial end fixity in connections

(2) Depending on the element in which measurements are taken to understand its structural behaviour, the following rules can help in reducing the number of sensors to the minimum required:

- If the neutral axis in the main structure shifted due to contribution of the secondary load carrying system or an unintended composite behaviour, strain gauges, applied only to both flanges in the middle of a girder span, measure reliably the position of the neutral axis.

- To evaluate longitudinal distribution of forces, the recommended locations for the strain gauges are the middle and the quarter points of the span.

- To gain information about secondary bending effects or partial end fixity, strain gauges have to be applied only in cross-section near the members support or connection.

- For structural systems such as orthotropic decks carrying load in two directions it is advisable to use fewer multi-axial strain gauges (rosettes) instead of many uni-axial strain gauges, since the values of strains in three directions must be known to deduce the principal stress values.

\subsubsection{Permanent loads}

(1) The partial safety factor values used in assessment calculations can be reduced by using information from measurements.

(2) A measurement campaign should be carried out to gain information on real geometry value affecting dead and permanent loads such as depth of concrete deck, of surfacing, etc. This will give information on real dimensions and variability in these dimensions (see section 3.3), allowing for the computation of variance coefficients. Typically, 10 measurements per parameter (like the concrete slab thickness) shall be taken using a non-destructive instrument or a destructive method. Using the resulting variance coefficients together with the figures given in section 4.3 , one can deduce updated partial safety factor values.

(3) To evaluate the level of build-in stresses due to permanent loads, erection process, settlements, repair welding, etc., the following procedure can be applied. The procedure is semi-destructive and is similar to the one used in several other domains such as tunnels or residual stress measurements. It consists in measuring the strain values in a cross section under constant load, than in boring a hole near the strain gages (in their measuring direction). When the strain gages are reconnected, the new strain values give information about the build-in strains that were present before and liberated by the drilling.

\subsubsection{Variable loads}

\subsubsection{General}

(1) In addition, the traffic loads or density change during the life of every bridge and in order to compute the remaining fatigue life, one must evaluate past, present and future traffic on the bridge. Therefore it is crucial to get an accurate estimation of the load and load effect distributions on bridges for fatigue issues. Any overestimation or crude assumption will 
highly penalise steel structures or bridges sensitive to fatigue, i.e. light structures. The same applies for wind actions.

(2) Variable loads can be measured as follows:

- By counting methods for traffic (using humans, video image treatment, or wires on the road)

- By installing on the road weight-in-motion (WIM) systems, either temporary or permanent, for measuring traffic volume and weights

- By installing devices such as anemometers or accelerometers to measure wind speeds or wind effects on a structure

- By instrumenting some elements, usually the ones identified as being critical, with strain measurement systems (strain gauges, optic fibers, ...)

(3) The last possibility is the only one to investigate action effects in the structure, at a particular location. When measuring traffic one must still rely on proper modelling of the structure to derive action effects representing realistic behaviour. With wind loadings, one shall decide if it is important to know the direction of the wind or only it's intensity in one particular direction.

(4) For past variable loads, it is often difficult to get information from the authority, even for the case of railway bridges where theoretically databases with past traffic should exist. For future variable loadings, the authority shall discuss with the engineer in order to define a realistic loading scenario, if possible based on extrapolations on past and present data or measurements.

(5) One particular measurement issue of great importance is the differentiation between static and dynamic effects, as it is explained below. Static effect can be found by performing measurements with vehicles of known weights and geometries, placed in specific locations or moving very slowly across the bridge (typically $5 \mathrm{~km} / \mathrm{h}$ ). The difference between these static measurements and the data obtained under vehicles moving at the allowable speed characterises the dynamic effects and the deduced dynamic amplification.

\subsubsection{Dynamic amplification measurements}

(1) In the past, some methods have been developed and used for calculation of stress influence lines on the basis of measured values. Special software were written, for example by the German railways; they used an adapted procedure from BRAUNE [Lit. 32] to get the influence line for a special load model from the engine BR 232 based on measured data.

(2) Dynamic factors are usually the conservative upper limit of all dynamic influences, which in reality will not be reached. Stress-time curves, determined during the measurement of static traffic load from the vehicles in certain positions and during passage with the maximum allowed speed, give different values for main, cross and roadway beams. Speeds between 10 and $50 \mathrm{~km} / \mathrm{h}$ do not result in significantly different dynamic behaviour. The dynamic factor is a proportional component.

(3) Dynamic factor values correspond to a lower percentage for high loads than for smaller vehicles. Experimental determining of dynamic factors should be based on measurements with the maximum allowed load on the evaluated bridge.

\subsubsection{Weight in motion systems (WIM)}

(1) Continuous or sequential collection of WIM data on various types of road help to improve the knowledge - on longer periods of time - on operating traffic loads in different countries 
and sites [Lit. 84]. WIM data collected together with measurements of traffic load effects in existing bridges, can in addition give valuable information on dynamic effects on different bridge types and bridge elements. WIM data, combined with computer simulations, will reduce the uncertainties on the load side in fatigue assessment/design.

(2) These considerations motivate the need for accurate WIM data, measured over long time periods, or at least periodically along the bridge lifetime. If no WIM data are available for a given structure, it is still possible to use other traffic patterns (records) for fatigue assessments, but they should be carefully chosen in the existing databases as representative of the real traffic conditions. Particular attention should be paid to the axle and vehicle load distributions and to the traffic volume. For local effects, the vehicle silhouettes and axle groups have also to be considered. Even if traffic measurements are carried out on an existing bridge, the fatigue assessment should take into account the whole past history and possible changes in the traffic pattern.

(3) If traffic data are available for a given bridge for fatigue calculation, they still must be used with caution. For local effects, such as some details in orthotropic steel decks, the traffic measurements may be considered lane by lane, because the transverse influence length is very limited, and shorter than the lane width. But for global effects, such as those linked to the bending moment of a span (e.g. details of steel main girders), the traffic data should be collected simultaneously on all the traffic lanes, and the time history recorded, in order to provide the whole load configuration on the bridge deck at any time. If not, the data collected on one lane shall be used together with structural analysis to get the global effects.

(4) Another important question to be investigated before using traffic data for fatigue assessment is the representativeness of the traffic sample. Most of the detailed (vehicle by vehicle) traffic records are limited to a few days or to a few weeks because of the limited memory size of the WIM systems. When calculating bridge lifetimes up to 50 to 200 years (or more), a strong hypothesis is made about the stationary nature of the traffic process (winter / summer, day / night, working days / weekend, holidays, etc.). Even if the long-term changes are unpredictable, and thus not considered in these studies, the short traffic measurement period(s) must nevertheless be representative of longer ones. Measurements periods shorter than a week should in principle be avoided, because of the weekly periodicity and week-end effect, and the choice of the week of record within the year should be done carefully.

(5) The use of traffic samples for fatigue verification requires a simulation programme [Lit. 120, Lit. 121], with a clear description explaining all the internal assumptions, as well as an users' manual. Such a software requires both the traffic data and the influence lines or surfaces of the bridge load effects to be considered, and a few more pieces of information given by the user (e.g. sampling rate). Then it computes in real time the stress range histograms (stress ranges and corresponding probabilities of occurrence determined using, for example, "level crossings" or "rainflow" analysis), as well as the fatigue damage and lifetime for any given fatigue classes. 


\section{REMEDIAL MEASURES}

\subsection{Introduction}

(1) These recommendations deal only with fatigue damages caused by repeated loading on existing steel structures. Fatigue loading can cause damages, e.g. cracks. After cracks are identified and the cause of damage is assessed, remedial measures, such as repair and strengthening or other measures have to be chosen, see also stepwise procedure phase IV (see Fig. 2-1).

(2) For a sufficient choice of an appropriate remedial measure it must be clarified whether the identified damage is caused by fatigue and if yes, which kind of fatigue failure it is.

(3) Reliable control, whether the damage is really caused by fatigue, is possible

- by controlling the crack propagation

- by controlling the crack mouth opening under cyclic loading (visual inspection under traffic)

- by measurement of an identical un-damaged detail under cyclic loading (e.g. traffic)

- or by analysis of the crack surface by means of the scanning electron microscope (minimal invasive sampling)

(4) In general, the engineer has to identify the areas with the highest sensitivity to fatigue in a structure. Typical locations of fatigue cracking differ between welded and riveted structures as identified in section 5.2.1 and 5.2.2. Knowledge about the locations and causes of fatigue cracks is valuable for selecting appropriate remedial measures.

(5) Every engineer, who works in the field of the assessment of existing steel structures, is kindly asked to report on his experiences in order to extent the online-database on fatigue failures [Lit. 44] in particular for fatigue failures in riveted and bolted connections.

(6) For more information on remedial measures as well as on damage cases see [Lit. 2, Lit. 103 to Lit. 109].

\subsection{Locations of fatigue cracking}

\subsubsection{Welded structures}

(1) Welded structures can have fatigue cracks starting from either the weld root or from the weld toe. Fatigue cracks starting form the weld root are much more difficult to identify. Concerning crack propagation, one has to differentiate between a continuously growing process, starting usually at the weld and propagating into secondary or main structural elements and fatigue cracks arresting in low stress areas to relieve the restraint condition. The later one is in general not that serious compared to the first type of crack propagation.

(2) The following list gives an overview of typical fatigue failure causes in welded structures:

(w1) poor weld or weld defects (fabrication)

(w2) lack of fusion (fabrication)

(w3) cold cracks (environmental conditions)

(w4) restraint (geometrical imperfection, distortion, out of plane bending)

(w5) vibration (traffic, wind, earthquake - low cycle fatigue, lateral bracing) 
(w6) web gaps (e.g. gap between lateral gusset plate and transverse web stiffener)

(w7) geometrical changes (end of cover plate, joints, stiffener, diaphragms)

(w8) web breathing (repeated web buckling deformation)

(3) More detailed information can be obtained from the IIW-XIII-WG5 website [Lit. 44].

(4) In order to reduce fatigue cracking in general, strengthening of structures should consider the rules given in "Good design practice" [Lit. 65].

\subsubsection{Riveted and bolted structures}

(1) The magnitude of stress concentration and tensile stresses is dictated by the geometry of the detail and the fabrication process. Fatigue crack initiation may start from micro-cracks around the rivet hole, resulting from hole making or riveting process.

(2) In bearing type connections both stress concentration and residual stresses are responsible for susceptibility to fatigue failure. The major reasons for fatigue cracking in riveted and bolted structures are:

(r1) hole making or riveting process (micro-cracks due to punching or drilling of the holes or due to bad workmanship during riveting)

(r2) change of geometry (cracks at the holes perpendicular to the main tension stress in net cross section, e.g. end of cover plates, gusset plates, etc.)

(r3) change of geometry ( cracks in the gross cross section, e.g. in the tension flange near the web stiffener)

(r4) thin connection plates (too thin gusset plates or other structural members)

(r5) out-of-plane bending, distortion, restraint, diaphragms

(r6) secondary stresses due tension rods

(r7) cut outs, local stress concentration

(r8) frozen or corroded bearings or joints (e.g. cracks from temperature differences or secondary stresses)

(r9) poor structural detail with low fatigue strength and high loading

(3) More detailed information is given in the WGA-0903-06 document [Lit. 61] for riveted structures.

\subsection{Repair and strengthening}

\subsubsection{General}

(1) If a fatigue crack was detected and the causes were ascertained thoroughly, retrofit measures must be undertaken to repair the cracked structural member. If certain details were evaluated to be weak parts of the structure in terms of fatigue, the fatigue performance may be increased by applying adequate strengthening measures.

(2) In general the repair and strengthening methods have to consider the cause of the damage or failure, and reliability based decisions have to be undertaken to control the repair and strengthening process for critical details.

\subsubsection{Welded structures}

(1) The following listing contains the most important repair and strengthening methods for welded structures:

(w-a) removal of crack by grinding 
(w-b) re-welding

(w-c) surface treatments such as TIG dressing, hammer peening or grinding

(w-d) adding plates or fibre reinforced plastics strips (FRP strips)

(w-e) bolted splices using high strength preloaded bolts

(w-f) shape improving

(w-g) stop holes, for detailed information concerning the hole diameter see e.g. [Lit. 89]

(w-h) modification of the connection detail

(2) Table 5-1 proposes in a similar way as to [Lit. 44] and [Lit. 64] which repair method can be used for repair of fatigue cracks in relation to the fatigue failure causes given in section 5.2.1.

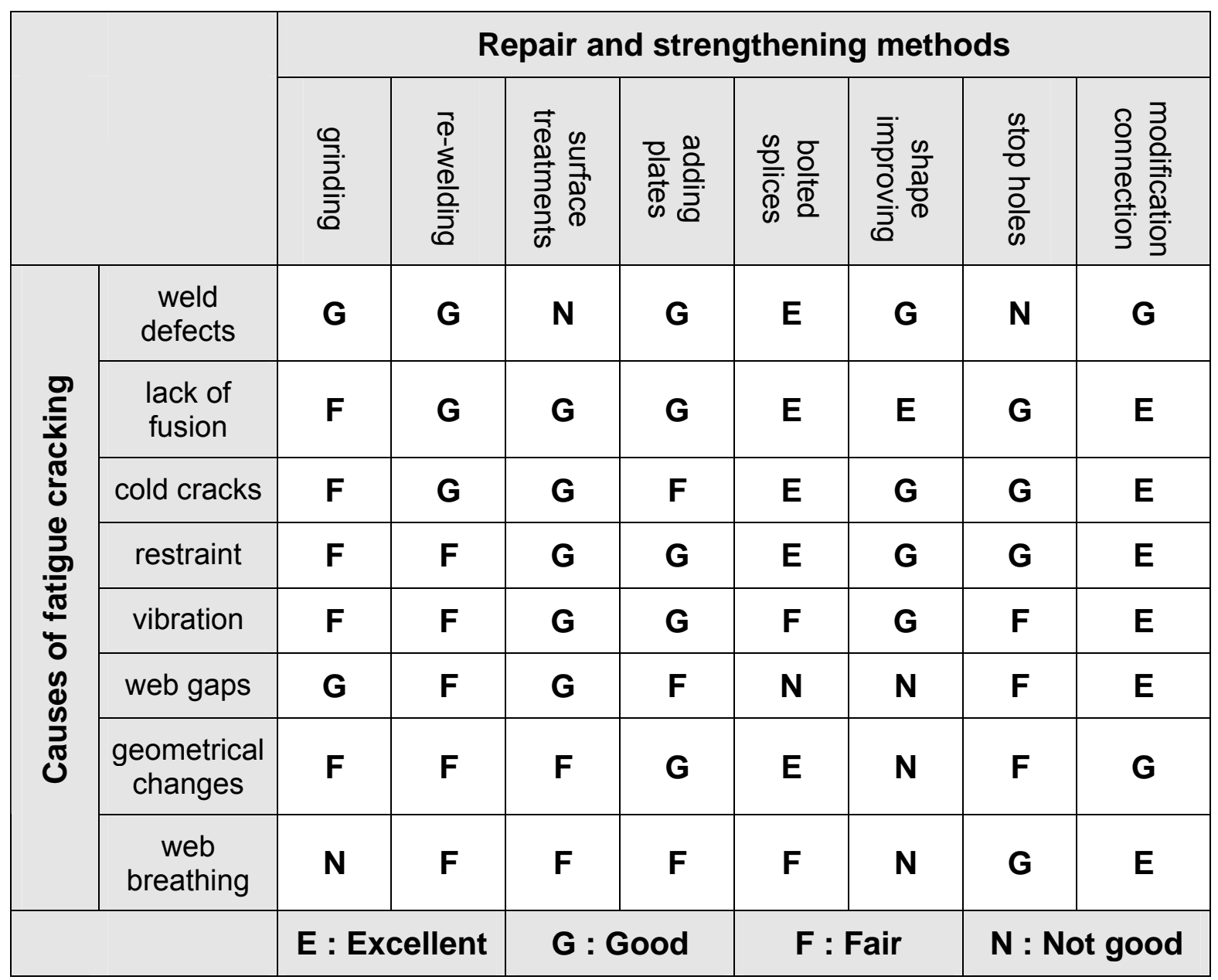

Table 5-1: Applicability of repair and strengthening methods for fatigue failures in welded structures

\subsubsection{Riveted and bolted structures}

(1) The following listing contains the most common repair and strengthening methods for riveted and bolted structures. In each single case a verification of the efficiency of the chosen method is recommended.

(r-a) strengthening by means of pre-stressed bolts or injection bolts,

(r-b) adding additional structural members, e.g. filler plates, cover plates or angles

(r-c) repair-welding (verification of weldability needed, see section 3.4.2.3

(r-d) adding fibre reinforced plastics strips (FRP strips)

(r-e) changing the static system

$(\mathrm{r}-\mathrm{f}) \quad$ stop holes, for detailed information concerning e.g. the hole diameter see [Lit. 89]

(r-g) repair of the bearing conditions 
(2) Table 5-2 gives a proposal for the applicability of repair methods in riveted structures in relation to the fatigue failure causes given in section 5.2.2.

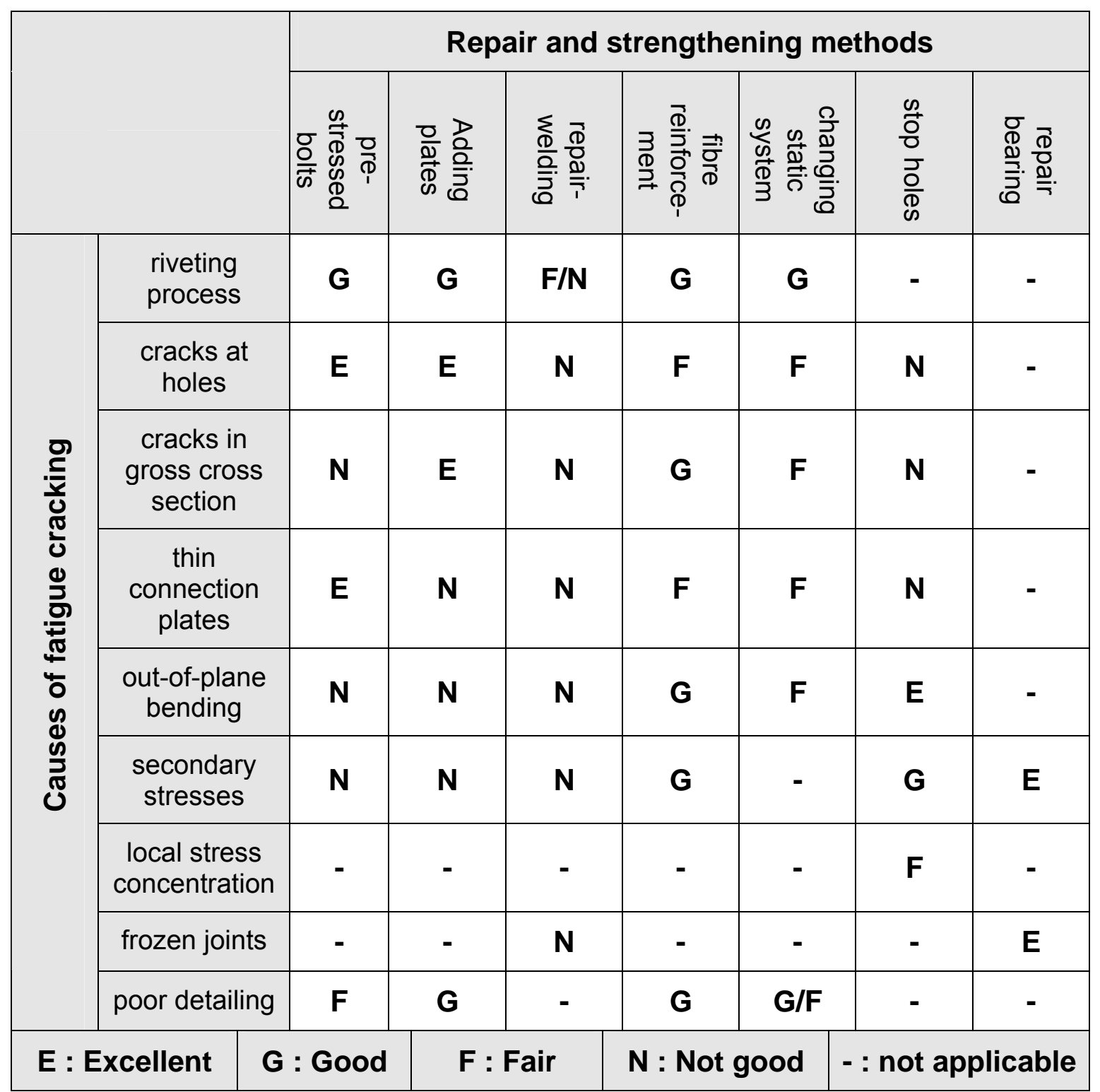

Table 5-2: $\quad$ Applicability of repair and strengthening methods for riveted and bolted structures

\subsubsection{Other Measures}

\subsubsection{General}

(1) It can be seen in Fig. 2-1 that apart from repair and strengthening, several other measures exist for the remediation of bridges or bridge members that fail to meet the predefined acceptance criteria for any of the three phases of fatigue assessment. These include:

- intensification of monitoring, and/or

- reduction of traffic load or volume, and/or for the worst cases

- demolition of the structure.

\subsubsection{Intensified monitoring}

(1) Intensified monitoring may be justified when it can be shown by expert methods such as deterministic or probabilistic fracture mechanics calculations that the reliability of the 
structure can be maintained at an adequate level provided that inspections are conducted at an intensified level and that during these inspections, no fatigue damage is detected.

(2) Intensified monitoring may also encompass continuous monitoring methods. These methods may include simple vehicle counting methods, continuous WIM systems, continuous strain measurement systems (at or near fatigue critical details), or acoustic monitoring, see e.g. [Lit. 70], [Lit. 71] or [Lit. 72].

(3) These methods should only be used by, or in consultation with experts with experience in these areas. The choice of continuous monitoring over other suitable remediation measures will depend largely on economic considerations, as well as the availability of the proper expertise. It has to be considered that not all monitoring methods are applicable on railway bridges due to the strong electromagnetic fields.

\subsubsection{Reduction of traffic load or volume}

(1) Another measure which may be taken to extend the fatigue life of a steel bridge is the reduction of traffic load or volume. Reduction of the traffic load, in particular, is believed to be an excellent method for resolving a wide range of fatigue problems that may be used for welded or riveted structures (see section 5.2). If traffic load or volume reduction measures are to be taken, they should be justified on the basis of calculations on a detailed (Phase II) or expert (Phase III) level, see Fig. 2-1. Where possible, the successful enforcement of these measures should be verified with weigh stations and/or vehicle counting methods.

(2) A very simple and useful measure for orthotropic decks is re-positioning the road lanes about $60 \mathrm{~cm}$. It is by far the most cost effective method but at the same time one only gain a factor two at a time. If there is enough space on the bridge deck one can adopt this method without taking any traffic measurements.

\subsubsection{Demolition}

(1) In case none of the above mentioned measures helps to keep the structure in service, the final measure would consequently be to demolish the structure. However, for very old structures, one should think about the cultural value of the structure and may save it by, for example, changing its affectation and build a new structure next to it.

\subsection{Case studies}

\subsubsection{General}

(1) The following sections include a short summary on most common fatigue failure problems which have been found in existing steel bridges as well as proposals for adequate repair and strengthening methods.

\subsubsection{Welded structures}

(1) Table 5-3 gives an overview about typical fatigue failures of welded structures and resulting adequate repair and/or strengthening methods. The characters and numbers in brackets are related to locations and causes of fatigue cracking mentioned in section 5.2 and repair or strengthening methods mentioned in section 5.3. Majority of cases are taken from [Lit. 64], [Lit. 44], [Lit. 66], [Lit. 19]. Some of the following constructional details are bad with respect to fatigue and should never be chosen for bridges. 


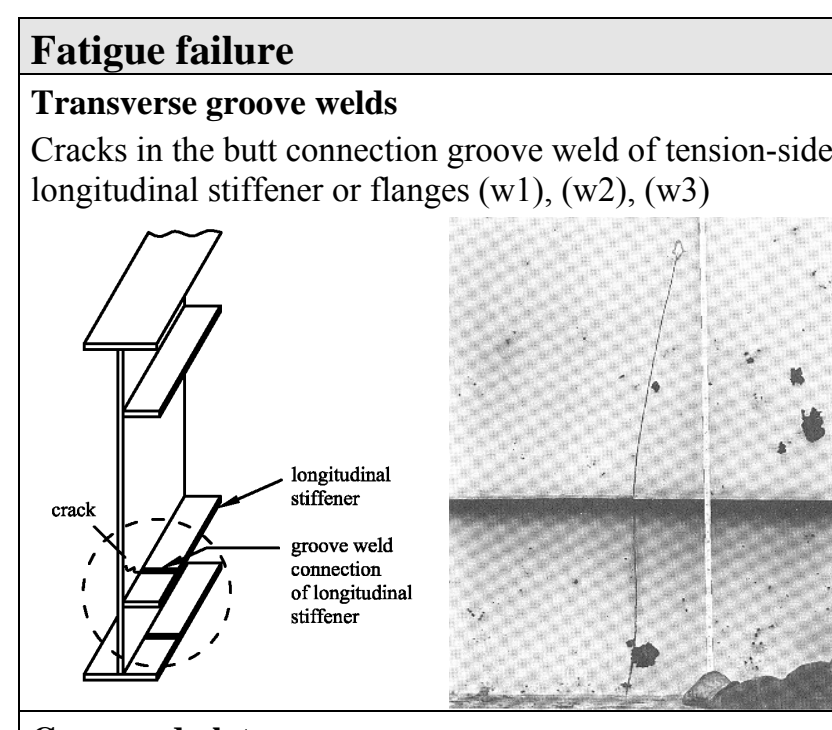

\section{Cover end plates}

Cracks at transverse front welds at cover plate end (w7), (w1)

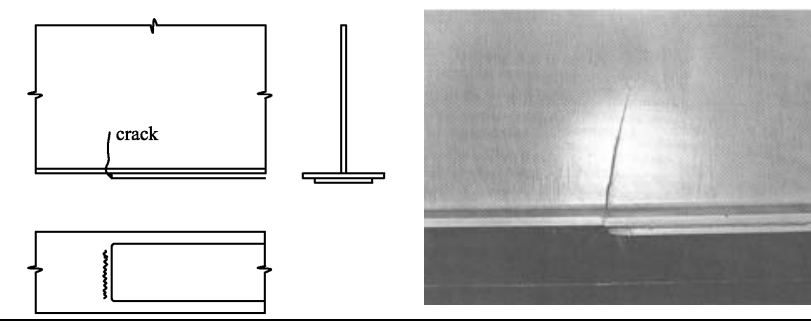

Gusset plates on flanges

Cracks in welded gusset plate joint on flanges (w7), (w1)
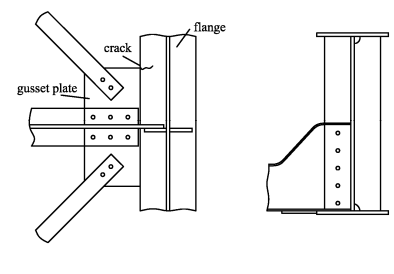

\section{Coped end of deck plate girder}

Cracks at the coped end of deck plate girders (w7)

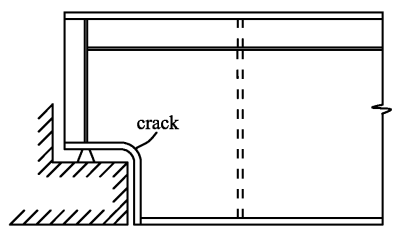

\section{Cross bracing connections}

Fatigue cracks at the cross bracing connection detail on the upper flange (w4), (w1)
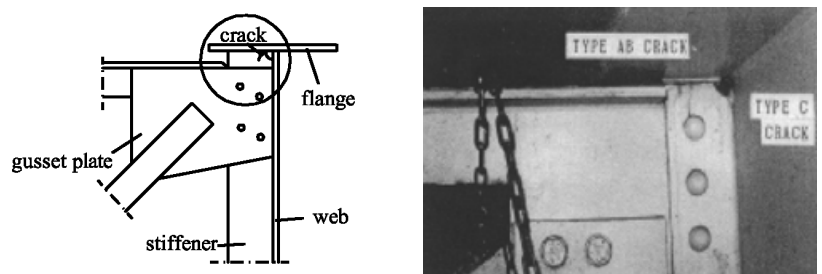

Repair

- adding a filler plate or

FRP (w-d)

- splicing by using bolts

(w-e)

- re-welding and surface

treatments if cracks are

small and have not

reached the web (w-b)

and (w-c)
Strengthening

- adding filler plate or

FRP (w-d)

- splicing by using bolts

(w-e)

- re-welding (w-b)
Depending on the

surface crack length:

- long cracks $\mathrm{L}<40 \mathrm{~mm}$ : stop holes (w-g) and splicing with bolts (w-e)

- short cracks $\mathrm{L}<10 \mathrm{~mm}$ : surface treatments such as TIG dressing or hammer peening (w-c)

- stop holes (w-g)

- improving of weld toe detail (w-f)
- improving the weld toe detail (w-f)

- surface treatments such as grinding and/or peening ( $\mathrm{w}-\mathrm{c}$ ) - adding filler plate or FRP (w-d)

- shear splices using bolts or injection bolts (w-e)

- improving of weld toe detail (w-f)

- surface treatments (w-c)
- adding bolt connection with rib plates (w-e) - adding plates or FRP (w-d) treatment (w-c)

- reinforcement by splice

plates (w-e)
- improve the weld toe

detail (w-f)

- full penetration welding

(w-b) and surface treatment (w-c) such as grinding and/or peening (w-c)

- use symmetrical connections (w-h) 


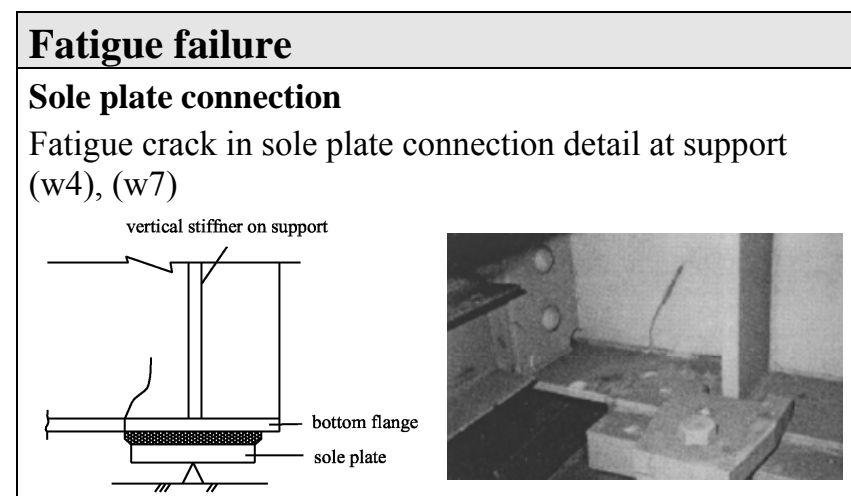

\section{Cut out web (mouse-hole)}

Fatigue crack in the web or flange, initiated at the fillet weld toe of the cut out web (w7)

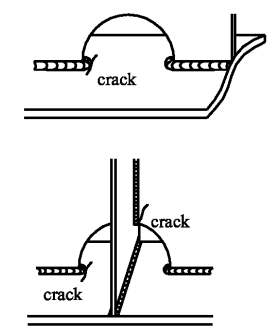

\section{Orthotropic deck}

Orthotropic steel bridge deck, different details with low fatigue strength (w4), (w7), (w1), (w2)

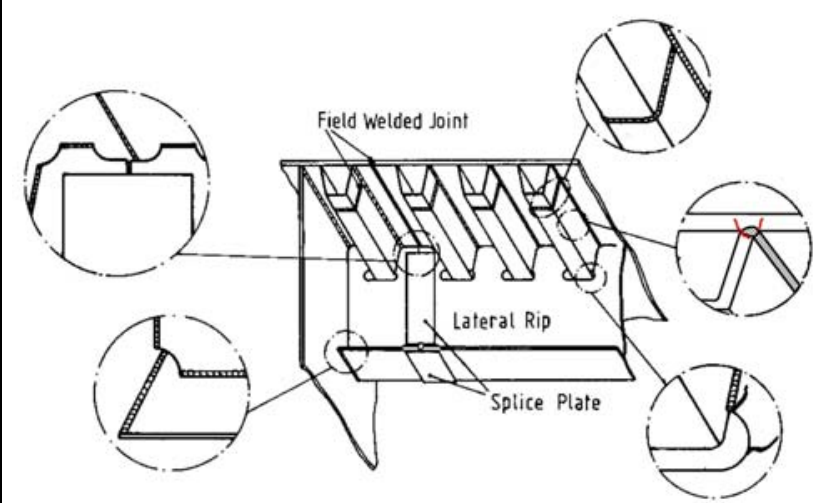

\section{Hanger and pinned connections}

Cracks induced by vibration, e.g. by wind or traffic (w4), (w5)

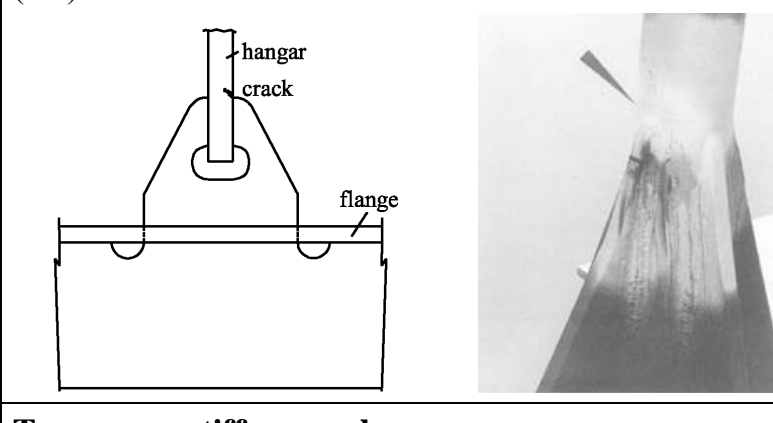

\section{Transverse stiffener web gaps}

Cracks near the end of a vertical web stiffener (w6), (w1)
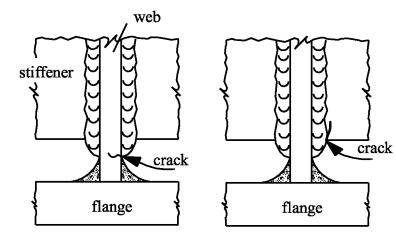

\section{Repair}

- adding plates or ribs to

the web of the

supported girder (w-d)

- reinforcement by bolted

splices (w-e)

- stop holes (w-g)

- stop holes (w-g) when

crack in the web

- adding filler plate or

FRP (w-d)

- stop holes (w-g)

- adding filler plate or

FRP (w-d)
Strengthening

- adding plates or ribs to

the web of the

supported girder (w-d)

- reinforcement by bolted

splices (w-e)

- modification of

connection detail (w-h)

- adding filler plate or

FRP (w-d)

- increasing the curvature

ratios of the cut outs

(w-f)

- full penetration welding

(w-b) and surface

treatment $(\mathrm{w}-\mathrm{c})$

- preventive stop holes

(w-g)

- strengthening deck

plate by thicker steel

deck or thicker

pavement (w-h)

- adding steel plates or

FRP strips (w-d)
- re-welding of small

cracks followed by

surface treatments

(w-b) and (w-c)
- change of the static system or connection detail (w-h)

- improvement of weld quality by surface treatment methods (w-c)

- increase curvature ratios (w-f)
- stop holes (w-g)

- weld toe finishing by

TIG-dressing or grinding (w-c)
- prevention out-of-plane distortion of the girder web (w-h)

- increase flexibility of the connection (w-h) 


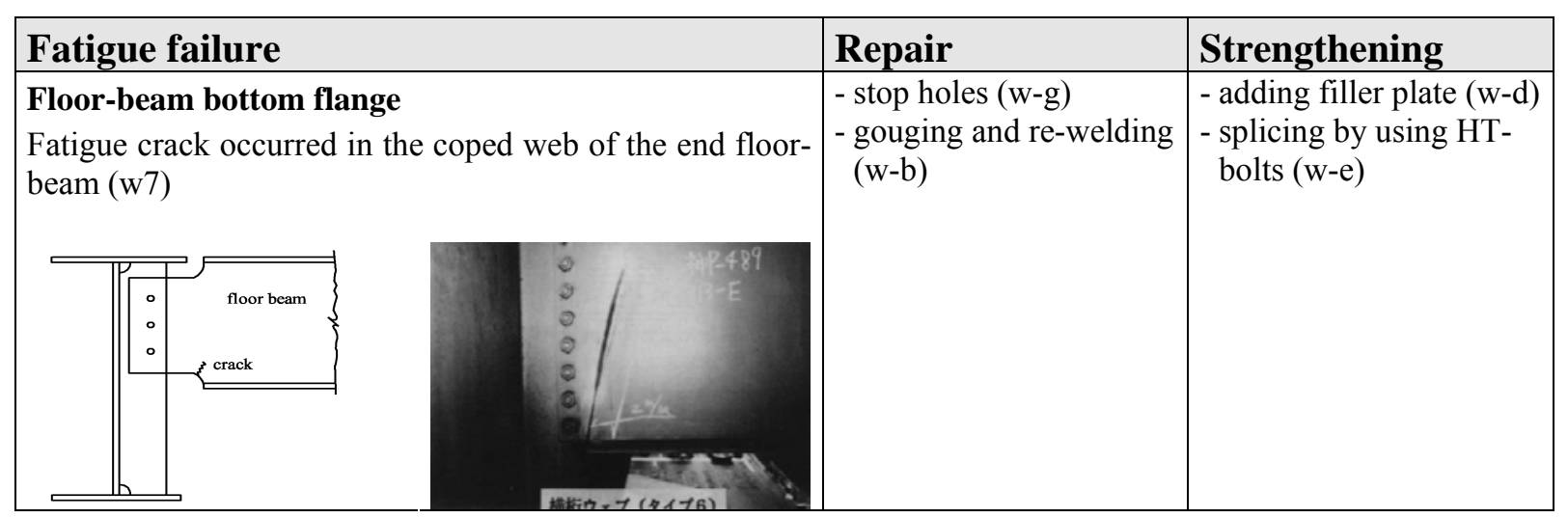

Table 5-3: Typical fatigue failures of welded structures and recommended remedial measures

\subsubsection{Riveted and bolted structures}

(1) The Table 5-4 gives an overview about typical fatigue failures of riveted and bolted structures and resulting adequate repair and/or strengthening methods. The characters and numbers in brackets are related to above mentioned locations and causes of fatigue cracking (section 5.2) and repair or strengthening methods (section 5.3). Majority of cases are taken form [Lit. 12], [Lit. 13], [Lit. 67].

(2) Existing riveted structures should not be welded without detailed verification of the weldability of the used old steel (see section 3.4.2.3).

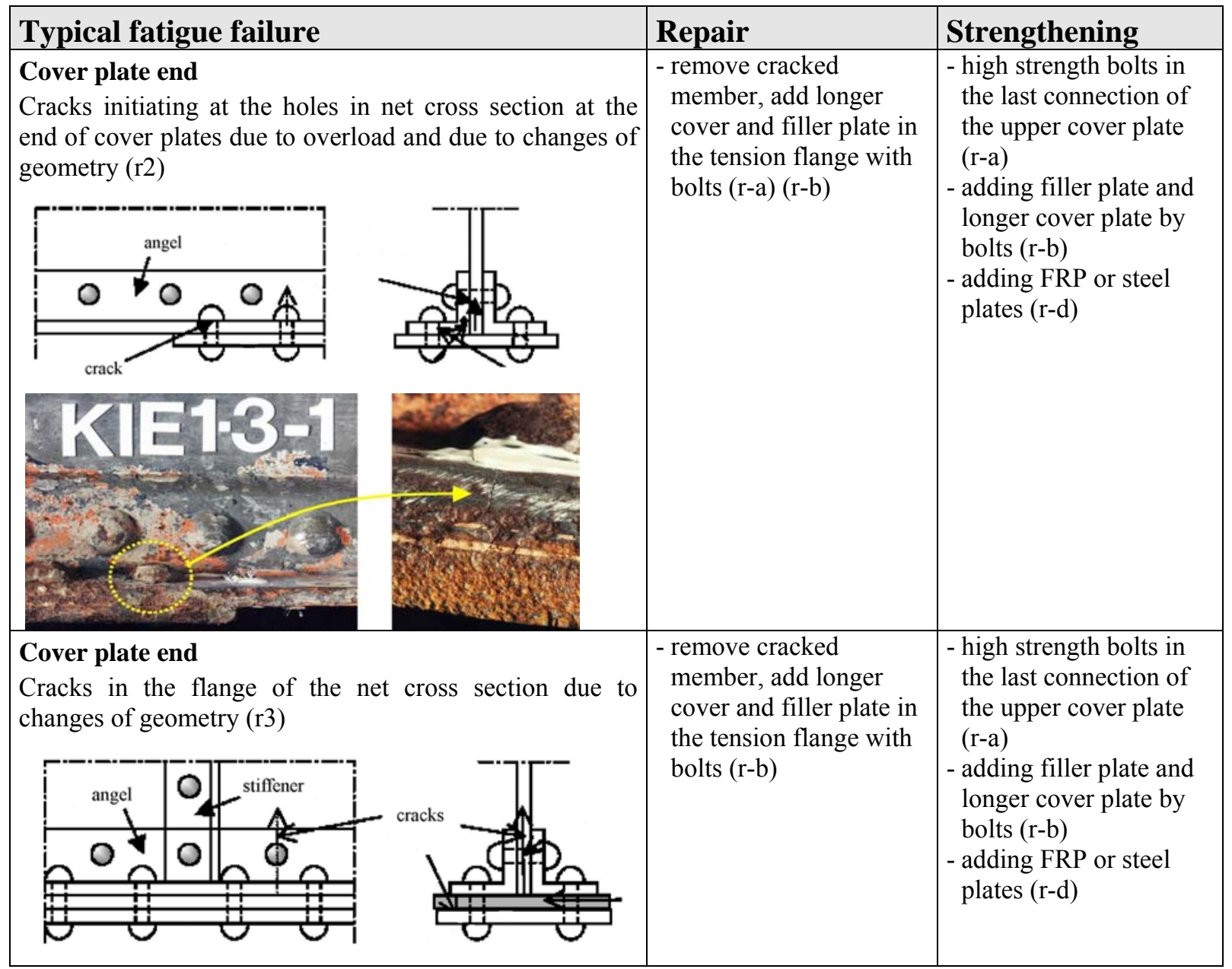




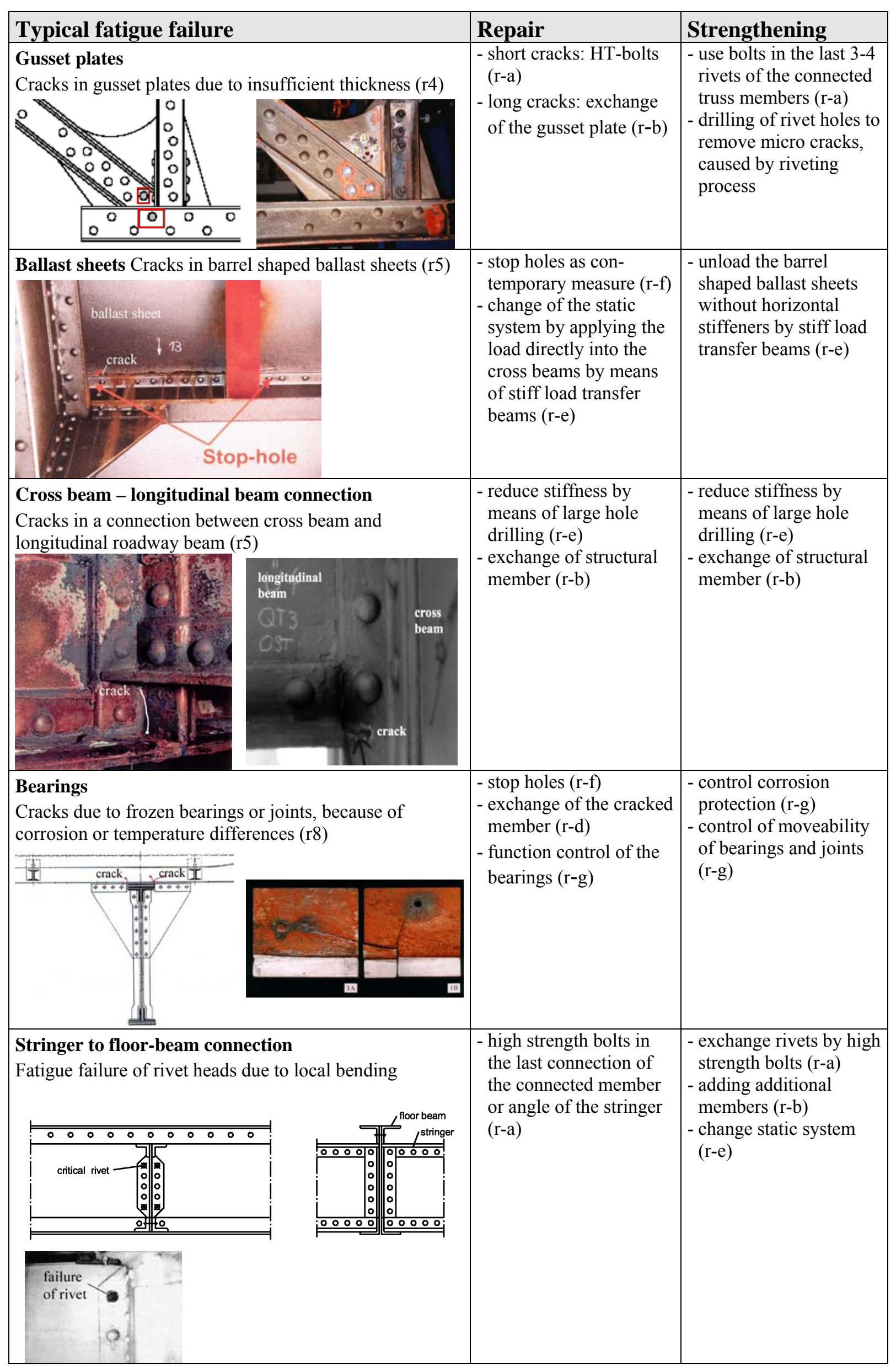

Table 5-4: Typical fatigue failures of riveted / bolted structures and recom. remedial measures 


\section{EXAMPLE}

\subsection{Remaining fatigue life of a main girder of a riveted railway bridge}

\subsubsection{General information}

(1) The single-track railway riveted bridge was built in 1895 and it is still being used today. The bridge is composed of two equal trusses. The structural system of each truss is given in Fig. 6-1. In 2000, after over 100 years of service, there is a motivation for assessment since the bridge has reached the end of its design working life. Therefore, an assessment is carried out to determine the residual service life of the bridge.

(2) It has to be noted that, in old bridges fatigue damages occur in main girders often rail bearers, longitudinal and cross girders of the bridge deck and its connections show fatigue problems. However, for the following example it is assumed that these more critical bridge members will be replaced and the aim of the following determination is to examine only the main girders.

(3) More examples can be found e.g. in [Lit. 113]. 


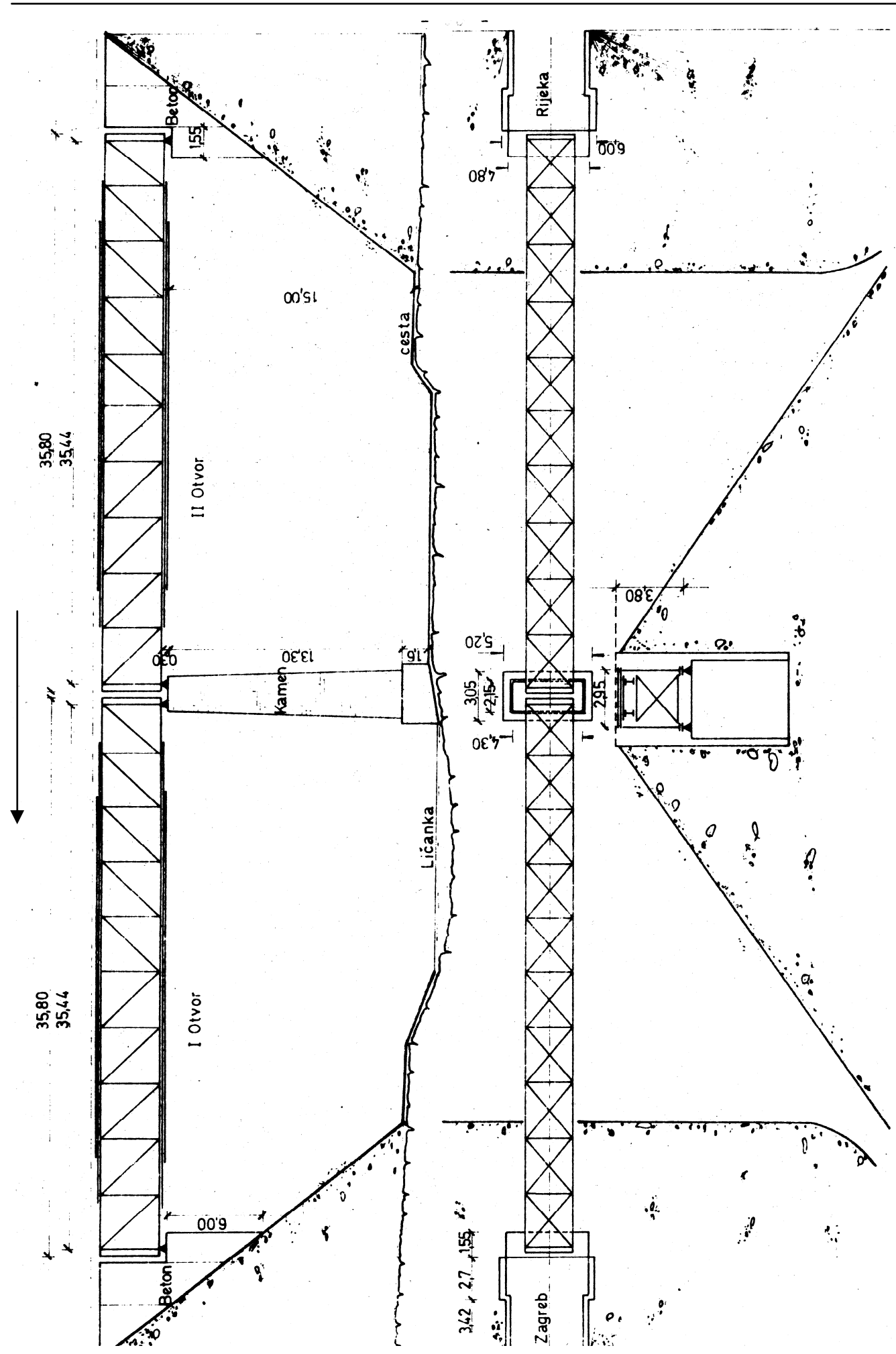

Fig. 6-1:

A general view of a truss railway bridge

(4) Concerning the number of locomotives and wagons involved, the explanation is as follows:

- The bridge is located on a section with large slope.

- One locomotive can pull 500 tons on that slope.

- For example, four locomotives would be necessary for a train of 2000 tons.

- After the train crosses the bridge, three locomotives return to the point of departure, and one keeps pulling the train.

(5) It is clear that essentially only locomotives have to be taken into account, which have crossed the bridge in the past. 


\subsubsection{Calculation basis}

(1) Since the bridge has been in use for 105 years, there is a higher probability of failure due to fatigue than due to static overloading - according to data from the listed reference [Lit. 62]. Data about traffic load and about materials were obtained from the railways archives.

(2) The structural system of the main truss is shown in Fig. 6-2.

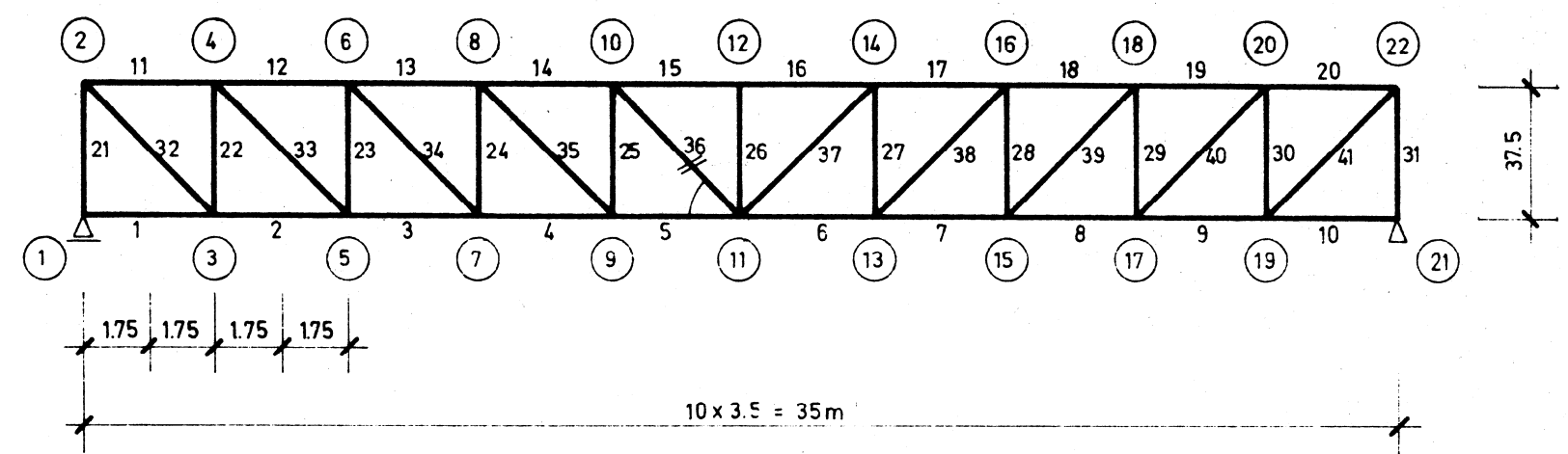

D36 - diagonal element which was analysed

Fig. 6-2: $\quad$ Structural system of the main truss

(3) It should be noted that each specific structural element has a different fatigue life. The diagonal element in the middle of the span (D-36) was estimated as the most critical. The greatest number of cycles and the greatest stress range are expected to occur in this element (ordinates of the influence line are both positive and negative). It was confirmed by reports of measurements that the greatest stress range was at this element.

(4) Properties of member D36:

- Cross-section 4L 80x10, $\mathrm{A}_{\text {gross }}=4 \cdot 15.1=60.4 \mathrm{~cm}^{2}, \mathrm{~A}_{\text {net }}=4 \cdot 13.0=52.0 \mathrm{~cm}^{2}$

- Riveted connection $\phi 16$

- Member length $\mathrm{L}=5.13 \mathrm{~m}$.

\subsubsection{Selection of the S/N-curve}

(1) The analysed element was built using rivets, which corresponds, according to section 3.5.2, to the detail category 71 .

\subsubsection{Phase I: Preliminary evaluation}

(1) No phase I evaluation was carried out, because it was decided to go directly to phase II as detailed data on traffic was available to do a Miner's sum.

\subsubsection{Phase II: Detailed investigation; Formation of the stress range spectrum}

(1) Data on traffic was collected from the railways archives. In cases where no data could be found the values were estimated by trend-lines. The following data was used:

- Number of trains each year, see Fig. 6-3

- Tons transported yearly, see Fig. 6-4 


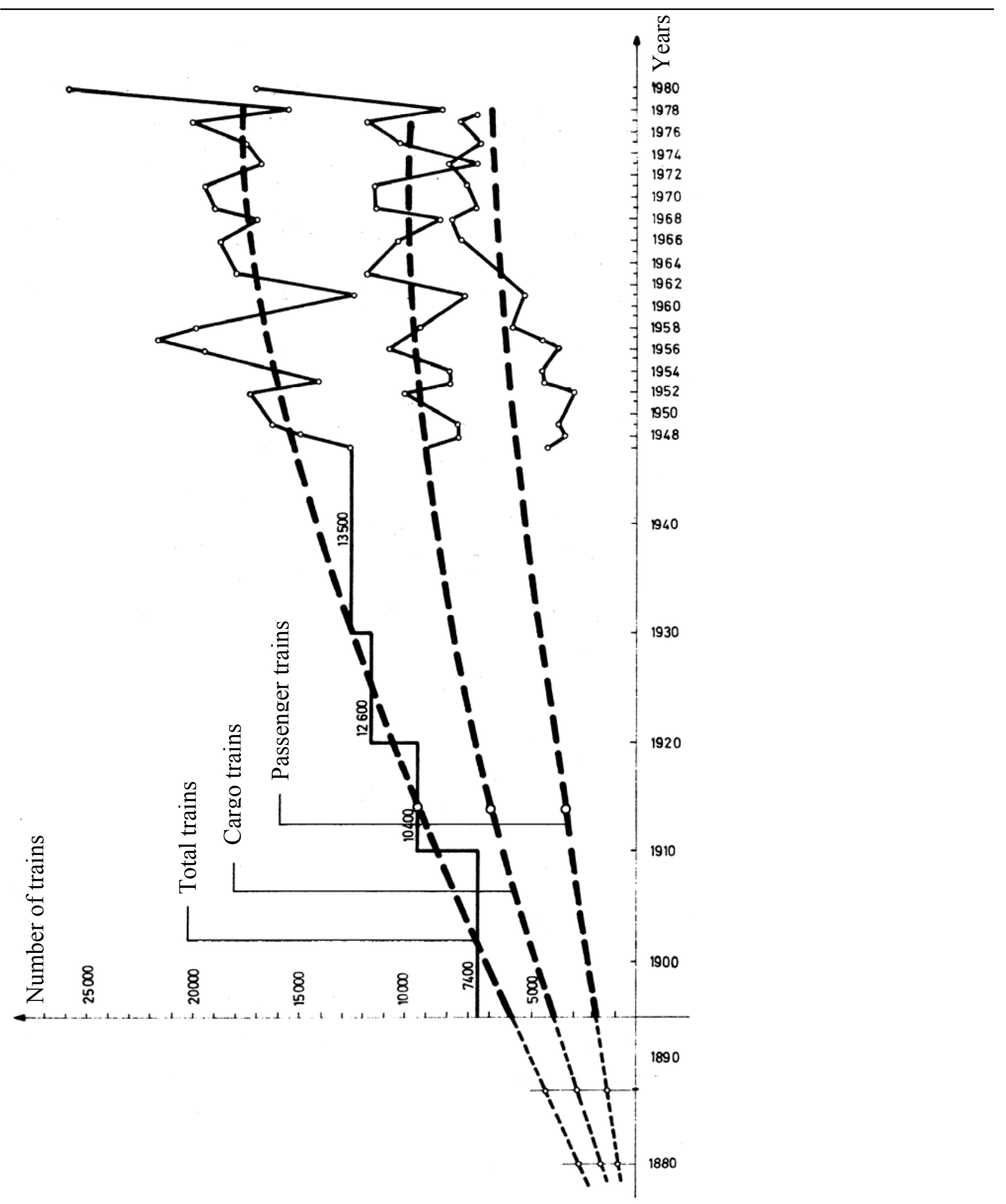

Fig. 6-3: $\quad$ Number of trains each year 


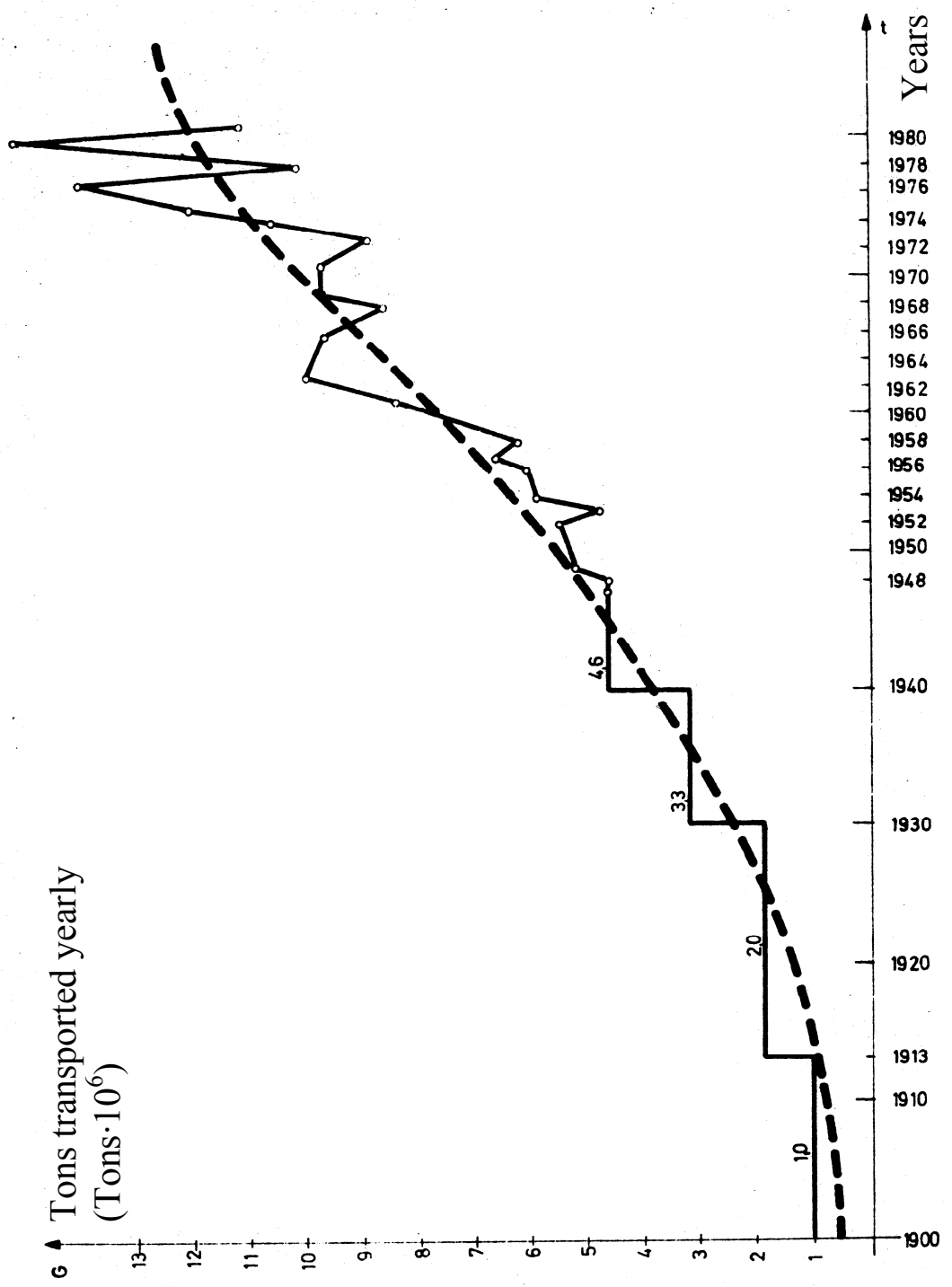

Fig. 6-4: $\quad$ Totals of yearly transported cargo

(2) The data on locomotives and wagons are given in the following tables.

\begin{tabular}{|c|c|c|c|}
\hline \multirow{2}{*}{ Years } & \multicolumn{2}{|c|}{ Cargo wagons mass [tons $/ \mathrm{m}$ ] } & \multirow{2}{*}{$\begin{array}{c}\text { Passenger wagons mass } \\
{[\text { tons } / \mathrm{m}]}\end{array}$} \\
\hline & Empty & Loaded & \\
\hline $1895-1913$ & 1.6 & 2.8 & 2.0 \\
\hline $1914-1959$ & 1.6 & 4.6 & 2.0 \\
\hline $1960-1980$ & 1.6 & 6.4 & 2.0 \\
\hline
\end{tabular}

Table 6-1: $\quad$ Data on wagons

\begin{tabular}{|c||c|}
\hline Years & Locomotive type \\
\hline $1895-1913$ & S 123 \\
\hline $1914-1946$ & S 32 \\
\hline $1947-1959$ & S 38 \\
\hline $1960-1980$ & E 362, 2E 362, E 320 \\
\hline
\end{tabular}

Table 6-2: Data on locomotives

(3) Characteristics of particular locomotive types are shown in Fig. 6-5. 


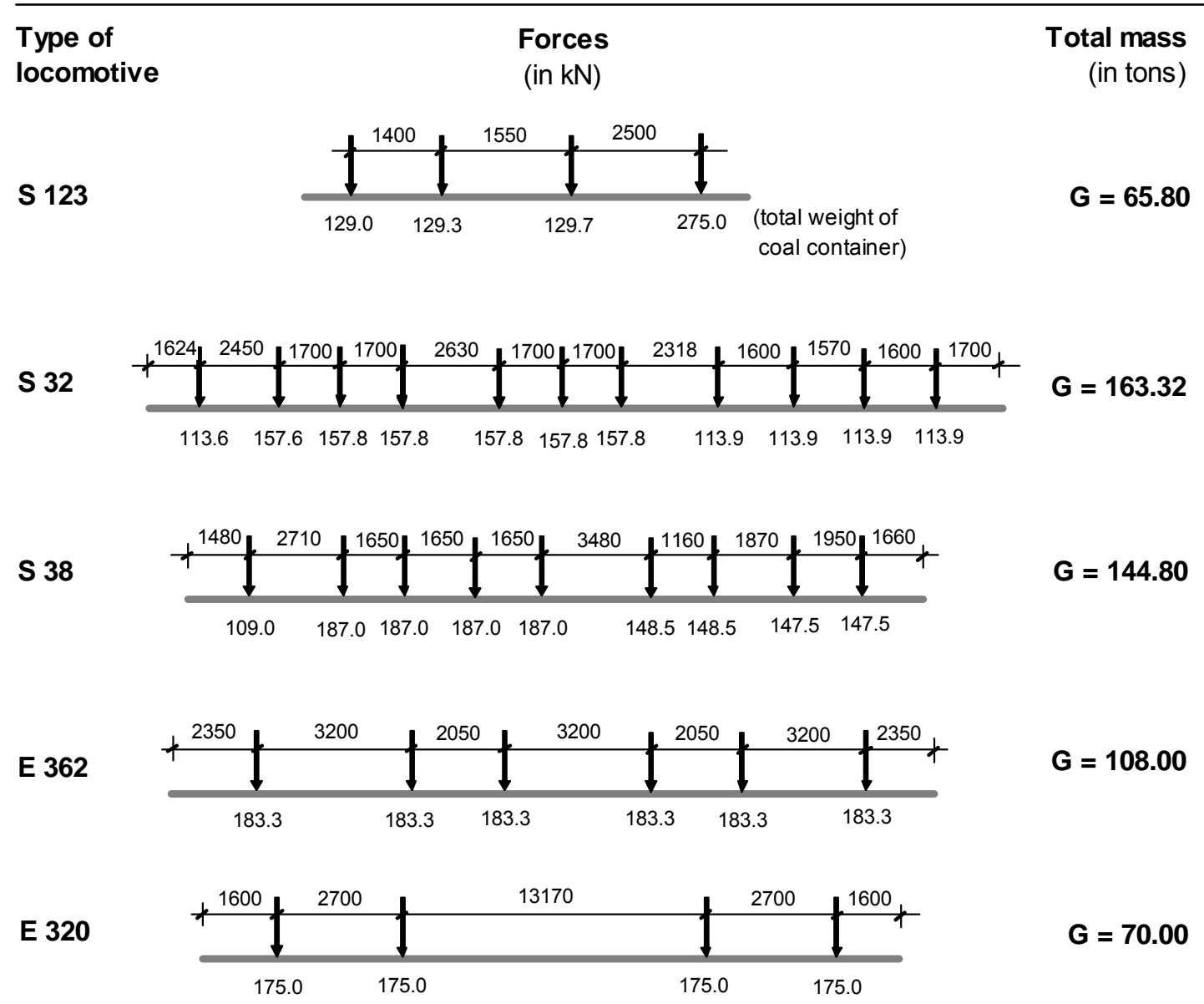

Fig. 6-5: $\quad$ Distance between axles and axle loads

\subsubsection{Formation of the stress range spectrum}

(1) On the basis of the data from section 6.1.5, as well as the data on the relevant cross section (see section 6.1.2), the stress ranges and the number of crossings were obtained (time period of $1895-1980)$ :

$\begin{array}{cll}\text { Passenger wagon (1 type) } & \Delta \sigma=15.0 \mathrm{~N} / \mathrm{mm}^{2} & \mathrm{n}=784284 \\ \text { Cargo wagon (3 types) } & \Delta \sigma=17.4 \mathrm{~N} / \mathrm{mm}^{2} & \mathrm{n}=90680 \\ & \Delta \sigma=25.6 \mathrm{~N} / \mathrm{mm}^{2} & \mathrm{n}=481834 \\ & \Delta \sigma=33.8 \mathrm{~N} / \mathrm{mm}^{2} & \mathrm{n}=879545 \\ \text { Locomotive (5 types) } & \Delta \sigma=44.8 \mathrm{~N} / \mathrm{mm}^{2} & \mathrm{n}=140220 \\ \text { S } 123 & \Delta \sigma=61.0 \mathrm{~N} / \mathrm{mm}^{2} & \mathrm{n}=368580 \\ \text { S 32 } & \Delta \sigma=68.2 \mathrm{~N} / \mathrm{mm}^{2} & \mathrm{n}=234695 \\ \text { S 38 } & \Delta \sigma=52.2 \mathrm{~N} / \mathrm{mm}^{2} & \mathrm{n}=318280 \\ \text { E 362 } & \Delta \sigma=47.4 \mathrm{~N} / \mathrm{mm}^{2} & \mathrm{n}=17885 \\ \text { 2E 362 } & \Delta \sigma=12.4 \mathrm{~N} / \mathrm{mm}^{2} & \mathrm{n}=17885 \\ \text { (two stress ranges) } & \Delta \sigma=27.7 \mathrm{~N} / \mathrm{mm}^{2} & \mathrm{n}=62780 \\ \text { E 320 } & \Delta \sigma\end{array}$

(2) The calculation is based on the net cross-sectional area of the member D36.

(3) The actual traffic has now reached the maximum capability of the railway line. Construction of a new railroad is expected in the future (double track). The stress range spectrum for the time period from 1980 until the present and the corresponding number of crossings of the actual traffic for 1 year are: 


$$
\varphi \cdot \sum \mathrm{k} \cdot \Delta \sigma
$$

Passenger wagon (1 type)

$$
\begin{array}{lll}
\text { Passenger wagon (1 type) } & 1.161 .1715 .0=20.4 \mathrm{~N} / \mathrm{mm}^{2} & \mathrm{n}=41000 \\
\text { Cargo wagon (type with max. load) } & 1.161 .1733 .8=45.9 \mathrm{~N} / \mathrm{mm}^{2} & \mathrm{n}=65000 \\
\text { Locomotive (E 362) } & 1.161 .1752 .2=70.8 \mathrm{~N} / \mathrm{mm}^{2} & \mathrm{n}=20000
\end{array}
$$$$
\text { Locomotive (E 362) }
$$

(4) Values of $\varphi$ and $\Sigma \mathrm{k}$, see 6.1.7 and 6.1.8.

\subsubsection{Determination of the dynamic factor $\varphi$}

(1) Testing on the bridge was done using the type E 362 locomotive.

Locomotive speed $\mathrm{v} \approx 0 \mathrm{~km} /$ hour

$$
\begin{aligned}
& \sigma_{\max }=+27.2 \mathrm{~N} / \mathrm{mm}^{2} \\
& \underline{\underline{\sigma_{\min }}}=-20.0 \mathrm{~N} / \mathrm{mm}^{2} \\
& \Delta \sigma=47.2 \mathrm{~N} / \mathrm{mm}^{2}
\end{aligned}
$$

(2) Stress history for a speed locomotive obtained by measurements for the element D-36 (diagonal) can be seen in Fig. 6-6.

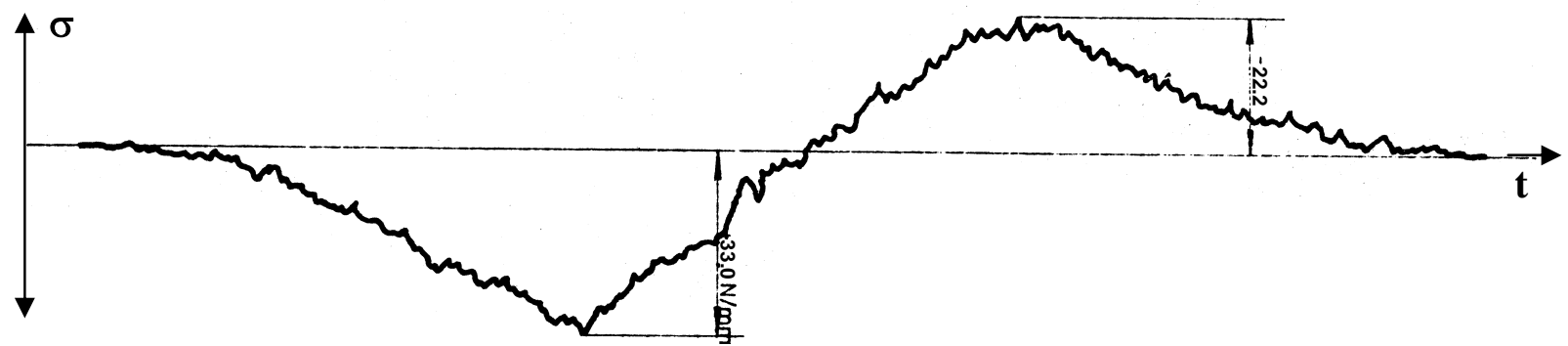

Fig. 6-6: $\quad$ Stress history for a speed locomotive type $E 362$ at $v=55 \mathrm{~km} / \mathrm{hour}$

(3) Locomotive speed $\mathrm{v}=55 \mathrm{~km} /$ hour

$$
\begin{aligned}
\sigma_{\max } & =+33.0 \mathrm{~N} / \mathrm{mm}^{2} \\
\underline{\underline{\sigma_{\min }}} & =-22.2 \mathrm{~N} / \mathrm{mm}^{2} \\
\Delta \sigma & =55.2 \mathrm{~N} / \mathrm{mm}^{2}
\end{aligned}
$$

(4) Now the dynamic factor can be calculated by: $\varphi=\frac{55.2}{47.2}=1.169$.

(5) Chosen $\varphi=1.17$

\subsubsection{Taking into account secondary stresses}

(1) Secondary stresses must not be neglected when dealing with fatigue.

a. Because of the difference in the structural system secondary stresses were determined for bridge loading with the UIC scheme. The following results were obtained:

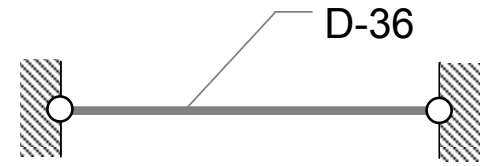

$$
\Delta \sigma_{1}=93 \mathrm{~N} / \mathrm{mm}^{2}
$$

$$
\mathrm{k}_{1}=\frac{\Delta \sigma_{2}}{\Delta \sigma_{1}}=\frac{100}{93} \cong 1.08=8 \%
$$

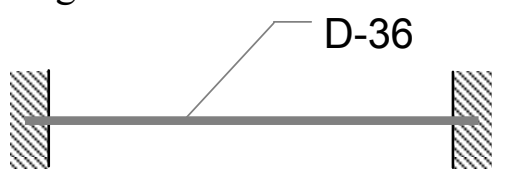

$$
\Delta \sigma_{2}=100 \mathrm{~N} / \mathrm{mm}^{2}
$$

b. Because of the eccentric connection, the influence of assembly, etc. the following secondary stresses were empirically estimated:

$$
\mathrm{k}_{2}=8 \% \text {. }
$$


c. Total secondary stresses $\sum \mathrm{k}=\mathrm{k}_{1}+\mathrm{k}_{2}$ amount to $16 \%$ of the primary stresses.

(2) All stress ranges are multiplied by $\varphi \cdot \Sigma \mathrm{k}$. Thus for example for the values of passenger wagons from 6.1.6:

$$
\Delta \sigma=15.0 \cdot 1.17 \cdot 1.16=20.4 \mathrm{~N} / \mathrm{mm}^{2} \text { etc., see section } 6.1 .9 .
$$

\subsubsection{Stress range spectrum for the calculation of the remaining fatigue life}

(1) With stress range spectrums from section 6.1.6 and by considering the dynamic factor and secondary stresses the following stress range spectrums and damage accumulation were obtained:

a. For the time period $1895-1980$

\begin{tabular}{|c|c|c|c|c|}
\hline$\varphi \cdot \sum_{\left[\mathrm{N} / \mathrm{mm}^{2}\right]} \mathrm{k} \cdot \Delta \sigma$ & ni & $\mathrm{m}$ & $\mathrm{N}_{\mathrm{i}}$ & $\frac{\mathrm{n}_{\mathrm{i}}}{\mathrm{N}_{\mathrm{i}}}$ \\
\hline 92.6 & 235000 & \multirow{5}{*}{3} & 902000 & 0.26053 \\
\hline 82.8 & 369000 & & 1261000 & 0.29262 \\
\hline 70.8 & 318000 & & 2017000 & 0.15766 \\
\hline 64.3 & 18000 & & 2693000 & 0.00668 \\
\hline 60.8 & 140000 & & 3185000 & 0.04396 \\
\hline 45.9 & 880000 & \multirow{3}{*}{5} & 9615000 & 0.09152 \\
\hline 37.6 & 63000 & & 26067000 & 0.00242 \\
\hline 34.7 & 481000 & & 38939000 & 0.01235 \\
\hline 23.6 & 90000 & \multirow{3}{*}{$\infty$} & $\infty$ & 0.00000 \\
\hline 20.4 & 784000 & & $\infty$ & 0.00000 \\
\hline 16.8 & 18000 & & $\infty$ & 0.00000 \\
\hline & $\sum \mathrm{n}_{\mathrm{i}}=3396000$ & & & $\sum \frac{\mathrm{n}_{\mathrm{i}}}{\mathrm{N}_{\mathrm{i}}}=0.86775$ \\
\hline
\end{tabular}

Table 6-3: $\quad$ Damage accumulation calculation for the time period $1895-1980$

The result is given in Fig. 6-7.

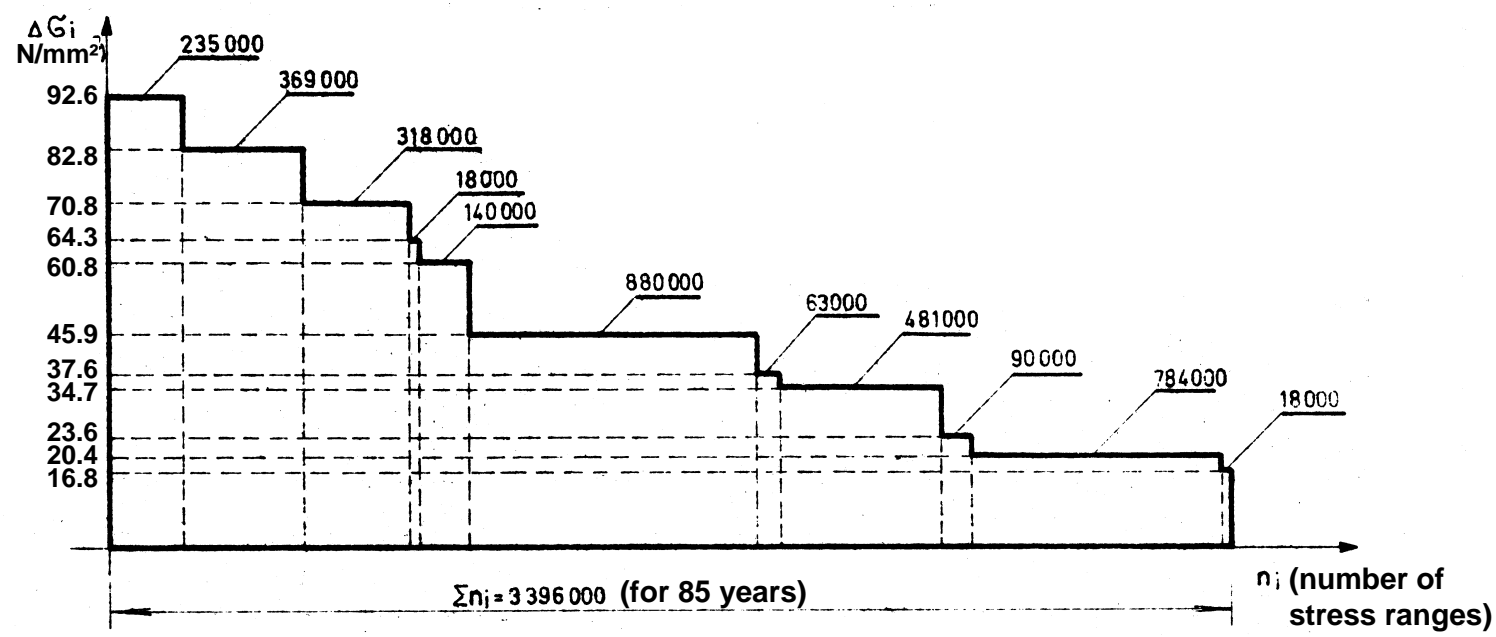

Fig. 6-7: $\quad$ Stress range spectrum (for the time period 1895 - 1980) 
b. For the time period 1980 - today

\begin{tabular}{|c|c|c|c|c|}
\hline $\begin{array}{c}\varphi \cdot \sum \mathrm{k} \cdot \Delta \sigma \\
{\left[\mathrm{N} / \mathrm{mm}^{2}\right]}\end{array}$ & $\mathrm{n}_{\mathrm{i}}$ & $\mathrm{m}$ & $\mathrm{N}_{\mathrm{i}}$ & $\frac{\mathrm{n}_{\mathrm{i}}}{\mathrm{N}_{\mathrm{i}}}$ (for 1 year) \\
\hline 70.8 & 20000 & 3 & 2017000 & 0.00992 \\
\hline 45.9 & 65000 & 5 & 9615000 & 0.00676 \\
\hline 20.4 & 41000 & $\infty$ & $\infty$ & 0.00000 \\
\hline \hline & $\sum \mathrm{n}_{\mathrm{i}}=126000$ & & & $\sum \frac{\mathrm{n}_{\mathrm{i}}}{\mathrm{N}_{\mathrm{i}}}=0.01668$ \\
\hline
\end{tabular}

Table 6-4: $\quad$ Damage accumulation calculation for each year in the time period 1980-today

The result shows Fig. 6-8.

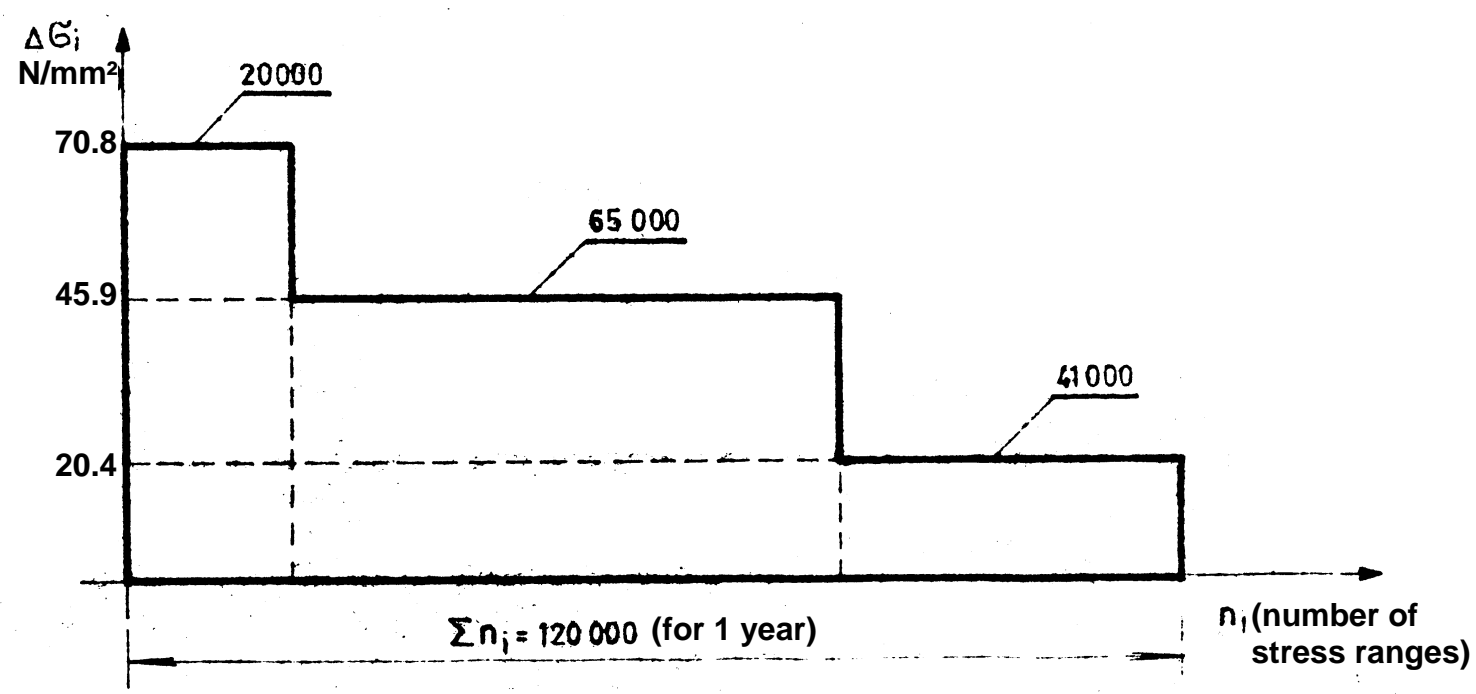

Fig. 6-8: $\quad$ Stress range spectrum for the time period 1980 -today (for 1 year)

\subsubsection{Calculation of the remaining fatigue life}

\subsubsection{Accumulated damage during service life 1895 - today}

(1) The damage during service life can be estimated as follows:

a. Service life $1895-1980$ :

Assumption: The bridge is always used with the stress range spectrum according to Table 6-3.

What follows from Table 6-3 is:

$\sum \frac{\mathrm{n}_{\mathrm{i}}}{\mathrm{N}_{\mathrm{i}}}=0.86775$ (for 85 years)

b. Service life since 1980:

Assumption: The bridge is in use since 1980 with the stress range spectrum according to actual traffic (Table 6-4).

What follows from Table 6-4 is:

$\sum \frac{\mathrm{n}_{\mathrm{i}}}{\mathrm{N}_{\mathrm{i}}}=0.01668$ (for 1 year) 
c. It is considered that fatigue life is reached if the condition from Miner's hypothesis is reached:

$$
\sum \frac{\mathrm{n}_{\mathrm{i}}}{\mathrm{N}_{\mathrm{i}}}=1
$$

Therefore, if the year 1980 is taken as the starting point (for the stress range spectrum according to actual traffic can be applied), fatigue life is reached in the year:

$$
\mathrm{Y}=1980+\frac{1-0.86775}{0.01668} \cong 1988 \text {. }
$$

Check:

- From $1895-1980$, the damage is $\sum \frac{\mathrm{n}_{\mathrm{i}}}{\mathrm{N}_{\mathrm{i}}}=0.86775$.

- From $1980-1988$, the damage is $\sum \frac{\mathrm{n}_{\mathrm{i}}}{\mathrm{N}_{\mathrm{i}}}=8 \cdot 0.01668=0.13344$.

- From $1895-1988$, the damage is $0.86775+0.13344 \cong 1$.

\subsubsection{Conclusion Phase II: Remaining fatigue life}

(1) The following conclusion can be drawn:

a. Fatigue life was obtained with the help of calculations from two stress range spectrums. The first part of the fatigue life was determined for the time period 1895 - 1980 (Table 63 ), and the second part for the period starting from 1980 and on (Table 6-4). The total fatigue life was obtained as a sum of these two parts, according to section 6.1.10.1:

$\mathrm{T}_{\mathrm{FL}}=85+8=93$ years.

b. Service life from 1895 to 2000 is:

$\mathrm{T}_{\mathrm{SL}}=105$ years.

c. Calculated remaining fatigue life is:

$\mathrm{T}_{\mathrm{RFL}}=\mathrm{T}_{\mathrm{FL}}-\mathrm{T}_{\mathrm{SL}}=93-105=-12$ years.

There is no remaining fatigue life! It had expired 12 years before the year in which this assessment was undertaken. The member chosen for the analysis cannot be considered safe any more.

\subsubsection{Phase III: Expert investigation and Phase IV: Further measures}

\subsubsection{General}

(1) At this point, a decision had to be made. According to Chapter 2, the critical point is whether the consequences - in terms of risks and costs - are large.

(2) The member analysed (see Fig. 6-2) is an important element in the functioning of the truss, as it is not redundant within the actual structural system. As the member failed the Phase II verification, further action was therefore clearly required.

(3) In this case, it was decided that the member be checked for the existence of possible fatigue cracks.

(4) Two possible results of this check exist:

- No crack is found 
- One or more cracks are found.

(5) The result can also change over time. For example, the first check can show no cracks while subsequent checks can reveal the existence of one or more cracks.

(6) The possible resulting scenarios are given below.

\subsubsection{No cracks found}

(1) In the case that the first detailed inspection brought no new elements - no cracks found - it could be reasonably decided to intensify monitoring in the years to come, with arbitrarily chosen inspection periods, based on codes and/or experience or based on fracture mechanics approach using assumed fictive cracks equal to the approach given in the following section.

\subsubsection{Cracks found}

(1) If during the first detailed inspection - or during the subsequent intense monitoring phase - a crack or cracks were found, one possibility might be to consider a fracture mechanics approach (see Fig. 2-1), in order to calculate the crack size and its growth with the application of additional load cycles over time. This growth might be used for the establishment of a specific and strict inspection plan, with inspection periods shorter than the calculated remaining fatigue life.

(2) To demonstrate this possibility, it is assumed, for illustrative purposes, that a crack with a visible length of $5 \mathrm{~mm}$ has been detected, as shown in Fig. 6-9. The determination of the remaining fatigue life can then proceed using a rather simplistic approach as shown below. More detailed but also more complicated fracture mechanics calculation methods can be found in literature, e.g. [Lit. 78, Lit. 85, Lit. 87].

(3) The remaining fatigue life is estimated by integrating the Paris' law over the crack depth range $\mathrm{a}_{0}$ to $\mathrm{a}_{\mathrm{c}}$, see Equation (2-5). The values for the crack growth parameters $\mathrm{C}, \mathrm{m}, \Delta \mathrm{K}, \mathrm{a}_{0}, \mathrm{a}_{\mathrm{c}}$ are assumed as follows:

1. The material constants for old steel are given in section 3.4.1:

$\mathrm{C}=4.0 \times 10^{-13}$

$\mathrm{m}=3.0$ (units in $\mathrm{N}(\mathrm{mm})^{-3 / 2}$ and $\mathrm{mm}$ )

2. The applied stress intensity factor range, $\Delta \mathrm{K}$, is determined according to Equation (2-3).

3. The following correction factor is applied to consider the finite width of the plate [Lit. 85, Lit. 86]:

$$
Y=\frac{1}{\sqrt{\cos \left(\frac{\pi \cdot a}{2 \cdot w}\right)}} \text { and } \mathrm{w}=35 \mathrm{~mm} \text { (see Fig. 6-9) }
$$

4. As mentioned above, it is assumed that an existing crack is detected that extends $5 \mathrm{~mm}$ on either side of the rivet head, which is assumed to have a diameter of $24 \mathrm{~mm}$. The initial defect depth is thus:

$$
a_{0}=\frac{24 m m}{2}+5 m m=17 m m
$$

5. Finally, it is assumed that the remaining fatigue life will be used up when the crack grows to the outside edge of the angle leg, i.e.:

$$
\mathrm{a}_{\mathrm{c}}=\mathrm{w}=35 \mathrm{~mm}
$$

(4) The equivalent stress range is then calculated using Equation (2-7): 


$$
\Delta \sigma_{E, \text { net }}=\left(\frac{\sum\left(n_{i} \cdot \Delta \sigma_{i}^{m}\right)}{\sum n_{i}}\right)^{1 / m}=\left(\frac{13.7169 \cdot 10^{9}}{1.26 \cdot 10^{5}}\right)^{1 / 3}=47.7 \mathrm{MPa}
$$

(5) The resulting net section stress range is then converted to a gross section stress range:

$$
\Delta \sigma_{E, \text { gross }}=47.7 \cdot\left(\frac{52.0}{60.4}\right)=41.1 M P a
$$

(6) With this information, a crack depth versus number of cycles curve can be plotted, as shown in Fig. 6-9. Using this curve, different inspection strategies could be considered:

- For example, if no action is taken, it can be determined that the calculated remaining fatigue life of the detail with a $5 \mathrm{~mm}$ visible crack would be 3.6 years.

- If a strategy is chosen wherein the detail is to be inspected at least three times before the crack reaches critical depth, it can be seen that the detail should be inspected at least every 1.2 years (every 14.4 months). Based on the results of these inspections, it may then be possible to revise the calculated remaining fatigue life of the detail.
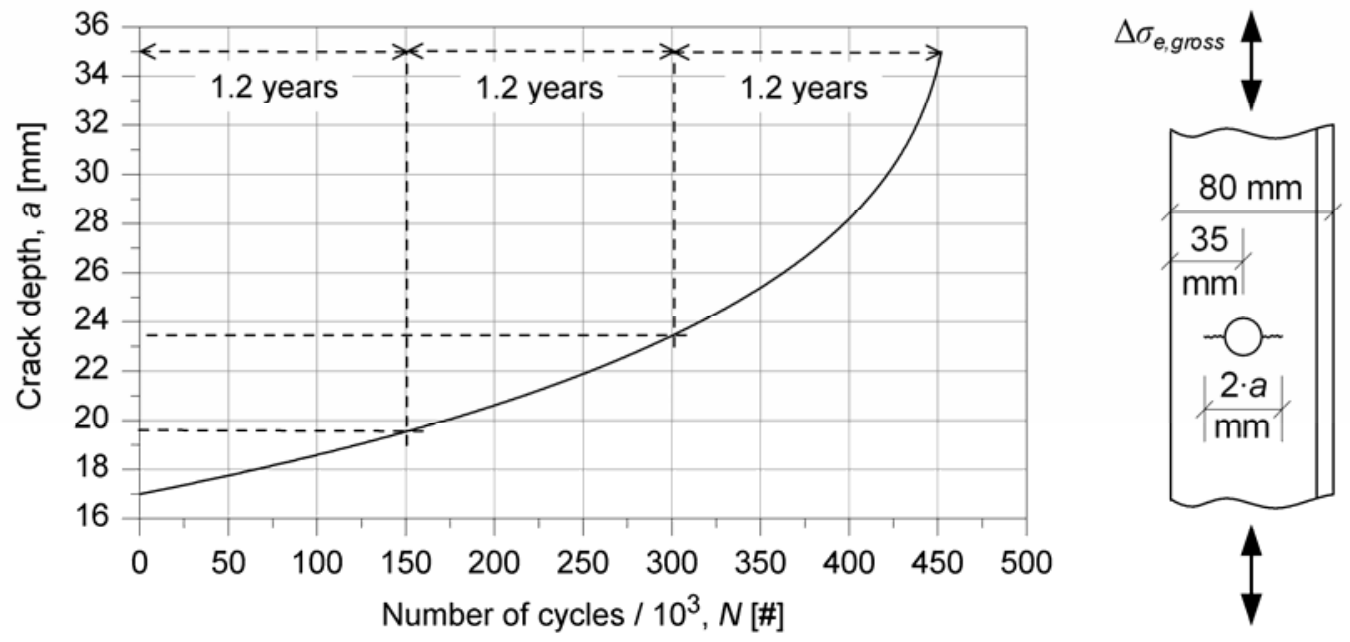

Fig. 6-9: $\quad$ Fracture mechanics calculation for riveted fatigue detail

\subsubsection{Conclusion}

(1) Using a similar approach, the remaining fatigue life can be calculated for all bridge elements. In this example, calculation was done for the diagonal element of the main truss (D 36), which was estimated to be the most critical for fatigue.

(2) No Phase I (see Fig. 2-1) evaluation was carried out as detailed data traffic was already available.

(3) The Phase II assessment showed that the studied member had no remaining fatigue life. Due to the fact that this member could no longer be considered safe, further measures were necessary.

(4) A Phase III investigation could have resulted in the following two possible further measures (Phase IV):

- If no cracks had been found, the measure chosen could have been to intensify inspection and monitoring in the future.

- If the inspection of the critical detail had resulted in the detection of a crack, fracture mechanics calculations could have been carried out to estimate the remaining life of the detail and/or to determine an appropriate inspection strategy, as demonstrated. 


\section{LITERATURE}

Lit. 1 Oehme, P.: "Schäden an Stahltragwerken - eine Analyse (Damage Analysis of Steel Structures)", IABSE Proceedings P-139/89, November 1989

Lit. 2 Fisher, J.W.: "Fatigue and Fracture in Steel Bridges - Case Studies", 1984, ISBN 0-47180469-X

Lit. 3 Carper, K.: Conference on Failures in Architecture \& Engineering: What are the Lessons?, EPFL, Lausanne, May 1998

Lit. 4 Carper, K.: ASCE book on failure cases, second revised edition, 1998

Lit. 5 Siebke, H.: "unpublished data"

Lit. 6 Seemann, K., Gümpel, P., Schwarze, J., Jäkle, V.: "Dynamische Festigkeitsuntersuchung an der Mettnau-Brücke in Radolfzell / Examination of the dynamic strength of a bridge in the town of Radolfzell", Stahlbau 69 (2000), Heft 1, P. 1-9

Lit. 7 Ewert, S.: "Die größten Stahl-Vollwandträger-Brücken”, Stahlbau 68, 1999, Heft 3

Lit. 8 JCSS (Joint Committee on Structural Safety), "Probabilistic Assessment of Existing Structures", RILEM Publications, 2001

Lit. 9 Kunz, P.: "Probabilistisches Verfahren zur Beurteilung der Ermuedungssicherheit Bestehender Bruecken aus Stahl", Doctoral thesis $N^{\circ} 1023$, Swiss Federal Institute of Technology, Lausanne, Switzerland, 1992

Lit. 10 Blanchard, J., Bussell, M., Marsden, A., Lewis, D.: "Appraisal of existing ferrous metal structures", (Journal) Stahlbau 66 (1997), Heft 6, pp. 333-345, Ernst \& Sohn Verlag, Germany

Lit. 11 Langenberg, P.: "Bruchmechanische Sicherheitsanalyse anrißgefärdeter Bauteile im Stahlbau", Dissertation, RWTH Aachen, Shaker Verlag, Band 14/95, 1995, ISBN 3-82651102-6

Lit. 12 Muncke, M.; Quoos, V.; Tschumi, M.; Sedlacek, G.; Feldmann, M.; Kühn, B.; Brandes, K.; Helmerich, R.; Hirt, M.; Nussbaumer, A.; Bassetti, A.; Geissler, K.; Gut, J.; Kunz, P.; Liechti, P.: "Vereinheitlichter Sicherheitsnachweis für bestehende Stahlbrücken", Endbericht im Rahmen der Zusammenarbeitsvereinbarung DB AG - SBB, 31.05.2001

Lit. 13 Helmerich, R.: „Alte Stähle und Stahlkonstruktionen - Materialuntersuchungen, Ermüdungsversuche an originalen Brückenträgern und Messungen von 1990 bis 2003“, BAM, Forschungsbericht 271, Berlin, 2005, ISBN 3-86509-362-0

Lit. 14 BS PD 6493: "Guidance on methods for assessing the acceptability of flaws in fusion welded structures", British Standard Institute, 1991

Lit. 15 ORE DT 176 (D154): "Statistische Auswertung von Ermüdungsversuchen an Nietverbindungen in Flussstahl", Forschungs- und Versuchsamt des Internationalen Eisenbahnverbandes ORE, Utrecht, 1986

Lit. 16 Boström, S.: "Crack Location in Steel Structures Using Acoustic Emission Techniques", Department of Civil and Mining Engineering, Division of Steel Structures, University of Technology, Lulea, 1999

Lit. 17 Hensen, W.: "Grundlagen für die Beurteilung der Weiterverwendung alter Stahlbrücken", Dissertation am Lehrstuhl für Stahlbau an der RWTH Aachen, Heft 21, 1992

Lit. 18 Stötzel, G.: „Verfahren zur Beurteilung der Sicherheit bei Weiterverwendung alter Stahlbrücken“, Dissertation am Lehrstuhl für Stahlbau, RWTH Aachen, Heft 39, Shaker Verlag, 1998

Lit. 19 Mang, F., Bucak, Ö.: „Tauglichkeit und Lebensdauer von bestehenden Stahlbauwerken“, Beitrag im Stahlbauhandbuch für Studium und Praxis 1, Teil B, StahlbauVerlagsgesellschaft $\mathrm{mbH}$ Köln, 1996 
Lit. 20 Bucak, Ö., Mang, F.: "Erfahrungen mit alten Stahlkonstruktionen", Stahlbau, 67. Jahrgang, Heft 1, 1998, P. $46-60$

Lit. 21 Bhadeshia, H.K.D.H.: "Lecture 7: Weld Microstructure Model", Course MP10, Process Modelling, Department of Materials Science \& Metallurgy, University of Cambridge

Lit. 22 Linnert, G.E.: „Welding Metallurgy Vol. 2“, American Welding Society

Lit. 23 Ricker, D.T.: „Field Welding to Existing Steel Structures“, Engineering Journal, American Institute of Steel Construction, $1^{\text {st }}$ Quarter 1988, page 1-16

Lit. 24 Jefferson, T.B., Woods, G.: „Metals and How to Weld Them“, James F. Lincoln Arc Welding Foundation

Lit. 25 Technical report, IIW Doc. IX-535-67 (1967)

Lit. 26 Uwer, D., Höhne, H.: "Charakterisierung des Kaltrißverhaltens von Stählen beim Schweißen", Schweißen \& Schneiden 43 (1991), S. 195-199 und IIW-Doc.IX-1630-91

Lit. 27 Ito, Y., Bessyo, K.: "Weldability formula of high strength steels related to heat-affected zone cracking", IIW-Doc.IX-576-68

Lit. 28 Cottrell, C.L.M.: "Controlled Thermal Severity Cracking Test Simulates", Practical Wleded Joints, Welding Journal (1953), page 257 s

Lit. 29 v.d. Linden, H., Schönherr, W.: "Compilation of Cold Cracking Tests", IIW-Doc.IX-752-71

Lit. 30 ANSI/AWS Specification D1.1 Latest edition

Lit. 31 Helmerich, R.; Brandes, K.: „Dokumentation von Ermüdungsversuchen an genieteten Querträgern einer schweißeisernen Trogbrücke“, BAM 248, 2002

Lit. 32 Braune, W.: "Beitrag zur Feststellung der Belastbarkeit von Ingenieurbauwerken durch die Bestimmung von Einflusslinien aus Dehnungsmessungen unter beliebigen wandernden Lasten", Die Bautechnik, 54. Jahrgang, H. 5, Berlin, Mai 1977

Lit. 33 Boström, S.: "Crack Location in Steel Structures Using Acoustic Emission Techniques“, Department of Civil and Mining Engineering, Division of Steel Structures, University of Technology, Luleå, 1999

Lit. 34 Brandes, K.; Herter,J.; Helmerich, R.: „Non-Destructive Testing being essential part of the safety assessment of old steel bridges", Seiken Symposium No.26, University of Tokyo, Japan, 2000, S. 127-13

Lit. 35 Dahl, W., Langenberg, P., Sedlacek, G., Hensen, W.: "Sicherheitsüberprüfung von Stahlbrücken", DFG-Zwischenbericht zum Forschungsvorhaben Da85/62 und Se351/9, Aachen 1990 und 1992

Lit. 36 ASTM E 813-81: "Standard test method for $J_{i c}$, a measure of fracture toughness", American Society for Testing and Materials, Annual Book of ASTM Standards, Philadelphia, USA, 1987

Lit. 37 ASTRA (Swiss highway administration), „Lastfaktoren für Eigenlast und Auflast zur Beurteilung der Tragsicherheit bestehender Strassenbrücken", VSS Bericht 530, Bundesamt für Strassen, Vereinigung Schweizerischer Strassenfachleute, Zürich, 1998.

Lit. 38 Fatigue of steel bridge decks - Staalbouwkundig genootschap - November 1998 (in Dutch)

Lit. 39 Dijkstra, O.D.:"Fatigue in orthotropic steel decks in traffic bridges" 8th Portuguese Conference on Fracture, February 2002

Lit. 40 NEN 2063: Arc welding - Fatigue loaded structures - Calculation of welded joints in unalloyed and low-alloy steel up to and including Fe 510 (Fe 52) NNI, March 1988 (in Dutch)

Lit. 41: ENV 1993-1-1: Eurocode 3 : Design of steel structures - Part 1.1 : general rules and rules for buildings. February 1992

Lit. 42: Käpplein, R., Wielgosch-Frey,A.: „Historische Eisen- und Stahlkonstruktionen: Untersuchen, Berechnen, Instandsetzen“, SFB 315, University of Karlsruhe 
Lit. 43: Nockemann, Ch., Tillack, G.-R., Belton, C., Scharmach, M.: "Metric for reliability measurement with special focus on application factors", $15^{\text {th }}$ WCNDT, Rome, 2000

Lit. 44: http://iiw-wg5.cv.titech.ac.jp/: International Institute of Welding (IIW), Commission XIII: Fatigue of welded components and structures, Working Group 5 (WG5): Repair of fatigue loaded welded structures, Homepage

Lit. 45: Helmerich, R., Brandes, K.: "Ermüdungsversuche an Fachwerkträgern der Berliner UBahn-Linie U1", Stahlbau 71 (2002), H. 11, S.789-797

Lit. 46: Dijkstra, O. D., Straalen, IJ. J. van: "Fracture mechanics and fatigue of welded structures. IIW International Conference on Performance of Dynamically Loaded Structures", July, 1997, San Francisco, CA, USA.

Lit. 47: ENV 1991-3: Eurocode 1 - Basis of design and actions on structures - Part 3: Traffic loads on bridges, March 1995

Lit. 48: prEN 1993-1-9: Eurocode 3 : Design of steel structures, Part 1.9 : Fatigue, May 2003

Lit. 49: prEN1991: Eurocode 1 : Actions on structures

Lit. 50: IIW, International institute of welding: "Recommendations for fatigue design of welded joints and components" A. Hobbacher (ed.), Doc. XIII-1965-03/XV-1127-03, Cambridge: Abington, 2003

Lit. 51: Miner, M.: "Cumulative Damage in Fatigue", Journal of Applied Mechanics, pp. A159A164, 1945

Lit. 52: Broek, D.: "Elementary Engineering Fracture Mechanics", Kluwer Academic Publishers, 1986

Lit. 53: Gurney, T.R.: "Fatigue of Welded Structures", Cambridge University Press, Cambridge, 1968

Lit. 54: Madsen, H.O., Krenk, S., Lind, N.C.: "Methods of Structural Safety", New Jersey, Prentice Hall Incorporated, 1986

Lit. 55: Melchers, R.E.: "Structural Reliability Analysis and Prediction", Second Edition, Chichester, John Wiley and Sons Incorporated, 1999

Lit. 56: Cremona C. et al.: "Experimental Assessment Methods and Use of Reliability Techniques", BRIME PL97-2220, 1999

Lit. 57: Woodward R.J. et al.: "Bridge Management in Europe", Final Report, BRIME PL97-2220, 2001

Lit. 58: Richtlinie 805 “Tragsicherheit bestehender Brückenbauwerke”, incl. Bekanntgabe 1 to 3, DB Netz AG, Zentrale, Theodor-Heuss-Allee 7, 60486 Frankfurt am Main

Lit. 59: Moses, F., Schilling, C.G., Raju, K.S.: "Fatigue Evaluation procedures for steel bridges", NCHRP Report 299, Transport Research Board, Washington D.C., 1987

Lit. 60: prEN 1991-2: Eurocode 1: "Action on structures" - Part 2: "Traffic loads on bridges", July 2002

Lit. 61: Helmerich, R.: "Analysis of literature, online libraries and test reports on the subjects fatigue failure details, repair and strengthening", Report WGA-0903-06 of ECCS Technical Committee 6 "Fatigue", Working Group A, 11.03.2003, http://icom.epfl.ch/ECCSTC6/

Lit. 62: Siebke.H.: "Grundgedanken zur Bemessung stählerner Eisenbahnbrücken auf Betriebsfestigkeit vor wahrscheinlichkeitstheoretischem Hintergrund", Schweißen und Schneiden 32, 1980/8

Lit. 63: Kühn, B., Nussbaumer, A.: "Literature investigation in mainly German and English literature with the aim to find information and/or references on "evaluation of real mean stress in old structures", Report WGA-0902-06 of ECCS Technical Committee 6 "Fatigue", Working Group A, 15.10.2002, http://icom.epfl.ch/ECCSTC6/

Lit. 64: Miki, C.: "Repairing and reinforcing of fatigue damaged steel bridges", WRC Proceedings IIW, pp. 286-298. 1998 
Lit. 65: Piringer, S., et al.: "Good Design Practice", European Convention for Constructional Steelwork ECCS, Technical Committee 6, Fatigue, ECCS N¹05, 2000

Lit. 66: Lüesse, G., Ruscheweyh, H., Verwiebe, C., Günther, G. H.: "Regen-Wind-induzierte Schwingungserscheinungen an der Elbebrücke Dömitz", Stahlbau 65 (1996), Heft 3, pp. 105-114

Lit. 67: Akesson, B.: "Fatigue life of riveted railway bridges", Dissertation at Chalmers University, Göteborg, 1994

Lit. 68: CAN/CSA-S6-00: Canadian Highway Bridge Design Code and Commentary, Canadian Society for Civil Engineering (CSCE), 2000

Lit. 69: Kühn, B., et al.: "Review by questionnaire on guidelines and standards on the assessment of existing structures", Report WGA-0604-06 of ECCS Technical Committee 6 "Fatigue", Working Group A, 2004, http://icom.epfl.ch/ECCSTC6/

Lit. 70: Li, Z. X., Chan, T. H. T., Ko, J. M.: "Fatigue analysis and life prediction of bridges with structural health monitoring data - Part I: methodology and strategy", International Journal of Fatigue, Volume 23, Issue 1, January 2001, Pages 45-53

Lit. 71: Chan, T. H. T., Li, Z. X., Ko, J. M.: "Fatigue analysis and life prediction of bridges with structural health monitoring data - Part II: application", International Journal of Fatigue, Volume 23, Issue 1, January 2001, Pages 55-64

Lit. 72: Gong, Z.; Nyborg, E.O.; Oommen, G.: "Acoustic emission monitoring of steel railroad bridges", Materials Evaluation, Vol. 50, No. 7, pp. 883-887 (Jul. 1992), NDT \& E International, Volume 28, Issue 6, December 1995, Page 392

Lit. 73 Swiss-code SIA 263 : 2003 "Steel Structures", Swiss Society of Engineers \& Architects, Post-box, CH-8039 Zurich, 2003

Lit. 74 Lukić, M.: "Évaluation et maintenance probabilistes des assemblages soudés vis-à-vis de la fatigue et de la rupture - application aux ponts mixtes", Thèse de doctorat de l'École Nationale des Ponts et Chausses, 3 décembre 1999

Lit. 75 Newman, IC; Raju, IS: "An empirical stress-intensity factor equation for the surface crack. Engineering Fracture Mechanics", V24, No 6, pp 789-802, 1996

Lit. 76 Smith, IFC; Smith, RA: "Measuring Fatigue Cracks in fillet Welded Joints", International Journal of Fatigue, No. 4, pp 41 - 45, 1982

Lit. 77 Bremen, U.: "Amelioration du comportement à la fatigue d'assemblages soudés : étude et modelisation de l'effet de contraintes residuelles", EPFL Thesis no. 787, Lausanne, 1989

Lit. 78 Stephens, R.I. ; Fatemi, A. ; Stephens, R.R; Fuchs, H.O: "Metal Fatigue in Engineering", $2^{\text {nd }}$ Ed. John Wiley and Sons, Inc. 2001

Lit. 79 SIA 160, Actions on structural works, Swiss Society of Engineers and Architects, Zurich, 1989

Lit. 80 CTICM, Recommandations pour le calcul des structures de mats d'éclairage de grands expaces, Construction Métallique, CTICM, St-Rémy-lès-Chevreuse, $N^{\circ} 2$, June 1995, pp. 3-28

Lit. 81 EN 1991-1-4, Actions on structures - Wind actions, CEN, Brussels, 2005

Lit. 82 Dally, J.W.; Riley, W.F. and McConnel, K.J.: "Instrumentation for engineering measurements", $2^{\text {nd }}$ edition, John Wiley and Sons, New York, 1993

Lit. 83 Doebelin, E.O.: "Measurement systems: application and design", $4^{\text {th }}$ edition, McGraw-Hill book Company, New York, 1990

Lit. 84 Weight-in-Motion of Road Vehicles, COST action 323, final Report in 2 vol., Ed. Bernard Jacob, LCPC, France, 1999, ISBN 92-828-6786-2, November 1999

Lit. 85 Hirt, M.A. \& Bez, R. TGC Volume 10 - Construction Métallique. Presses Polytechniques et Universitaires Romandes, 1996

Lit. 86 Albrecht, P. \& Yamada, K.: "Rapid Calculation of Stress Intensity Factors", Journal of Structural Engineering, ASCE, Vol. 103, No. ST2, pp. 377-389, 1977 
Lit. 87 Blumenauer, H., Pusch, G.: „Technische Bruchmechanik“, Deutscher Verlag für Grundstoffindustrie, Leipzig \& Stuttgart, 3. Auflage, 1993

Lit. 88 Research project: Sustainable Bridges - Assessment for Future Traffic Demands and Longer Lives, Contract No.: TIP3-CT-2003-001653, Start date and end date: 2003-12-01 - 2007-11-30, Doc. No.: D 5.2 Guidelines for monitoring of steel railway bridges, Date of preparation: 2005-03-15, Author/s: Oliver Hechler, Andreas Lösche (Lehrstuhl für Stahlund Leichtmetallbau, RWTH Aachen, Germany), Bertram Kühn (PSP, Planung und Entwicklung im Bauwesen $\mathrm{GmbH}$, Aachen, Germany)

Lit. 89 Fisher, J.W., Barthelemy, B.M., Mertz, D.R., Edinger, J.A., NCHRP Report 227: "Fatigue Behaviour of Full Scale Welded Bridge Attachments", Transportation Research Board, National Council, Washington, D.C., 1980

Lit. 90 ISO 16587 : Condition Monitoring of Structures, General Guidelines

Lit. 91 ISO 16587 : Condition Monitoring of Structures, Detailed methods

Lit. 92 ISO 14963: Guidelines for dynamic tests and investigation on bridges and viaducts

Lit. 93 EN 10025 : Hot rolled products of structural steels, Part 1 to Part 6, 2005

Lit. 94 DVS-Merkblatt R 1001 (Ausgabe 10/1985), Prüfung der Kaltrissigkeit geschweißter Stähle - Implant-Test

Lit. 95 Helmerich, R.; Brandes, K.,Herter, J.: "Full scale laboratory fatigue tests on riveted steel bridges", IABSE Workshop, Lausanne 1997, pp. 191 ff., March 1997

Lit. 96 Schaper, G.: "Stählerne Brücken", Verlag von Wilhelm Ernst \& Sohn, Berlin, 1949

Lit. 97 Mang, F., Steidl, G., Bucak, Ö.: "Altstahl im Bauwesen", Schweißen und Schneiden 37 (1985), Heft 1, S. 10-14

Lit. 98 Stranghöner, N.: "Werkstoffwahl im Stahlbrückenbau”, Habilitationsschrift, angenommen an der TU Dresden, 2005

Lit. 99 Möll, R.: "Grundhafte Erneuerung des großen Palmhauses im Palmgarten in Frankfurt am Main", Stahlbau 69, 2000, S. 741-755

Lit. 100 Möll, R.: "Altstahlschweißen und Nieten im Zuge der Grunderneuerung des Eisernen Steges in Frankfurt am Main, Stahlbau 66, 1997, S. 1-11

Lit. 101 Lüddecke, F.: "Ein Beitrag zur Ertüchtigung bestehender Stahltragwerke unter besonderer Berücksichtigung des Fügeverfahrens Schweißen", BAM Dissertationsreihe Band 17, ISBN 3-86509-533-X, ISSN 1613-4249, Wirtschaftsverlag N.W., Verlag für neue Wissenschaft $\mathrm{GmbH}, 27568$ Bremerhaven.

Lit. 102 Hay, D. R., Hay, J. R., Cavaco, J., Hay, T.: "Structural Acoustics for Bridge Reliability Evaluation", Paper $7^{\text {th }}$ International Conference on Short and Medium Span Bridges, Montreal, Canada, 2006, pp. TS-019-1 to TS-019-10

Lit. 103 Hanson, Koob, Fisher: "Evaluation of Fatigue Life and Retrofitting on the Benicia-Martinez Bridge", Transportation Research Record 1290, Vol. 1, March 1991

Lit. 104 Fisher, Daniels: "An Investigation of the estimated Fatigue Damage in Members of the $380 \mathrm{ft}$ Main Span, Fraser River Bridge”, AREA Bulletin 658, Proceedings Vol. 77, JuneJuly 1976

Lit. 105 Fisher, Kaufmann, Koob, White: "Crack, Fracture Assessment and Repair of the Green River Bridge", I-26, $4^{\text {th }}$ International Bridge Engineering Conference, TRB, Conference Proceedings 7, August 1995

Lit. 106 Fowler, Prince, Blevins, Massarelli, Fisher: "When Steel Cracks: A Case Study of Virginias I-77 Bridge over the New River", Proceedings International Bridge Conference, Pittsburg, $P A$, June 2001

Lit. 107 Fisher, Bower, Serag, Irwin: "Improving the Performance of AMTRAK's 95 year old Susquehanna River Bridge", Stahlbau, Vol. 71, N0. 2, February 2002 
Lit. 108 Sivakumar, Khoury, Fisher, Wright: "Hoan Bridge Brittle Fracture and Retrofit Design", Proceedings, New York City $2^{\text {nd }}$ Bridge Conference, Recent Developments in Bridge Engineering, K. Mahmoud, ed., Swets \& Zeitlinger, Lisse, October 2003

Lit. 109 Connor, Hodgson, Fisher: "Evaluation and Retrofit of Floorbeams Cracking on a Tied Arch Bridge", Bridge Structures, Vol. 1, No. 3, September 2005, Taylor and Francis

Lit. 110 Crocetti, R., Al-Emrani, M., Akesson, B., Edlund, B.: "Constant Amplitude Fatigue Limit for Riveted Girders", ACTA Polytechnica-Eurosteel '99, Prague, Vol. 39, No. 5/1999, P. 105109

Lit. 111 Zhou, Y.E., Yen, B.T., Fisher, J.W., Sweeney, R.A.P.: "Examination of Fatigue Strength (Sr-N) Curves for Riveted Bridge Members"

Lit. 112 Fisher, J.W., Mertz, D.R., Zhong, A.: "Steel Bridge members under Variable Amplitude Long Life Fatigue Loading", NCHRP Report 267, TRB Washington, DC 1983

Lit. 113 Geißler, K., Graße, W., Brandes, K.: "Bewertung bestehender Stahlbrücken", chapter in "Stahlbau-Kalender 2006", Hrsg.: Ulrike Kuhlmann, Ernst \& Sohn Verlag, ISBN 3-43301821-9

Lit. 114 Kühn, B.: "Criteria to proof the weldability of old steels", Report WGA-0107-06 of ECCS Technical Committee 6 "Fatigue", Working Group A, http://icom.epfl.ch/ECCSTC6/

Lit. 115 BS 6835-1:1998: Method for the determination of the rate of fatigue crack growth in metallic materials

Lit. 116 ASTM E647 : Standard Test Method for Measurement of Fatigue Crack Growth Rates, 15-Jun-2005

Lit. 117 Fisher, J. W., Nussbaumer, A.C., Keating, P.B., Yen, B.T.: "Resistance of Welded Details under Variable Amplitude Long-Life Fatigue Testing", National Cooperative Highway Research Program (NCHRP) Report 354, Highway Research Board, Washington, D.C., 1993

Lit. 118 Milne, I., Ainsworth, R.A., Dowling, A.R., Stewart, A.T: "Assessment of the integrity of structures containing defects." Rep. No. R/H/R6-Revision3, CEGB, 1986

Lit. 119 Manual for Railway Engineering, Chapter 15, Steel Structures, Part 7, Existing Bridges, Article 7.3.4.2 Fatigue, and Part 9, Commentary, Article 9.7.3.4.2, 2007, American Railway Engineering and Maintenance-of-Way Association (AREMA), Lanham, MD. www.AREMA.org

Lit. 120 Drosner, S.: "Beitrag zur Berechnung der dynamischen Beanspruchung von Brücken unter Verkehrslasten", Thesis, Schriftenreihe Stahlbau - RWTH Aachen, Herausgeber: Prof. Dr.-Ing. G. Sedlacek, Heft 16, 1989

Lit. 121 Merzenich, G.: "Entwicklung eines europäischen Verkehrslastmodells für die Bemessung von Straßenbrücken", Thesis, Schriftenreihe Stahlbau - RWTH Aachen, Herausgeber: Prof. Dr.-Ing. G. Sedlacek, Heft 29, 1994

Lit. 122 Sedlacek, G., Kammel, C., Kühn, B., Hensen, W.: "Condition assessment and inspection of steel railway bridges, including stress measurements in riveted, bolted and welded structures", Background document D3.4, European Research Project: Sustainable Bridges - Assessment for Future Traffic Demands and Longer Lives, Project start and end date: 2003-12-01 - 2007-11-30, http://www.sustainablebridges.net/

Lit. 123 http://www.bam.de/microsites/zfp_kompendium/welcome.html

Lit. 124 Bagayoko, L., et al.: "Guideline for Load and Resistance Assessment of Existing European Railway Bridges - Advices on the use of advanced methods", Final report D4.2, European Research Project: Sustainable Bridges - Assessment for Future Traffic Demands and Longer Lives, Project start and end date: 2003-12-01 - 2007-11-30

Lit. 125 Sedlacek, G, Hechler, O., Lösche, A., Kühn, B.: "Guidelines for monitoring of steel railway bridges", Final report D5.2.1, European Research Project: Sustainable Bridges Assessment for Future Traffic Demands and Longer Lives, Project start and end date: 2003-12-01 - 2007-11-30, Date of preparation: 2005-03-31 


\title{
EUR 23252 EN - Joint Research Centre
}

Title: Assessment of Existing Steel Structures: Recommendations for Estimation of the Remaining Fatigue Life

Author(s): B. Kühn, M. Lukić, A. Nussbaumer, H.-P. Günther, R. Helmerich, S. Herion, M.H. Kolstein, S. Walbridge, B. Androic, O. Dijkstra, Ö. Bucak

Editors: $\quad$ G. Sedlacek, F. Bijlaard, M. Géradin, A. Pinto and S. Dimova

Luxembourg: Office for Official Publications of the European Communities

$2007-89$ pp. $-21 \times 29.7 \mathrm{~cm}$

EUR - Scientific and Technical Research series - ISSN 1018-5593

\begin{abstract}
Due to the demand for freight volume on rail and road, traffic has increased significantly in the past years leading to an increasing number of heavy vehicles in the traffic flows and greater exploitation of their loading capacities. Because of environmental considerations there is also a tendency to further enhance the admissible loads in the design of new heavy vehicles (e.g. by increasing axle loads or using road trains). This all may affect the safety, serviceability and durability of existing bridges. Bridge authorities are therefore interested in agreed methods to assess the safety and durability of existing bridges and to make appropriate provisions for more refined maintenance methods, possible restriction of traffic, bridge-rehabilitation or substitution of old bridges by new ones where necessary.

For steel bridges including the old riveted ones there are numerous approaches to such assessments, partly standardized by national codes or recommendations. In the light of the development of the European single market for construction works and engineering services there is thus a need to harmonize them and to develop agreed European technical recommendations for the safety and durability assessment of existing structures. These recommendations should follow the principles and application rules in the Eurocodes and provide a scheme with different levels of analysis: a basic level with general methods and further levels with higher sophistication that call for specific expertise.

This technical report on "Recommendations for the estimation of remaining fatigue life" supported by the ECCS could be used as a basis for harmonizing National procedures and for the further evolution of the Eurocodes.
\end{abstract}


The mission of the JRC is to provide customer-driven scientific and technical support for the conception, development, implementation and monitoring of EU policies. As a service of the European Commission, the JRC functions as a reference centre of science and technology for the Union. Close to the policy-making process, it serves the common interest of the Member States, while being independent of special interests, whether private or national.

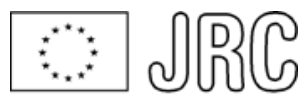

EUROPEAN COMMISSION

The European Convention for Constructional Steelwork (ECCS) is the federation of the National Associations of Steelwork industries and covers a worldwide network of Industrial Companies, Universities and Research Institutes. 